\title{
Johanna Edgren
}

Physical Disability in Community-dwelling

Older People after Hip Fracture

Randomized Controlled Trials

with Physical Rehabilitation 


\title{
Johanna Edgren
}

\section{Physical Disability in Community-dwelling Older People after Hip Fracture}

\author{
Randomized Controlled Trials \\ with Physical Rehabilitation
}

Esitetään Jyväskylän yliopiston liikuntatieteellisen tiedekunnan suostumuksella julkisesti tarkastettavaksi Historica-rakennuksen salissa H320 marraskuun 29. päivänä 2013 kello 12.

Academic dissertation to be publicly discussed, by permission of the Faculty of Sport and Health Sciences of the University of Jyväskylä, in the Historica building, auditorium H320, on November 29, 2013 at 12 o' clock noon.

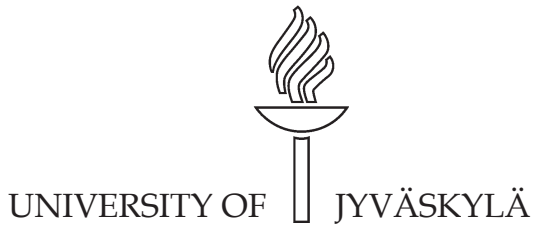

JYVÄSKYLÄ 2013 


\section{Physical Disability in Community-dwelling Older People after Hip Fracture}

Randomized Controlled Trials with Physical Rehabilitation 


\section{Johanna Edgren}

\section{Physical Disability in Community-dwelling Older People after Hip Fracture}

Randomized Controlled Trials with Physical Rehabilitation

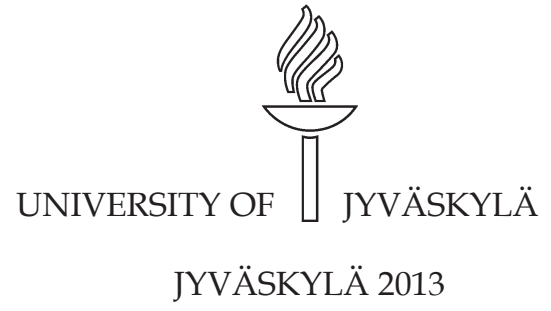


Editors

Ina Tarkka

Department of Health Sciences, University of Jyväskylä Pekka Olsbo, Sini Tuikka

Publishing Unit, University Library of Jyväskylä

URN:ISBN:978-951-39-5479-6

ISBN 978-951-39-5479-6 (PDF)

ISBN 978-951-39-5478-9 (nid.)

ISSN 0356-1070

Copyright @ 2013 , by University of Jyväskylä

Jyväskylä University Printing House, Jyväskylä 2013 
$\sim$ Dedicated to Janne, Arttu, Betsy, Emmy, and “Toukka" who can turn tears into laugh 


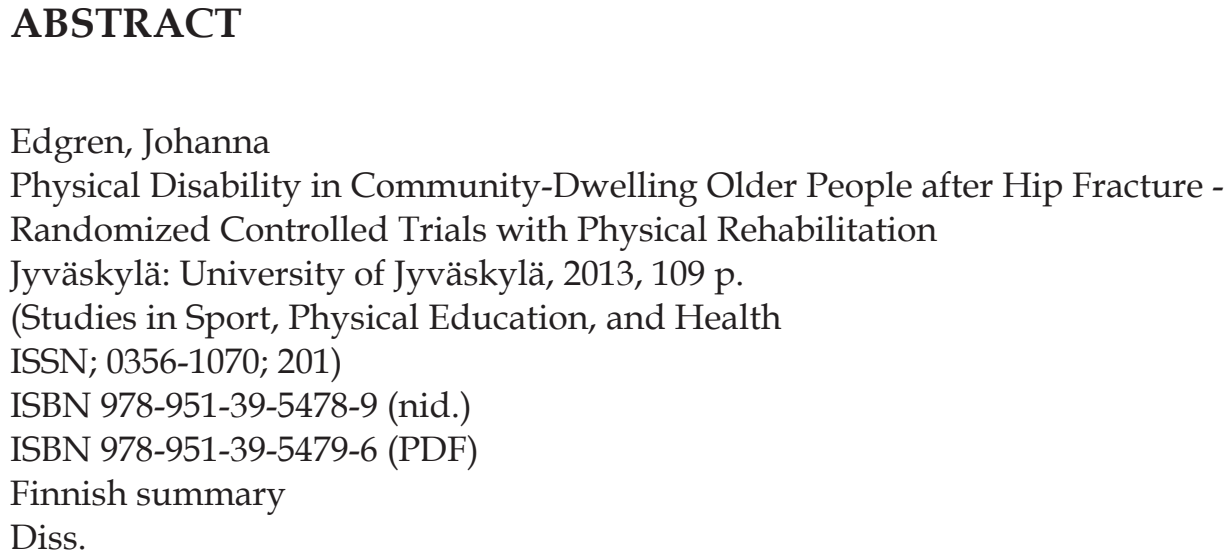

Less than half of the hip fracture survivors will regain their pre-fracture level of physical functional capacity. The purpose of this study was to investigate the effects of progressive resistance training and the effects of multi-component homebased rehabilitation among older people who had sustained a hip fracture. Additionally, the associations of decreased balance confidence and impaired functional balance in relation to physical disability were studied.

This study reports the results of two randomized controlled trials. The participants were community-dwelling men and women aged 60 and 60+. Of the 159 participants, 43 participated in 3-month resistance training (Hip Asymmetry). Additionally, 81 participated in a 1-year multi-component homebased rehabilitation program (ProMo). Physical disability (ADL and IADL) was assessed by a questionnaire. Balance confidence was assessed by the ABC Scale and functional balance by Berg Balance Scale. In the Hip Asymmetry study the measurements were performed before and after the training period and in the ProMo study at baseline and 3, 6, and 12 months thereafter.

Balance confidence and functional balance were strongly associated with physical disability. Theoretically, a ten-point decrease in the ABC score increased the risk for disability by $10 \%$ (IRR $0.99 ; 95 \%$ CI $0.98-0.99$ ) while the same decrease in the Berg score increased the risk for disability by $20 \%(0.98 ; 0.96-0.99)$. Resistance training improved independence especially in ADL (ANCOVA p=0.034). Home-based multi-component rehabilitation did not have a wide-ranging effect on disability. However, for the single disability items, borderline significant positive effects were observed for preparing food and handling medication (interaction $p=0.061$ and $p=0.061$, respectively). Additionally, the per-protocol analysis suggested that home-based multi-component rehabilitation may reduce ADL and IADL disability extensively.

Balance confidence and functional balance were strongly associated with physical disability. Additionally, the results indicate a beneficial effect of resistance training on physical disability. Multi-component home-based rehabilitation may also reduce both ADL and IADL disability more broadly.

Keywords: aging, balance, elderly, falls, functional capacity, disability, fractures, physical activity, physical therapy, rehabilitation, exercise 
Author's address

Supervisors

Reviewers

Opponent
Johanna Edgren, MSc

Gerontology Research Center

Department of Health Sciences

University of Jyväskylä

P.O.Box 35 (viv)

40014 University of Jyväskylä, Finland

johanna.edgren@jyu.fi

Professor Ari Heinonen, PhD

Department of Health Sciences

University of Jyväskylä

Jyväskylä, Finland

Professor Sarianna Sipilä, PhD

Gerontology Research Center

Department of Health Sciences

University of Jyväskylä

Jyväskylä, Finland

Professor Nina Beyer, PhD

Musculoskeletal Rehabilitation Research Unit

Institute of Sports Medicine

Department of Physical and Occupational Therapy

Bispebjerg Hospital

Copenhagen, Denmark

Associate professor Teresa Liu-Ambrose, PhD

Aging, Mobility, and Cognitive Neuroscience

Laboratory

Department of Physical Therapy

University of British Columbia

Vancouver, Canada

Professor Dawn Skelton, PhD

Institute of Applied Health Research

School of Health and Life Sciences

Glasgow Caledonian University

Glasgow, Scotland 


\section{ACKNOWLEDGEMENTS}

This doctoral study was carried out at the Gerontology Research Center and Department of Health Sciences, University of Jyväskylä in close collaboration with the Central Finland Health Care District, City of Jyväskylä and neighboring municipalities. I wish to thank everyone who has contributed to or otherwise participated in my research work during the last few years. Especially, I want to thank all the participants in the HIP ASYMMETRY and PROMO studies.

I am grateful of having had the opportunity to complete my doctoral thesis supervised by Professors Sarianna Sipilä, PhD, and Ari Heinonen, PhD. Thank you for providing me the possibility to conduct this study at the Gerontology Research Center and Department of Health Sciences. I thank you both for having faith in me when you accepted me as a research physiotherapist into the PROMO study and afterwards considered me as a potential doctoral student, although you barely knew me at that time. I hope I have met your expectations. Even though there were some rough times, I am grateful of having the privilege to work in an inspiring research project like PROMO during my doctoral education. In addition, I greatly appreciate your skillful guidance throughout this project. I have always been able to count on your straightforward thinking and scientific advises. I appreciate your knowledge and experience in the field of experimental research. Sarianna, in the beginning of this semester, we discussed that the learning process during the doctoral education is always different. Eventually, the most important thing is that there was a learning process, no matter what might have happened every now and then. Thank you for supporting me throughout this demanding growth period.

I would like to express my gratitude to the official reviewers of this doctoral thesis, Professor Nina Beyer, PhD, and Associate Professor Teresa LiuAmbrose, $\mathrm{PhD}$, for their careful review and constructive comments, which have improved the content of this thesis. I also want to thank Professor Dawn Skelton, PhD, for agreeing to be my opponent in the public defense of this thesis.

All of my co-authors deserve sincere thanks for sharing their time and knowledge with me during the writing process of the original publications: Professor Taina Rantanen, PhD, I greatly appreciate your experience and knowledge on the disablement process and the field of gerontological research. Additional thanks go to physicians Markku Alén, MD, PhD, Pirkko Jäntti, MD, $\mathrm{PhD}$, Mauri Kallinen, MD, PhD, Ilkka Kiviranta, MD, PhD, Mika Pekkonen, MD, PhD, and Jukka Vanhatalo, MD, head of the physiotherapy department Marja Arkela, PhD, post-doctoral researchers Erja Portegijs, PhD, and Mikaela von Bonsdorff, PhD, R\&D specialist Sanna Sihvonen, PhD, and a fellow doctoral student Anu Salpakoski, MSc. I also wish to thank the statisticians Markku Kauppinen, $\mathrm{PhD}$, and Timo Törmäkangas, $\mathrm{PhD}$, for their help with the statistical methods. In addition, I thank Michael Freeman for his assistance in revising the English language of this summary. 
I am grateful for the financial support I have received for carrying out my doctoral studies. This work was financially supported by the Finnish Cultural Foundation, the Juho Vainio Foundation, the Miina Sillanpää Foundation, and the Peurunka Physical Rehabilitation Institute. The HIP ASYMMETRY and PROMO studies were additionally supported by the Ministry of Education and Culture. In addition, PROMO study received financial support from the National Insurance Institution (KELA).

My very special thanks are dedicated to my colleagues and fellow doctoral students at GEREC and the Department of Health Sciences for providing a supportive and inspiring working environment. My colleague, Anu Salpakoski, thank you for sharing the "ProMo" experience with me. There were some times of struggle but also lots of laughs and eventually happiness and relief after finishing the recruitment period of the PROMO project. Additionally, I want to express my sincere thanks to my past and present colleagues, Katri Lihavainen, Inna Lisko, Inka Pakkala, and Irma Äyräväinen. Thank you for your warm friendship and support during these years. I will always remember you when looking back this time of my life. I also want to thank my dear friends outside the university, especially Minna, who numerous times offered me bed and breakfast when I was staying at Jyväskylä. In addition, I wish to thank my agility training mates at the Tampere region. Without friends my life would have been boring and empty. You have balanced my academic work, provided me the right perspective toward living and reminded me about the important little things in life.

Lastly, I want to express my warm gratitude to my parents, Raija and Hannu, my brother, Pekka, and his family, Marjo, Urho, and Martti. During my childhood and teens I have always been encouraged to study and educate myself. I think I am still on that way. I thank my parents for letting me find my place in this world. Pekka, even though we were fighting all the time when we were young, I am glad that nowadays we can share our thoughts and support each other when needed.

Finally, I own my dearest thanks to my beloved husband, Janne, and our three little rascals. Our dogs, Arttu, Betsy, and Emmy, bring genuine joy and happiness into our life even during the worst days. Janne, I know it has not always been easy to be there for me throughout this long and harrowing process. However, you have always believed in me and I know that together we are strong. I sincerely admire your attitude towards life and I have tried to learn from you. Thank you for your love, understanding and support throughout these years. Our peculiar and growing family is the most important thing in my life.

Tampere, October 2013

Johanna Edgren 


\section{FIGURES}

FIGURE 1 Simplified study designs in the HIP ASYMMETRY and

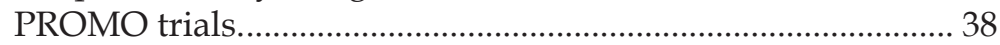

FIGURE 2 Flow chart of the HIP ASYMMETRY (Studies I, II) ................. 39

FIGURE 3 Flow chart of the PROMO (Studies I, III \& IV)......................... 41

FIGURE 4 Protocol of the PROMO study (Studies I, III \& VI) .................. 42

FIGURE 5 ADL and IADL sum scores and standard errors for the training (TG) and control (CG) groups; ANCOVA p-values are adjusted by baseline (HIP ASYMMETRY; Study II).......... 67

FIGURE 6 Change in self-reported difficulty in preparing meals and handling medication and interaction p-values in the crude GEE models (PROMO; Study IV) ................................................. 68

FIGURE 7 Mean changes, standard errors, and interaction p-values for the ADL and IADL sum scores: A\&B = All participants; $C \& D$ = Participants who were suspended or exercising with low frequency and therefore excluded from the analysis at issuing time point (PROMO; Study IV). 71

FIGURE 8 Means, standard errors, and interaction p-values in the crude GEE models for ABC sum score in the HIP ASYMMETRY (Study II) AND PROMO (Study IV). 


\section{TABLES}

TABLE 1 Randomized controlled trials on post-discharge hip fracture rehabilitation among community-dwelling older people ( $\geq 60$ years).

TABLE 2 Summary of the research designs, study participants, and main outcomes.

TABLE 3 Summary of the measurement methods and variables used in the study including references and reliability.

TABLE 4 Training Protocol for the weaker leg and stronger leg for strength and power exercises performed with resistance equipment (leg press, knee flexion, and hip abduction and adduction) or a weighted vest (ankle plantar flexion) (HIP ASYMMETRY; Study II).

TABLE 5 Baseline characteristics of older people with a previous hip fracture.

TABLE 6 Characteristics of older people with a previous hip fracture in the HIP ASYMMETRY $(n=78)$ and PROMO $(n=81)$ studies stratified by functional capacity; Good functional capacity was defined as difficulty in less than four basic or instrumental activities of daily living; Decreased functional capacity was defined as difficulty in four or more basic or instrumental activities of daily living.

TABLE 7 IRR's and 95\% CI's for physical disability in the negative binomial regression model with $\mathrm{ABC}$ and BBS scores separately and together in the same model (HIP ASYMMETRY + PROMO; Study I).

TABLE 8 Mean number and standard deviation of exercises, and exercise compliance (PROMO; Study IV).

TABLE 9 Proportion of self-reported difficulty in ADL/IADL in the training and control groups (HIP ASYMMETRY; Study II)... 67

TABLE 10 Number and proportions of participants reporting difficulty in ADL (PROMO; Study IV).

TABLE 11 Number and proportions of participants reporting difficulty in IADL (PROMO; Study IV)

TABLE 12 ADL and IADL sum score values, training effects and mean differences between groups (PROMO; Study IV). 


\section{LIST OF ORIGINAL PUBLICATIONS}

The thesis is based on following publications which will be referred to by their Roman numerals. Additionally, some unpublished data are included in the thesis.

I Johanna Edgren, Anu Salpakoski, Taina Rantanen, Ari Heinonen, Mauri Kallinen, Mikaela B von Bonsdorff, Erja Portegijs, Sanna Sihvonen \& Sarianna Sipilä: Balance confidence and functional balance are associated with physical disability after hip fracture. Gait \& Posture 2013; 37(2):201-205. DOI: 10.1016/j.gaitpost.2012.07. 001.

II Johanna Edgren, Taina Rantanen, Ari Heinonen, Erja Portegijs, Markku Alén, Ilkka Kiviranta, Mauri Kallinen \& Sarianna Sipilä: The effects of progressive resistance training on physical disability among older community-dwelling people with history of hip fracture. Aging Clinical and Experimental Research 2012; 24(2):171175.

III Sarianna Sipilä, Anu Salpakoski*, Johanna Edgren*, Ari Heinonen, Markku A Kauppinen, Marja Arkela-Kautiainen, Sanna E Sihvonen, Maija Pesola, Taina Rantanen \& Mauri Kallinen: Promoting mobility after hip fracture (ProMo): study protocol and selected baseline results of a year-long randomized controlled trial among community-dwelling older people. BioMed Central Musculoskeletal Disorders 2011; 7(12):277. DOI: 10.1186/1471-247412-277. *Equal contributors

IV Johanna Edgren, Anu Salpakoski, Sanna E Sihvonen, Erja Portegijs, Mauri Kallinen, Marja Arkela, Pirkko Jäntti, Jukka Vanhatalo, Mika Pekkonen, Taina Rantanen, Ari Heinonen \& Sarianna Sipilä: Effects of a home-based physical rehabilitation program on physical disability after hip fracture: A randomized controlled trial. Submitted to the Journal of Gerontology - Series A: Medical Sciences 


\section{ABREVIATIONS}

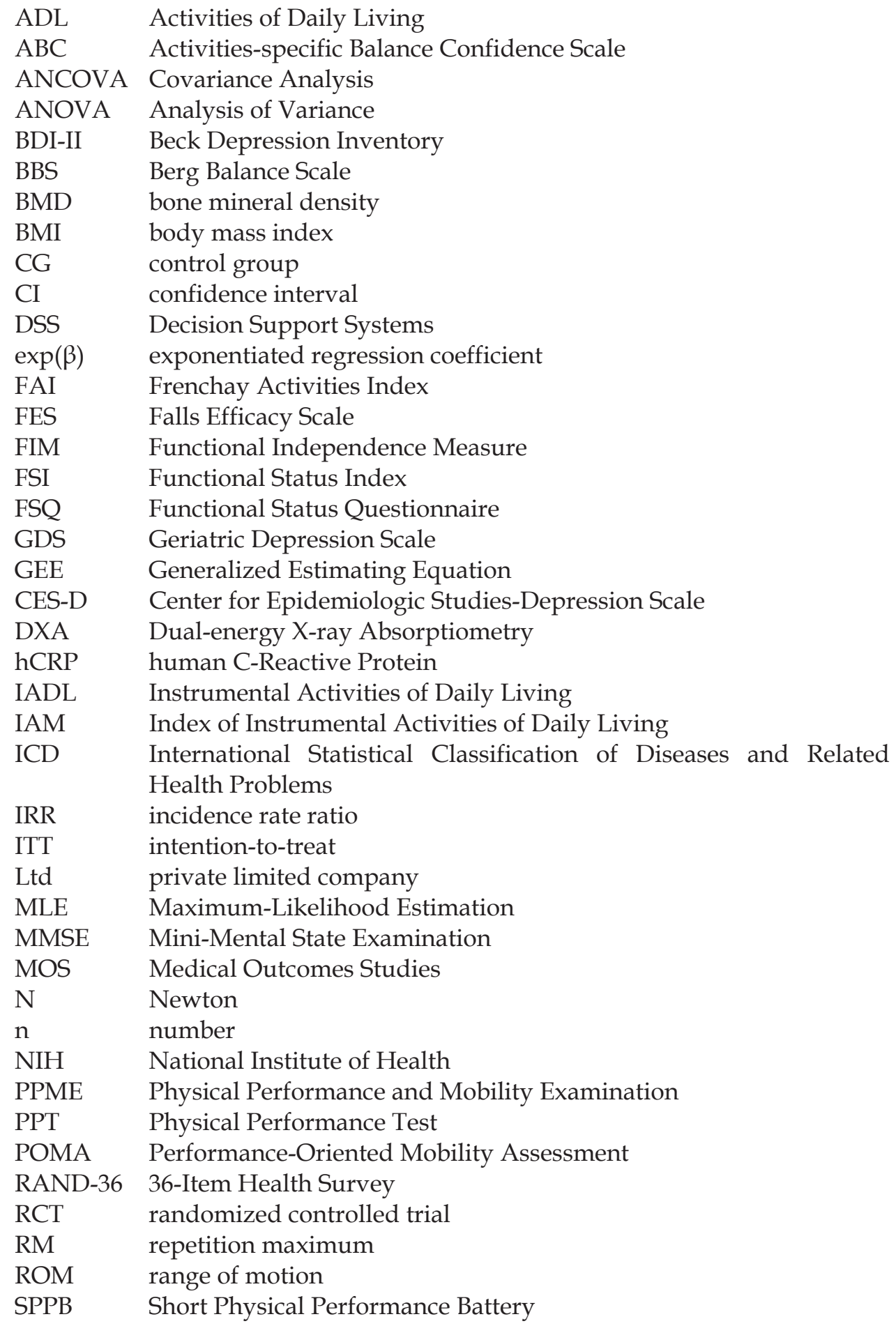




$\begin{array}{ll}\text { SD } & \text { standard deviation } \\ \text { SE } & \text { standard error } \\ \text { SF-12 } & \text { 12-Item Short Form Survey } \\ \text { SF-36 } & \text { 36-Item Short Form Survey } \\ \text { srl } & \text { Società a Responsabilità Limitata i.e. limited liability company } \\ \text { TG } & \text { training group } \\ \text { TUG } & \text { Timed Up-and-Go } \\ \text { W } & \text { Watt } \\ \text { WHOQOL } & \text { Quality of life scale developed through the World } \\ & \text { Health Organization }\end{array}$




\title{
CONTENTS
}

\author{
ABSTRACT \\ ACKNOWLEDGEMENTS \\ FIGURES \\ TABLES \\ LIST OF ORIGINAL PUBLICATIONS \\ ABREVIATIONS
}

1 INTRODUCTION

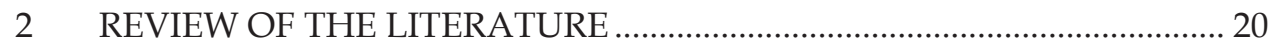

2.1 Hip fractures and physical disability among older people ................ 20

2.1.1 Common risk factors for hip fractures ........................................ 21

2.1.2 Physical disability and other devastating outcomes of hip

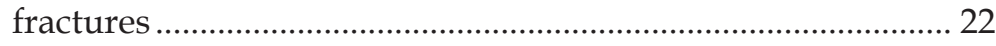

2.1.3 Assessing physical disability ........................................................ 23

2.1.4 Treatment of hip fractures ......................................................... 27

2.2 Rehabilitation approaches aiming at improving physical

functioning after hip fracture............................................................... 28

2.2.1 Selection criteria for the systematic literature review.............. 29

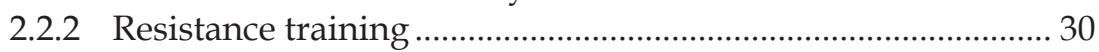

2.2.3 Multi-component physical training interventions delivered

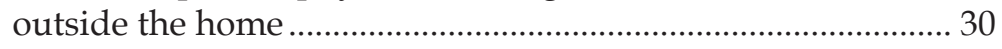

2.2.4 Multi-component home-based interventions ........................... 31

2.2.5 Summary of the randomized controlled trials with outpatient rehabilitation interventions aiming at improving physical functioning after hip fracture..................... 31

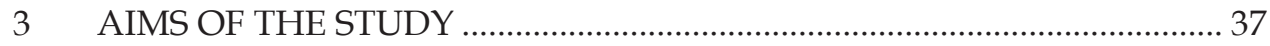

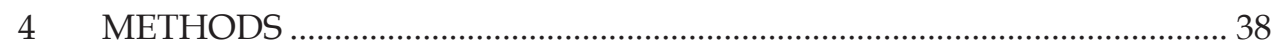

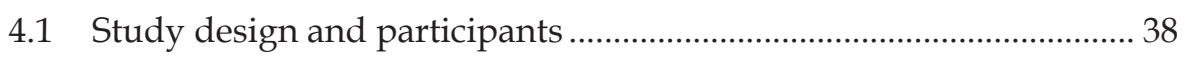

4.1.1 HIP ASYMMETRY (Studies I \& II) .............................................. 39

4.1.2 PROMO (Studies I, III \& IV) ........................................................... 40

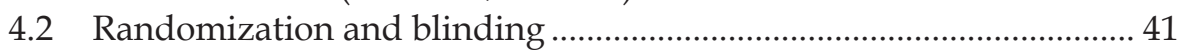

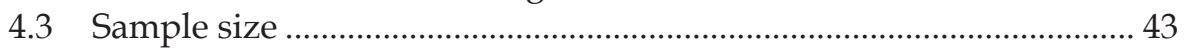

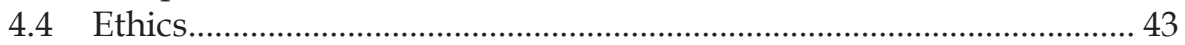

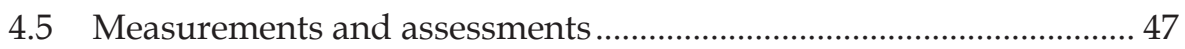

4.5.1 Physical disability ...................................................................... 47

4.5.2 Balance confidence....................................................................... 48

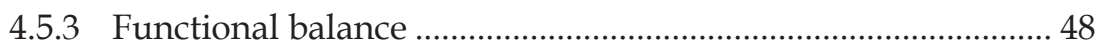

4.5.4 Other descriptive, mediating and confounding factors ........... 48

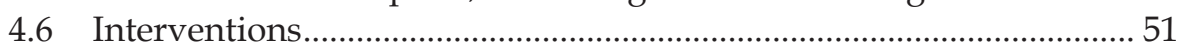

4.6.1 Standard care (Studies II, III \& IV) .......................................... 51 
4.6.2 Individually tailored progressive resistance training (Study II)

4.6.3 PROMO - Individually tailored multi-component home-based rehabilitation program (Studies III \& IV)............. 53

4.7 Statistical methods .................................................................................. 56

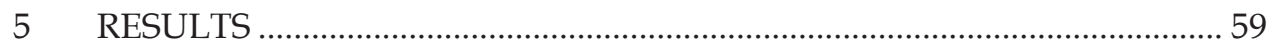

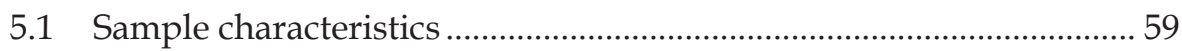

5.2 Associations of balance confidence and functional balance with

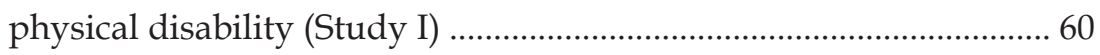

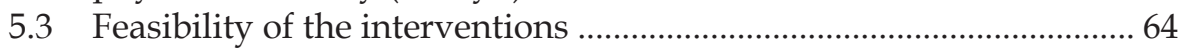

5.3.1 Feasibility of progressive resistance training (Study II) ........... 64

5.3.2 Feasibility of multi-component home-based rehabilitation

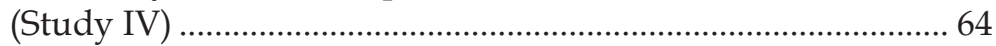

5.4 Effects of the interventions on physical disability ................................. 65

5.4.1 Effects of progressive resistance training (Study II) ................. 65

5.4.2 Effects of multi-component home-based rehabilitation

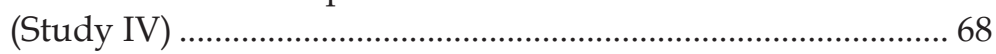

5.5 Effects of the interventions on balance confidence

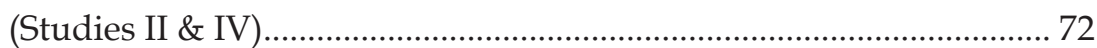

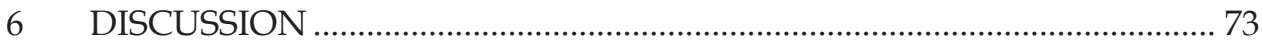

6.1 Effects of the interventions on physical disability ............................... 73

6.1.1 Effects of progressive resistance training ................................... 73

6.1.2 Effects of multi-component home-based rehabilitation .......... 75

6.2 Balance confidence and functional balance as determinants of physical disability .............................................................................. 78

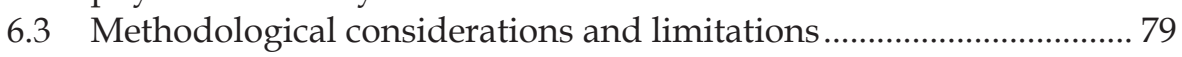

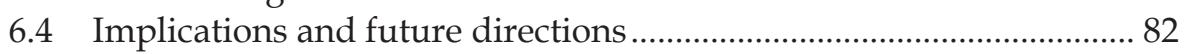

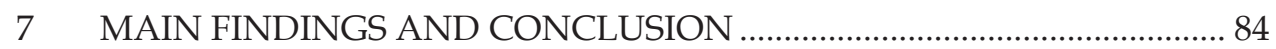

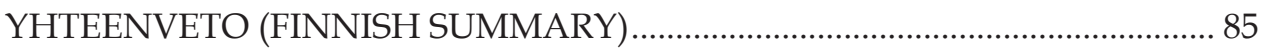

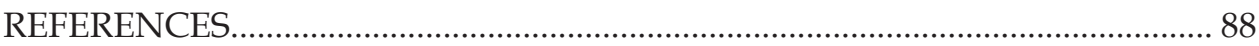

APPENDIX: Online search criteria

ORIGINAL PUBLICATIONS (Studies I-IV) 


\section{INTRODUCTION}

Hip fracture is among the most devastating traumas in older people. Previous studies have clearly demonstrated that hip fracture patients comprise a special group of older people with high risk for long-lasting physical disability (Lönnroos et al. 2006, Fiatarone Singh et al. 2009). Less than half of hip fracture survivors will regain their pre-fracture level of functional capacity (Eastwood et al. 2002, de Luise et al. 2008) and up to 30\% will be permanently institutionalized. Moreover, hip fracture patients often suffer from impaired postural balance (Sherrington \& Lord 1998), fear of falling (Sihvonen et al. 2009), persistent pain (Herrick et al. 2004, Visser et al. 2000) and muscle weakness (Sherrington \& Lord 1998), leading to physical inactivity (Salpakoski et al. 2011). All these factors together have an essential role in the development of prolonged mobility difficulty, which in turn predicts the onset of physical disability in tasks essential for independent living in the community (Rantanen et al. 1999).

Disability can be defined as difficulty in performing the activities of daily living in a social context, and thus reflects an imbalance between a person's functional capacity and the requirements of the environment (Verbrugge \& Jette 1994). The activities of daily living can be divided into basic (ADL) (Katz et al. 1963) and instrumental (IADL) activities (Lawton \& Brody 1969). ADL tasks are fundamental self-care related activities such as eating and bathing. IADL tasks are somewhat more complicated (e.g. preparing meals or using public transport) and comprise aspects of psychological and social capability. On the other hand, while not absolutely necessary for daily functioning, IADL tasks enable independent living in a community. When functional capacity decreases, difficulties usually begin with IADL and later proceed to ADL (Gill, Williams \& Tinetti 1995).

Fractures in older people result usually from the combination of a fall and low bone density (Karlsson et al. 2013). Approximately 95\% of all hip fractures are caused by a fall (Järvinen et al. 2008, Karinkanta et al. 2010). Hence, risk factors for falls are also risk factors for fractures. Risk factors of falling can be divided into intrinsic (e.g. low body mass, medical co-morbidities, 
musculoskeletal diseases, cognitive impairment, sensory impairments, gait and balance disorders) and extrinsic risk factors (e.g. slippery or uneven surfaces, poor lighting, chairs and armchairs without handrails, and unsuitable footwear) (Tinetti et al. 1995, Järvinen et al. 2008, Gillespie et al. 2012, Cameron et al. 2012). The various risk factors interact with each other, and there is large individual variation (Karinkanta et al. 2010). Moreover, individuals with multiple risk factors are at especially high risk for fracture (Cummings et al. 1995).

After a previous hip fracture, impaired functional balance and muscle weakness are considered to be among the most common risk factors for further falls and fractures (Sihvonen et al. 2009, Tinetti, Speechley \& Ginter 1988, Tinetti et al. 1995). Moreover, poor lower limb explosive power combined with asymmetry between limbs may be stronger predictor of falls than more traditional measurements of strength in older people who live independently (Skelton, Kennedy \& Rutherford 2002). Balance control and adequate muscle strength together have a fundamental role in coping with various activities of daily living, particularly those which require independent standing or walking (e.g. housework or shopping). Furthermore, those who have experienced a fall with a traumatic consequence often suffer from low balance confidence (i.e. fear of falling), even several years after the incident (Sihvonen et al. 2009). In addition, impaired balance confidence is independently associated with physical performance (e.g. muscle strength and gait speed) (Liu-Ambrose et al. 2006). Thus low balance confidence may lead to avoidance of physical activity, in turn leading to an increase in and prolonging physical disability (Jellesmark et al. 2012). Furthermore, low balance confidence is an independent risk factor for future falls ( $\mathrm{Li}$ et al. 2003, Kulmala et al. 2007) and it has shown to be associated with quality adjusted life years (Davis, Marra \& Liu-Ambrose 2011). Therefore fear of falling should be taken into consideration when designing and implementing rehabilitation programs.

Based on previous research, it is known that progressive resistance training can improve muscle strength (Häkkinen \& Häkkinen 1995, Skelton et al. 1995, Sipilä et al. 1996), muscle mass (Wieser \& Haber 2007), functional ability (Skelton et al. 1995), aerobic capacity (Wieser \& Haber 2007), dynamic balance (Holviala et al. 2006), and health related quality of life (Brovold, Skelton \& Bergland 2013) among older adult. Additionally, prior studies have indicated that balance training may improve functional balance (Li et al. 2005, Salminen et al. 2009) and gait speed (Vrantsidis et al. 2009), reduce fall risk (Sihvonen et al. 2004) and fear of falling (Vrantsidis et al. 2009), and maintain overall physical functioning ( $\mathrm{Li}$ et al. 2005, Gine-Garriga et al. 2010) even in frail older people. However, in clinical populations, such as hip fracture patients, there is insufficient evidence on whether improved muscle strength and functional balance can affect perceived difficulty in performing daily activities (Liu \& Latham 2009, Liu \& Latham 2010). The associations of low balance confidence and balance impairments in relation to physical disability should be studied more carefully to better understand the factors potentially affecting recovery and rehabilitation processes after a hip fracture. Additionally, more research is 
needed on what kind of rehabilitation would be the most effective in reducing physical disability after a hip fracture.

The search for an optimal rehabilitation model for hip fracture patients has evoked increasing interest in home rehabilitation partly because it can be considered a feasible, easily accessed, and cost-effective rehabilitation option also for the frailest and most diseased persons. When rehabilitation is implemented outside the home, it requires equipment, facilities and the ability to travel. Immediately after hospital discharge hip fracture patients are often weak and tired, and therefore not able to participate in rehabilitation elsewhere than home on a regular basis. Moreover, it is precisely frail person who would potentially benefit most from home-based rehabilitation. Thus far, insufficient evidence exists on the effects of home-based rehabilitation programs on physical disability among older people who have suffered a hip fracture, as the previous research has yielded conflicting results (Zidén, Kreuter \& Frändin 2010, Orwig et al. 2011).

The purpose of this study was to investigate the effects of individually tailored progressive resistance training and the effects of a multi-component home-based rehabilitation program on physical disability among communitydwelling older people who have sustained a previous hip fracture. In addition, the associations between balance confidence and impaired functional balance in relation to physical disability were studied. 


\section{REVIEW OF THE LITERATURE}

\subsection{Hip fractures and physical disability among older people}

Hip fractures are fractures of the proximal femur. They can be subdivided into intra-capsular fractures (those occurring proximal to the attachment of the hip joint capsule to the femur) and extra-capsular (those occurring distal to the hip joint capsule) (Handoll, Sherrington \& Mak 2011). The majority of hip fractures occur among people $\geq 50$ years, and about two-thirds occur in females (Duodecim 2011, Morrison et al. 2013). In Finland, approximately 7000 hip fractures (range 6 750-7 330) occurred annually during the years 1996-2008 (Duodecim 2011). Of these, 61\% were femoral neck fractures, 30\% trochanteric, and $9 \%$ pertrochanteric. Although the incidence of hip fractures has been on the decrease in several western countries (Gehlbach, Avrunin \& Puleo 2007, Leslie et al. 2010), the number of hip fractures is expected to rise with the worldwide aging of populations and longer life expectancy worldwide (Lönnroos et al. 2006, Cooper et al. 2011).

A fracture occurs when a force, such as a fall-related trauma, is applied to the bone (Kannus et al. 2005, Järvinen et al. 2008). Nearly all hip fractures (95\%) among older people result from a fall (Karinkanta et al. 2010). The rest occur mainly because of a collapse or load-induced strain on a weak bone (Karinkanta et al. 2010, Karlsson et al. 2013). Therefore, the type and severity of the fall/collapse, and bone density, determine whether a fracture occurs (Järvinen et al. 2008, Karlsson et al. 2013).

People suffering a hip fracture frequently have medical and physical problems associated with ageing, as well as impaired mobility (Handoll, Sherrington \& Mak 2011). Moreover, after hip fracture older people are at high risk for long-lasting disability (Magaziner et al. 2003, Rohde et al. 2010) i.e. difficulty in tasks which are essential for independent living in the community (Jette 2006). This may lead to institutionalization as well as marginalization in society. 


\subsubsection{Common risk factors for hip fractures}

Risk factors for fractures are numerous. They interact with each other and persons with multiple risk factors are at especially high risk for a fracture (Cummings et al. 1995, Karlsson et al. 2013). Falling is clearly the strongest single risk factor for hip fractures, since nearly all hip fractures are caused by a fall (Karinkanta et al. 2010). In particular, high age, previous falls and low physical activity are associated with higher risk for hip fractures, since they increase both the probability for falls and osteoporosis (Duodecim 2011). Onethird of older adults aged 65 years and older fall at least once each year. The rate increases substantially with increasing age, and approximately half of 80year-olds and older fall every year (Rubenstein \& Josephson 2002, Lord \& Sturnieks 2005). The incidence of hip fractures increases 13-fold between age 60 and 90. Accelerating loss of bone mineral density explains part of this increase. However, most of the increase is explained by the increasing number of fall accidents during aging (de Laet et al. 1997). Notably, number of falls among those living in an institution is two-fold higher than among those living at home (Rapp et al. 2008).

There are several ways of categorizing the risk factors for fractures. A Finnish group of medical experts (Duodecim 2011) has divided the risk factors for hip fractures into risk factors for falls and risk factors for osteoporosis (Duodecim 2011). Other common approach is to divide risk factors into those which can be modified with rehabilitation interventions (e.g. decreased muscle strength and impaired balance) versus those which cannot be modified (e.g. age, gender, ethnicity, inheritable diseases, and the number of previous falls) (Karinkanta et al. 2010). In this study we focus on risk factors which can be affected by physical rehabilitation and counseling.

Since falls are the most common reason for hip fractures, the risk factors for falls must also be considered risk factors for fractures (Kannus et al. 1999, Karinkanta et al. 2010). Falls result from an interaction between environmental characteristics (extrinsic risk factors) and a physiology inadequate to cope with these (intrinsic risk factors) (Karinkanta et al. 2010, Tinetti \& Kumar 2010). Based on prior research, the strongest modifiable risk factors for falling comprise functional- and mobility-related factors such as low muscle strength (de Rekeneire et al. 2003, Lloyd et al. 2009), gait abnormalities (Lord, Lloyd \& Li 1996, Tinetti \& Kumar 2010), and balance impairments (de Rekeneire et al. 2003, Lloyd et al. 2009). Additionally, the number of previous falls (Sihvonen et al. 2009, Tinetti \& Kumar 2010), fear of falling (Delbaere et al. 2010b, Hadjistavropoulos, Delbaere \& Fitzgerald 2011), falls efficacy (Kulmala et al. 2007, Delbaere et al. 2010b), musculoskeletal pain (Marcantonio et al. 2001, Panel on Prevention of Falls in Older Persons, American Geriatrics Society and British Geriatrics Society 2011), impaired vision (Lord et al. 1994, Lord \& Dayhew 2001), and use of specific medications (Lloyd et al. 2009, Panel on Prevention of Falls in Older Persons, American Geriatrics Society and British Geriatrics Society 2011) are important risk factors for falls. However, because the bone density and quality affect the breaking point at which a fracture occurs, 
it is important to recognize the factors that alter bone health throughout the life span (Kanis 2002, Järvinen et al. 2008).

Bone strength primarily reflects the integration of bone mineral density (BMD) combined with bone geometry, turnover, damage accumulation and mineralization of the bone (NIH Consensus Development Panel on Osteoporosis Prevention, Diagnosis, and Therapy 2001). BMD accounts for approximately $60-80 \%$ of bone strength. (NIH Consensus Development Panel on Osteoporosis Prevention, Diagnosis, and Therapy 2001, Järvinen et al. 2008, Lönnroos et al. 2006, Fiatarone Singh et al. 2009). According to the operational definition of the World Health Organization, BMD below 2.5 standard deviations (SD) of the mean in young, white adult women indicates osteoporosis (World Health Organization 1994). Osteoporosis increases the risk for fractures multifold, especially among those aged 60 or older (Kanis 2002).

\subsubsection{Physical disability and other devastating outcomes of hip fractures}

Outcomes of hip fractures are often devastating. Furthermore, co-morbidity and poly pharmacy often complicate the treatment of elderly patients and induce substantial risk for developing serious complications (de Luise et al. 2008, Abrahamsen et al. 2009). About one-third of hip fracture patients will die during the first post-fracture year, compared with an expected annual mortality of about $10 \%$ in this age group (Roche et al. 2005). Those who survive usually suffer from persistent pain (Visser et al. 2000, Herrick et al. 2004), muscle weakness (Sherrington \& Lord 1998), impaired postural balance (Sherrington \& Lord 1998, Sihvonen et al. 2009) and low balance confidence (Sihvonen et al. 2009, Jellesmark et al. 2012). All these factors together may lead to physical inactivity (Salpakoski et al. 2011), which has a central role in the development of mobility difficulty, physical disability and deterioration in quality of life for several years after the incident (Kirke et al. 2002, Magaziner et al. 2003, Rohde et al. 2010).

Finally, an elderly person sustaining a hip fracture might have difficulty even in coping with the basic activities of daily living that are essential for independency in the community (Jette 2006). This kind of disability involves individual and societal consequences that include greater use of health and social services (Ferrucci et al. 1997), lower subjective well-being (Tidermark et al. 2002), and increased mortality (Guralnik et al. 1991). Consequently, around 10$30 \%$ of hip fracture survivors will be compelled to move into an institution (Magaziner et al. 2000, Nurmi et al. 2003, de Luise et al. 2008). In Finland, the direct health care costs during the first post-fracture year are approximately $20000 €$ (Duodecim 2011). If a community-dwelling person is institutionalized due to hip fracture, the total health care cost for the first year will rise tremendously (Nurmi et al. 2003).

Several known factors are associated with recovery of the physical functioning after a hip fracture. Many diseases, such as depression (Morghen et al. 2010), cognitive impairments (Häkkinen et al. 2007), low pre-fracture functional capacity (Eisler et al. 2002), low post-operative functional capacity 
(Heinonen et al. 2004), late mobilization (Hoenig et al. 1997), malnutrition (Ponzer et al. 1999), and post-fracture delirium (Marcantonio et al. 2001), are associated with functional recovery after a hip fracture. Moreover, strong and resilient post-fracture fear of falling, together with balance impairments, potentially reduces the willingness to engage in physical activity, thereby complicating the rehabilitation process (Sherrington \& Lord 1998, Sihvonen et al. 2009, Jellesmark et al. 2012). Furthermore, among many older patients their muscle strength reserve is low and coping with daily activities requires maximal effort (Creditor 1993). On the other hand, bed rest, immobilization, and inactivity reduce muscle strength and bone density, and accordingly increase the risk for new falls and fractures (Neander et al. 1997, Fox et al. 2000, Karinkanta et al. 2010). Moreover, offending pain and problems of bone ossification are associated with poor physical functioning after a fracture (Borgquist et al. 1992, Tidermark et al. 2002). However, older age is not a barrier to recovery. Based on follow-up studies, the prognosis even for hip fracture patients over age 90 may be good (Shah et al. 2001, Tanaka, Tokimura \& Seki 2003, Pelavski Atlas et al. 2009).

\subsubsection{Assessing physical disability}

In this study, we define physical disability as difficulty in performing the activities of daily living in a social context. This is based on the definition given by Verbrugge and Jette (1994) stating that physical disability reflects an imbalance between a person's physical functional capacity and the requirements of the environment. Thus assessing the ability to cope with the activities of daily living is one way of mapping the functional capacity of an individual. The activities of daily living can be divided into basic (ADL) (Katz et al. 1963) and instrumental (IADL) activities (Lawton \& Brody 1969). ADL tasks are fundamental self-care related activities such as eating and bathing. IADL tasks are somewhat more complicated (e.g. preparing meals or using public transport) and comprise aspects of psychological and social capability. Although IADL tasks may not be absolutely necessary for daily functioning, they enable independent living in a community. When functional capacity decreases, difficulties usually begin with IADL and later proceed to ADL (Gill, Williams \& Tinetti 1995).

Mobility difficulty is usually measured in the laboratory setting using performance-based tests such as gait speed or maximal muscle strength or power. However, physical disability is typically assessed by self-report (Guralnik et al. 1989). Sometimes proxy or professional responses are also used. Assessment of physical disability can be carried out for instance at home, in an institution, or at the practice of the health care professional (Katz et al. 1963, Lawton \& Brody 1969).

When reporting perceived disability a person typically reflects on his/her functioning over at least a couple of days and may base the evaluation on reliance on various aids or equipment (Guralnik et al. 1989). In contrast, performance-based laboratory measurements examine performance only at a 
single point in time and do not reflect adaptations made to facilitate a person's daily living (Tinetti \& Ginter 1988, Guralnik et al. 1989, Myers et al. 1993). Consequently, international clinical intervention trials for conditions prevalent among elderly people (e.g. hip fractures) often include disability as one of the key outcomes (Chan et al. 2012).

Earlier studies have found good agreement between the results of selfreport measures of physical function and the results of performance-based measures in older people who have sustained a hip fracture, and thus either type of measure would be suitable for use in clinical trials (Latham et al. 2008). Previous research by Kivinen et al. (1998) showed that self-reported functional capacity and performance-based tests correlated significantly among 70- to 89year-old men, and that the risk for disability increased systematically with decreasing performance in every performance test. The researchers stated that the choice of what measurement or assessment tool to use in assessing functional status should be based on the research objective and the study population (Kivinen et al. 1998).

Many different disability scales, designed for specific purposes, and various modifications and combinations of these are available. The use of assessment tools varies according to the researcher's initial interests and prior experience. The contents of scales and comparisons between scales have been studied in several reviews (Kane \& kane 1981, Applegate, Blass \& Williams 1990, Reuben, Siu \& Kimpau 1992, Kidd \& Yoshida 1995, Chan et al. 2012). In practice, the content of different indexes has become established over the years, although some cultural variation exists. The tools most commonly used to assess for physical disability among older people, with special focus on the scales used in this dissertation, are described next.

\section{Measuring independence in the activities of daily living}

The Index of Activities of Daily Living (Index of ADL), described by Katz \& Ford (1963), was the first ADL index and it may also be the most familiar one. It was initially developed to assess functioning among chronically diseased persons and those transmitted to long-term care (Katz et al. 1963, Katz \& Akpom 1976). The Index of ADL covers six basic human functions: feeding, bathing, dressing, toileting, transferring, and continence. These are assessed dichotomously: able to cope without assistance/needs assistance. Based on the scores, functional capacity can be divided into seven categories (A-G): $A=$ totally independent in all six tasks, $G=$ needs assistance in all six tasks. Information is provided by health care professionals, the patient, or medical records. In the later versions of the index, especially in assessing community-dwelling persons, the item continence is usually left out (Jette \& Branch 1985, Laukkanen et al. 2001). Additionally, in the Finnish version, the assessment scale is often modified to form five categories ( $1=$ Able to manage without difficulty, $2=$ Able to manage with some difficulty, $3=$ Able to manage with major difficulty, $4=$ Able to manage only with the help of another person, and $5=$ Unable to manage even with help) to provide more accurate information on the level of functioning. 
The Katz ADL index can be administered by observation or interview and in some cases by interviewing a proxy. It provides an easy and objective method of classifying heterogeneous groups of people with chronic illnesses, disabilities and impairments, and describing their health needs and outcomes (Katz \& Akpom 1976). The Katz index has proved to be valid instrument to assess disability among older people (Gaugler et al. 2007, Wang, Sheu \& Protas 2007). Reliability assessments among, for instance, Turkish, Moroccan, and Dutch elderly populations have demonstrated good internal consistency for each ethnic group with Cronbach's alphas of 0.84-0.94 (Reijneveld, Spijker \& Dijkshoorn 2007). The disadvantage of the measure is that it provides insights on only a limited number of activities.

The Barthel Index assesses ten basic daily activities: eating, moving from wheelchair to bed and return, personal hygiene (wash face, comb hair, shave, clean teeth), getting on and off toilet, bathing, walking on a level surface (or if unable to walk, propel a wheelchair), ascending and descending stairs, dressing, controlling bowel, and controlling bladder (Mahoney \& Barthel 1965). Items are rated (0-10) according to the amount of assistance required to complete each activity, and the total score ranges from 0 to 100. The Barthel Index is usually used to assess functional capacity among institutionalized persons (e.g. neurological or geriatric patients) and the assessment is commonly carried out by a health care professional, although self-report can also be used (Mahoney \& Barthel 1965, Duffy et al. 2013). The weakness of the The Barthel Index is that the reliability and validity have been studied mostly among stroke patients. In other clinical groups (e.g. among hip fracture patients) the validity, reliability and sensitivity turned out to be low (Applegate, Blass \& Williams 1990, Laake et al. 1995, Potter, Evans \& Duncan 1995).

Measuring independence in the instrumental activities of daily living

The Index of Instrumental Activities of Daily Living, originally described by Lawton \& Brody (1976), is probably the instrument most commonly used to assess physical disability worldwide (Martin-Lesende et al. 2006). The tasks included in the IADL scale are more complicated and require more cognitive, psychological and social skills than the ADL tasks. On the other hand, IADLs are not essential for fundamental functioning, although they enable independent living in the community. When an individual's functional capacity decreases, difficulties usually begin with IADLs and later proceed to ADLs (Gill, Williams \& Tinetti 1995). IADL tasks are more culture- and gender-bound than those in the ADL scale. Traditionally, eight functional domains are measured: preparing meals, doing laundry, housekeeping, handling medication, using the telephone, using public transportation, and handling finances. Historically, women were scored in all eight domains, while men were not scored in the domains of food preparation, housekeeping, and laundering. Currently, recommendation is to assess all domains for both genders (Lawton et al. 2003). In the Finnish version, the IADL scale is often modified to form five functional categories as the case of the Katz ADL scale. The internal consistency of the 
Lawton IADL scale is reported to be 0.94 in a Spanish and 0.99 in a Chinese population (Hokoishi et al. 2001, Vergara et al. 2012). The validity of the scale has been proven to be excellent (Gaugler et al. 2007, Wang, Sheu \& Protas 2007).

The Instrumental Activity Measure (IAM) was originally developed to supplement the Functional Independence Measure (FIM) and has an instrumental structure similar to that of the FIM (Grimby et al. 1998, Daving, Andrén \& Grimby 2000). The IAM contains eight items assessed on a sevenpoint scale according to the subject's self-perceived difficulty in performing each activity. It is a feasible, reliable and valid measure for use among disabled persons (Daving, Andrén \& Grimby 2000, Daving, Claesson \& Sunnerhagen 2009).

The Frenchay Activities Index (FAI) is used, in particular, among stroke patients to assess rehabilitation outcomes (Wade, Legh-Smith \& Langton Hewer 1985). This index comprises three factors (domestic chores, leisure/work and outdoor activities) and yields a sum score ranging from 15 to 60. It has been shown to be a valid measure and to have acceptable reliability in different populations (Miller, Deathe \& Harris 2004, Wu et al. 2011, Imam \& Miller 2012).

\section{Multidimensional measures of disability}

Like all the aforementioned assessment tools, multi-dimensional disability scales also assess coping with activities of daily living but extend beyond these to include variables related to health, cognitive capacity, social relations, hobbies, psychological well-being, service use and living environment. Examples of these instruments are the Functional Independence Measure (FIM), the 36-Item Short Form Health Survey (SF-36), the Functional Status Questionnaire (FSQ), and the Functional Status Index (FSI) which are next described briefly.

The Functional Independence Measure (FIM) is an 18-item, seven-step scale developed to consistently assess the severity of a patient's disability and the functional outcomes of medical rehabilitation (Keith et al. 1987). However, the FIM mainly assesses the need of physical assistance and cognitive problems not perceived difficulty or quality of life. Therefore the Instrumental Activity Measure (IAM) was developed to supplement the FIM. However, the FIM is a reliable and valid instrument for the assessment of functional independence when used by trained medical rehabilitation clinicians (Granger et al. 1993, Hamilton et al. 1994, Daving, Claesson \& Sunnerhagen 2009).

The 36-Item Short Form Survey (SF-36) is a generic self-report health survey comprising 36 questions on eight dimensions covering health, functioning and well-being (Ware \& Sherbourne 1992, McHorney, Ware \& Raczek 1993). The SF36 is often referred to as a measurement of health-related quality of life. However, in some of the studies e.g. Mangione et al. (2005) and Crotty et al. (2003) (see Table 1) the physical function subscale of the SF-36 has been used to measure physical disability. The original SF-36 vas developed in the Medical Outcomes Study (MOS). Subsequently, a commercial version of the SF-36 was made available, while the original version, under the title RAND-36, can be 
obtained free of charge from the nonprofit RAND corporation (Hays, Sherbourne \& Mazel 1993). The SF-36 and RAND-36 include the same set of items and but the scoring is partially different. Both instruments have been found to be valid and reliable among different populations (Coons et al. 1998, Aalto et al. 1999, Tan et al. 2013, Thumboo et al. 2013). An even shorter health survey, the 12-Item Short Form Survey (SF-12) was subsequently put out by the developers of the SF-36 (Ware, Kosinski \& Keller 1996).

The Functional Status Questionnaire (FSQ), described by Jette \& Cleary (1986), is a generic 34-item self-report questionnaire providing a thorough assessment of physical, psychological, and social functioning (Jette et al. 1986). Some researchers as Host et al. (2007) (see Table 1) have used the physical function subscale of the FSQ as a measurement of perceived disability. The FSQ is primarily designed for clinical use in ambulatory patients. The items are scored by computer to produce six summary scale scores and six single-item scores. The developers report that the scales have good reliability and substantial convergent validity when used in primary care (Jette et al. 1986, Jette \& Cleary 1987). Jette (1987) has also developed another self-report questionnaire the Functional Status Index (FSI), which is less used but has proved to have considerable reliability and validity among hip fracture patients (Jette 1987).

\subsubsection{Treatment of hip fractures}

Currently, the majority of hip fractures are treated surgically, which enables earlier mobilization of the patient and avoids some of the complications of prolonged recumbence and immobilization (Handoll, Sherrington \& Mak 2011). Surgery involves either internal fixation, where the fracture is fixed using various implants to retain the femoral head, or replacing the femoral head with a semi or total prosthesis (Handoll, Sherrington \& Mak 2011). Surgery within the first 24 post-fracture hours reduces mortality and complications. Early surgery is also associated with the better improvement of physical functioning compared to delayed surgery (Grimes et al. 2002, Orosz et al. 2004).

Similarly, early mobilization during the first post-fracture day as well as intensive multidisciplinary geriatric evaluation and treatment during the postsurgery hospital period have been shown to decrease mortality and complications, and improve rehabilitation outcomes (Perez et al. 1995, Penrod et al. 2004, Zidén, Frändin \& Kreuter 2008, Mak et al. 2010). Insufficient pain treatment increases the possibility for delirium and other complications as well as restrains the rehabilitation process (Marcantonio et al. 2001, Milisen et al. 2001, Salpakoski et al. 2011). Thus proper pain assessment and follow-up is important after surgery, especially among those with impaired memory or cognition (Milisen et al. 2001, Gruber-Baldini et al. 2003).

The deficiency of standard treatment for this patient group has been emphasized in international publications for several decades now (Beaupre et al. 2005, Handoll et al. 2009, Giusti et al. 2011). Various treatment concepts have been described, adding especially geriatric expertise (both medical and nursing) to the surgical treatment. In some cases, logistical changes have also been made to 
optimize the treatment (Folbert et al. 2012). Finland has guidelines for good practice in hip fracture treatment issued by a group of experts (Duodecim 2011). The post-operative inpatient period is usually quite short among Finnish hip fracture patients. They are generally treated at the operating hospital for approximately seven days and then discharged to their local health care center for continuation rehabilitation, which will take 46 days on average (Nurmi et al. 2003). However, the selection of the post-operative rehabilitation unit depends on the patient's pre-fracture physical and psychological capacity as well as the goals of the rehabilitation. The usual discharge options in Finland are specialized geriatric rehabilitation unit, health care center, or long-term institutionalization (Duodecim 2011).

\subsection{Rehabilitation approaches aiming at improving physical functioning after hip fracture}

The initial aim of rehabilitation after hip fracture surgery is to to get people out of bed, weight-bearing, walking and functioning (Handoll, Sherrington \& Mak 2011). Mobilization should take place already during the first pos-surgery day, since early mobilization has been shown to be associated with better recovery of locomotion and physical functioning (Hoenig et al. 1997, Penrod et al. 2004, Zidén, Frändin \& Kreuter 2008, Handoll, Sherrington \& Mak 2011), and it also reduces post-operative complications (Kamel et al. 2003). Later, the aim of rehabilitation is to minimize impairments (such as reduced strength and impaired balance) and improve overall physical performance (Handoll, Sherrington \& Mak 2011).

Plenty of research has been carried out on acute post-operative rehabilitation programs following surgery for hip fracture (Handoll et al. 2009, Crotty et al. 2010, Handoll, Sherrington \& Mak 2011). However, continuation rehabilitation delivered after hospital discharge has been less studied. There is strong evidence that concentrated multidisciplinary geriatric rehabilitation is cost-effective (Swanson et al. 1998, Day et al. 2001, Huusko et al. 2002). Geriatric rehabilitation during the inpatient period typically takes place in the hospital ward, and involves a multidisciplinary team of health care professionals (Huusko et al. 2002, Handoll et al. 2009, Mak et al. 2010). Previous research has also indicated that, in particular those with cognitive impairments and other neurological diseases require intensive supported daily exercises and assessment as to whether there is a need for assistive devices (Jonsson, Sernbo \& Johnell 1995, Ramnemark et al. 2000, Muir \& Yohannes 2009). Additionally, the previous reseach literature suggests that multi-component rehabilitation programs should be utilized among older people who have sustained a hip fracture to maximize the effect of the rehabilitation on physical functioning (Liu \& Latham 2010, Akunne, Murthy \& Young 2012). Multi-component interventions consist of items which have been found effective in earlier studies, 
such as strength and balance training, fall risk assessment, and modification of the home environment. Overall, rehabilitation should be based on the aims of the individual patient and support coping in daily activities as well as moving outdoors (Huusko et al. 2002, Mak et al. 2010). In addition, a rehabilitation plan prepared together with the patient, his/her close relatives, and outpatient care, along with systematic continuation rehabilitation at home have been shown to improve physical functioning and quality of life (Huusko et al. 2002, Mak et al. 2010).

\subsubsection{Selection criteria for the systematic literature review}

Since the target group in this study comprises community-dwelling older people, the following systematic review of randomized controlled trials (RCT) concentrates solely on post-discharge physical rehabilitation programs aiming to improve physical functioning among community-dwelling people aged 60 and over recovering from surgery to repair an acute hip fracture. Only trials which did investigate physical functioning outcomes or did comprise physical exercise as a part of the intervention were included. Inpatient interventions (implemented mostly or fully in the hospital ward or inpatient rehabilitation unit) were excluded. From the methodological point of view, only RCTs with valid statistical methods were included.

The studies in this literature review have primarily been selected from three recent systematic Cochrane reviews dealing with physical rehabilitation practices after a hip fracture (Handoll et al. 2009, Crotty et al. 2010, Handoll, Sherrington \& Mak 2011). Ten research articles from eleven RCTs matched the aforementioned inclusion criteria. In addition, to detect other applicable or recently published research articles, a systematic online search was carried out in May 2013 using a selection of the keywords applied in the above-mentioned systematic reviews (see Appendix 1). The keywords were determined based on their relevance to the main outcome of this study. The databases searched were MEDLINE and PEDro - The Physiotherapy Evidence Database (both from 1990 to 2013). After the online retrieval, the original selection was complemented with five relevant research articles (Host et al. 2007, Zidén, Kreuter \& Frändin 2010, Orwig et al. 2011, Sylliaas et al. 2011, Sylliaas et al. 2012). The final selection comprised fifteen articles reporting the results of altogether eleven different randomized controlled trials (see Table 1 for details).

It should be noted that five publications in the selection were published after the research plan to this dissertation had been drawn up (Zidén, Frändin \& Kreuter 2008, Zidén, Kreuter \& Frändin 2010, Sylliaas et al. 2011, Sylliaas et al. 2012, Orwig et al. 2011). Thus, ten publications in the selection were already available when the planning of the present project began (Sherrington \& Lord 1997, Tinetti et al. 1999, Crotty et al. 2002, Hauer et al. 2002, Crotty et al. 2003, Binder et al. 2004, Sherrington, Lord \& Finch 2004, Mangione et al. 2005, Tsauo et al. 2005, Host et al. 2007). On three occasions, two articles were found that reported the short-term and long-term outcomes of the same trial (Crotty et al. 2002, Crotty et al. 2003, Zidén, Frändin \& Kreuter 2008, Zidén, Kreuter \& 
Frändin 2010, Sylliaas et al. 2011, Sylliaas et al. 2012). In addition, in one case, the first published publication reported the results of the intention-to-treat (Binder et al. 2004) and the second the results of the per-protocol analysis (Host et al. 2007). A summary of the study results on post hip fracture rehabilitation programs among community-dwelling older people ( $\geq 60$ years) is presented in Table 1.

\subsubsection{Resistance training}

Three trials investigated the effects of resistance training. The study by Hauer et al. (2002) tested supervised progressive resistance training combined with functional training. In the study by Mangione et al. (2005), strength training was home-based and done using a portable resistance exercise machine. The third trial investigated progressive strength training, including group and individual sessions, and was guided by physiotherapist (Sylliaas et al. 2011, Sylliaas et al. 2012). These three trials showed that progressive 12-week individual or groupbased resistance training may improve muscle force (Hauer et al. 2002, Mangione et al. 2005, Sylliaas et al. 2011, Sylliaas et al. 2012), balance (Sylliaas et al. 2011) and mobility (Hauer et al. 2002, Sylliaas et al. 2011), when compared to aerobic training, placebo activities or standard care among older people who have sustained a hip fracture. However, the changes in self-rated disability outcomes were not significant (Hauer et al. 2002, Mangione et al. 2005, Sylliaas et al. 2011, Sylliaas et al. 2012).

\subsubsection{Multi-component physical training interventions delivered outside the home}

Three trials investigated the effects of multi-component physical training interventions that were delivered outside the home. Sherrington et al. first studied the effects of functional weight-bearing exercises in the 1990's and again in the first decade of the present century. In these studies, the rehabilitation program given in an outpatient rehabilitation unit consisted of sit-to-stand, lateral step-up on to a block, forward step-up-and-over (stepping onto a block with both legs and down off it again), forward foot taps (tapping one foot up onto a block while supporting the weight on the other leg), and a stepping grid (stepping in different directions as guided by marks on the floor). The exercises were progressed by increasing the number of repetitions, lessening the hand support, increasing the height of the blocks, or decreasing the chair height. The results show that weight-bearing exercises specifically improved only the weight-bearing, muscle strength, and timed sit-to-stand test results (Sherrington \& Lord 1997, Sherrington, Lord \& Herbert 2004). This training method had no effect on self-reported physical disability outcomes. However, perceived physical disability was assessed only in the latter trial (Sherrington, Lord \& Herbert 2004).

Binder et al. (2004) investigated the effects of a six-month individually tailored progressive group physical therapy program, which consisted of 
strength, balance and stretching exercises, compared to low-intensity home exercise. Training was supervised by a physiotherapist and it was performed at an outpatient exercise facility. The results showed that the training positively affected both self-rated physical disability, as measured by the Functional Status Questionnaire (FSQ) physical function subscale, and performance-based mobility measures such as postural balance and gait speed (Binder et al. 2004). In addition, per-protocol analysis showed improvement in four more functional outcomes (Host et al. 2007).

\subsubsection{Multi-component home-based interventions}

Five trials studied the effects of multi-component home-based interventions compared to conventional care (Tinetti et al. 1999, Crotty et al. 2002, Tsauo et al. 2005, Zidén, Frändin \& Kreuter 2008, Orwig et al. 2011). The length of the tested interventions varied between one and six months. Three trials included both physical and functional therapy (Tinetti et al. 1999, Crotty et al. 2002, Zidén, Frändin \& Kreuter 2008). One of these trials also comprised home-visits by a nurse (Zidén, Frändin \& Kreuter 2008) and one trial included home visits by an occupational therapist, speech pathologist, and social worker (Crotty et al. 2002). Two interventions focused, in particular, on supported hospital discharge (Crotty et al. 2003, Zidén, Frändin \& Kreuter 2008). Additionally, one trial comprised a self-efficacy-based motivational component (Orwig et al. 2011). Physical therapy was included in every trial and the exercises consisted typically of strength, balance, stretching and transferring training. However, only one trial aimed specifically at improving independence in the activities of daily living (Crotty et al. 2002). All five trials succeeded in improving physical functioning in at least one performance-based measurement (e.g. gait, muscle strength, balance). However, only two trials (four publications) reported a significant positive effect in coping with daily activities (Crotty et al. 2002, Crotty et al. 2003, Zidén, Frändin \& Kreuter 2008, Zidén, Kreuter \& Frändin 2010).

\subsubsection{Summary of the randomized controlled trials with outpatient rehabilitation interventions aiming at improving physical functioning after hip fracture}

Moderate evidence exists on the positive effects of outpatient and home-based physical rehabilitation programs on physical functioning among older hip fracture patients. The content of rehabilitation interventions varies from traditional strength and balance training to complex multi-component and multi-professional programs. Considerable variation exists, in accordance with the selected outcome measurements of these clinical trials. Performance-based tests, which measure mobility and physical functioning in clinical or laboratory setting, are more commonly used than self-report measures of perceived disability in fundamental daily activities. One of the trials did not assess selfreported physical disability at all (Sherrington \& Lord 1997). Moreover, only 
one of the eleven selected trials in this literature review posited perceived physical disability as the main outcome measure (Crotty et al. 2003).

Three trials examined the effects of resistance training. All of them observed non-significant effects in disability outcomes (Hauer et al. 2002, Sylliaas et al. 2011). The other three trials studying the effects of multicomponent physical training interventions delivered outside the home reported conflicting results. The intervention which included weight-bearing exercises had no effect on physical disability outcomes (Sherrington, Lord \& Herbert 2004). The trial investigating the effects of group-based physical therapy showed a positive effect on both self-rated physical disability and on performance-based functional measures (Binder et al. 2004). Altogether five trials studied the effects of multi-component home-based interventions compared with conventional care (Tinetti et al. 1999, Crotty et al. 2002, Tsauo et al. 2005, Zidén, Frändin \& Kreuter 2008, Orwig et al. 2011). Although all five trials succeeded in improving physical functioning, at least in one performancebased measure, only two trials showed a positive effect on the ability to cope with daily activities (Crotty et al. 2002, Tsauo et al. 2005, Zidén, Frändin \& Kreuter 2008).

In conclusion, this literature review yielded conflicting results on the effects of outpatient rehabilitation programs delivered after hospital discharge aiming to improve physical functioning and reduce physical disability among older people who have sustained a hip fracture. More evidence is therefore needed, especially on home-based rehabilitation programs targeting improved physical functioning after hip fracture with perceived disability as an outcome measure. 


\begin{tabular}{|c|c|c|c|c|c|}
\hline \multirow{2}{*}{$\begin{array}{l}\text { Researchers } \\
\text { Resistance training }\end{array}$} & Participants (n) & Intervention & Outcome measures & \multicolumn{2}{|l|}{ Effect } \\
\hline & & & & & \\
\hline \multirow[t]{7}{*}{ Hauer et al. 2002} & \multirow[t]{7}{*}{ 28, Germany } & \multirow{7}{*}{$\begin{array}{l}\text { 12-week progressive supervised } \\
\text { resistance training and functional } \\
\text { training vs. placebo motor activities }\end{array}$} & Leg-press & \multicolumn{2}{|l|}{+} \\
\hline & & & Handgrip dynamometer & \multicolumn{2}{|l|}{+} \\
\hline & & & Timed Up-and-Go (TUG) & \multicolumn{2}{|l|}{+} \\
\hline & & & Stair climbing & \multicolumn{2}{|l|}{+} \\
\hline & & & Geriatric Depression Scale (GDS) & \multicolumn{2}{|l|}{+} \\
\hline & & & ADL (Barthel\&Mahoney 1965) & \multicolumn{2}{|l|}{ NS } \\
\hline & & & IADL (Lawton\&Body 1969) & \multicolumn{2}{|l|}{ NS } \\
\hline \multirow{5}{*}{$\begin{array}{l}\text { Mangione et al. } \\
2005\end{array}$} & \multirow[t]{5}{*}{ 41, USA } & \multirow{5}{*}{$\begin{array}{l}\text { 12-week home-based resistance or } \\
\text { aerobic training vs. no training }\end{array}$} & Lower limb strength (dynamometer) & \multicolumn{2}{|l|}{+} \\
\hline & & & 36-Item Short-Form Health Survey (SF-36) physical function subscale & \multicolumn{2}{|l|}{ NS } \\
\hline & & & 6-minute walk test & \multicolumn{2}{|l|}{ NS } \\
\hline & & & GaitMat II & \multicolumn{2}{|l|}{ NS } \\
\hline & & & Handheld digital strain-gauge dynamometer & \multicolumn{2}{|l|}{ NS } \\
\hline \multirow{8}{*}{$\begin{array}{l}\text { Sylliaas et al. } 2011 \\
\text { \& } \\
\text { Sylliaas et al } 2012\end{array}$} & \multirow[t]{8}{*}{ 150, Norway } & \multirow{8}{*}{$\begin{array}{l}\text { 3-month strength training guided by } \\
\text { physiotherapist combining group and } \\
\text { individual sessions: exercise sessions at } \\
\text { outpatient clinic twice per week and } \\
\text { home-training program once a week }\end{array}$} & Six-minute walk test & \multicolumn{2}{|c|}{$+(-11)+(-12)$} \\
\hline & & & Sit-to-stand test & + & + \\
\hline & & & Maximum step height test & + & + \\
\hline & & & Berg Balance Scale (BBS) & + & NS \\
\hline & & & Timed Up-and-Go & + & NS \\
\hline & & & Maximum gait speed test for $10 \mathrm{~m}$ & + & NS \\
\hline & & & The Nottingham Extended Activities of Daily Living score & NS & NS \\
\hline & & & 12-Item Short Form Health Survey (SF-12) physical function subscale & NS & NS \\
\hline \multicolumn{6}{|c|}{ Multi-component physical training interventions delivered outside home } \\
\hline \multirow{5}{*}{$\begin{array}{l}\text { Sherrington et al. } \\
1997\end{array}$} & \multirow{5}{*}{ 44, Australia } & \multirow{5}{*}{$\begin{array}{l}\text { 1-month home-based weight bearing } \\
\text { exercises vs. no specific exercises }\end{array}$} & Weight bearing (lateral step ability) & \multicolumn{2}{|l|}{+} \\
\hline & & & Postural control (sway-meter) & \multicolumn{2}{|l|}{ NS } \\
\hline & & & Quadriceps strength with string gauge & \multicolumn{2}{|l|}{ NS } \\
\hline & & & Functional reach & \multirow{2}{*}{\multicolumn{2}{|c|}{$\begin{array}{l}\text { NS } \\
\text { NS (Continues) }\end{array}$}} \\
\hline & & & Timed walking test & & \\
\hline
\end{tabular}




\begin{tabular}{|c|c|c|c|c|c|}
\hline \multirow{3}{*}{$\begin{array}{l}\text { Researchers } \\
\text { Sherrington et al. } \\
2004\end{array}$} & \multirow{2}{*}{$\begin{array}{l}\text { Participants (n) } \\
120, \text { Australia }\end{array}$} & \multirow{4}{*}{$\begin{array}{l}\text { Intervention } \\
\text { 4-month home-based weight bearing } \\
\text { exercises vs. home-based non-weight } \\
\text { bearing exercises vs. no exercises }\end{array}$} & \multirow{3}{*}{$\begin{array}{l}\text { Outcome measures } \\
\text { Strength of the knee extensor muscles with a string gauge } \\
\text { Timed sit-to-stand }\end{array}$} & \multicolumn{2}{|l|}{ Effect } \\
\hline & & & & \multicolumn{2}{|l|}{+} \\
\hline & & & & \multicolumn{2}{|l|}{+} \\
\hline & & & Functional reach & \multicolumn{2}{|l|}{+} \\
\hline & & & $A D L(K a t z 1967)$ & \multicolumn{2}{|l|}{ NS } \\
\hline & & & Weight bearing (lateral step ability) & \multicolumn{2}{|l|}{ NS } \\
\hline & & & Hand-held dynamometer & \multicolumn{2}{|l|}{ NS } \\
\hline & & & $6 \mathrm{~m}$ walking test & \multicolumn{2}{|l|}{ NS } \\
\hline & & & Physical Performance and Mobility Examination (PPME) & \multicolumn{2}{|l|}{ NS } \\
\hline & & & Postural control (sway-meter) & \multicolumn{2}{|l|}{ NS } \\
\hline \multirow{10}{*}{$\begin{array}{l}\text { Binder et al. } 2004 \\
\text { (intention-to- } \\
\text { treat) } \\
\& \\
\text { Host et al. } 2007 \\
\text { (per-protocol) }\end{array}$} & \multirow[t]{10}{*}{ 90, USA } & \multirow{10}{*}{$\begin{array}{l}\text { 6-month individually tailored } \\
\text { supervised progressive physical } \\
\text { therapy, including strength, balance } \\
\text { and stretching exercises performed at } \\
\text { an outpatient exercise facility vs. low- } \\
\text { intensity home exercise }\end{array}$} & Functional Status Questionnaire (FSQ) physical function subscale & $+(\mathrm{ITT})$ & $\sim(\mathrm{PP})$ \\
\hline & & & Modified Physical Performance Test (PPT) & + & $\sim$ \\
\hline & & & Timed stair climb & $\sim$ & + \\
\hline & & & Lower-extremity peak torques & $\sim$ & + \\
\hline & & & Need of assistive devices for mobility & $\sim$ & + \\
\hline & & & Self-selected and maximal gait speed & NS & + \\
\hline & & & $A D L($ Katz 1967) & NS & NS \\
\hline & & & IADL (Lawton\&Body 1969) & NS & NS \\
\hline & & & Cybex isokinetic dynamometry (muscle strength) & NS & NS \\
\hline & & & Berg Balance scale (BBS) & NS & NS \\
\hline \multicolumn{6}{|c|}{ Multi-component home-based interventions } \\
\hline \multirow[t]{9}{*}{ Tinetti et al. 1999} & \multirow[t]{9}{*}{ 304, USA } & \multirow{9}{*}{$\begin{array}{l}\text { 6-month systematic multi-factorial } \\
\text { home-based rehabilitation strategy } \\
\text { involving physical and functional } \\
\text { therapy vs. conventional care }\end{array}$} & Upper extremity strength & \multicolumn{2}{|l|}{+} \\
\hline & & & ADL (Katz 1967) & \multicolumn{2}{|l|}{ NS } \\
\hline & & & Berg Balance scale (BBS) & \multicolumn{2}{|l|}{ NS } \\
\hline & & & Performance-Oriented Mobility Assessment (POMA) & \multicolumn{2}{|l|}{ NS } \\
\hline & & & Timed $10 \mathrm{~m}$ walking & \multicolumn{2}{|l|}{ NS } \\
\hline & & & Chair rise & \multicolumn{2}{|l|}{ NS } \\
\hline & & & Stair climbing & \multicolumn{2}{|l|}{ NS } \\
\hline & & & Lower extremity strength & \multicolumn{2}{|c|}{$\begin{array}{l}\text { NS } \\
\text { NS (Continues) }\end{array}$} \\
\hline & & & Center for Epidemiologic Studies-Depression Scale (CES-D) & \multicolumn{2}{|c|}{ NS (Continues) } \\
\hline
\end{tabular}




\begin{tabular}{|c|c|c|c|c|c|}
\hline \multirow{6}{*}{$\begin{array}{l}\text { Researchers } \\
\text { Crotty et al. } 2002 \\
\text { (4-month results) } \\
\& \\
\text { Crotty et al. } 2003 \\
\text { (12-month results) }\end{array}$} & Participants (n) & Intervention & Outcome measures & \multicolumn{2}{|l|}{ Effect } \\
\hline & \multirow{8}{*}{ 66, Australia } & \multirow{8}{*}{$\begin{array}{l}\text { Early discharge and 4-month } \\
\text { individually tailored home-based } \\
\text { rehabilitation targeting in } \\
\text { improvement in the activities of daily } \\
\text { living vs. conventional care }\end{array}$} & Modified Barthel's Index & $+(-02)$ & $+(-03)$ \\
\hline & & & 36-Item Short Form Health Survey (SF-36) physical function subscale & + & + \\
\hline & & & Falls Efficacy Scale & + & $\sim$ \\
\hline & & & Timed Up-and-go (TUG) & NS & + \\
\hline & & & Mini-Mental State Examination & NS & $\sim$ \\
\hline & & & Activities-specific Balance Confidence Scale (ABC) & NS & $\sim$ \\
\hline & & & London Handicap Scale & NS & $\sim$ \\
\hline & & & Berg Balance Scale & NS & $\sim$ \\
\hline Tsauo et al. 2005 & 54, Taiwan & 12-week individualized home-based & WHOQOL-BREF (quality of life) & + & \\
\hline & & multi-factorial physical therapy & Walking velocity & + & \\
\hline & & program including e.g. strengthening, & Harris hip score & + & \\
\hline & & balance and transferring exercises) vs. & Lower limb strength (dynamometer) & + & \\
\hline & & & Hip range of motion & NS & \\
\hline Zidén et al. 2008 & 102, Sweden & 1-month multi-professional home & Functional Independence Measure (FIM) & $+(-08)$ & $+(-10)$ \\
\hline (one-month & & rehabilitation program focused on & Instrumental Activity Measure (IAM) scale & + & \\
\hline results) & & supported discharge, independence in & 36-Item Short Form Health Survey (SF-36) physical function subscale & + & + \\
\hline & & daily activities, and enhancing physical & Frenchay Activities Index (FAI) & + & + \\
\hline Zidén et al. 2010 & & activity and confidence in performing & Walking outdoors & + & + \\
\hline (12-month results) & & onventional care & Sit to stan & + & + \\
\hline & & & Timed up-and-go (TUG) & + & + \\
\hline & & & Falls Efficacy Scale FES(S) & + & + \\
\hline & & & Centre for Epidemiological Studies Depression Scale (CES-D) & NS & NS \\
\hline Orwig et al. 2011 & 208, USA & 6-month home-based Exercise Plus & Yale Physical Activity Scale & + & \\
\hline & & program delivered by physiotherapist & Step Activity Monitor & + & \\
\hline & & consisted of an exercise component & The Self-efficacy for Walking-Exercise Scale & + & \\
\hline & & including e.g. strength, balance and & Functional Status Index (FSI) & NS & \\
\hline & & stretching exercises and a self-efficacy & 36-Item Short Form Health Survey (SF-36) physical function subscale & NS & \\
\hline & & otivational component vs. & IADL (Older Americans Resources and Services Instrument) & NS & \\
\hline & & onal care & JAMAR handheld dynamometer & NS & \\
\hline & & & Lower Extremity Gain Scale & NS (Con & tinues) \\
\hline
\end{tabular}


TABLE 1

(Continues)

\begin{tabular}{|c|c|c|c|}
\hline Researchers & Participants (n) Intervention & Outcome measures & Effect \\
\hline Orwig et al. 2011 & & 6-minute walk test & NS \\
\hline \multirow[t]{5}{*}{ Continues } & & Bone mineral density (DXA) & NS \\
\hline & & Geriatric Depression Scale (GDS) & NS \\
\hline & & *Vote counting for functional performance or physical activity & $33 / 62$ \\
\hline & & \#Vote counting for perceived physical disability & $7 / 19$ \\
\hline & & ${ }^{\circ}$ Vote counting for other outcomes & $2 / 7$ \\
\hline
\end{tabular}

+ = positive effect; NS = non-significant effect; ITT = intention-to-treat; PP = per-protocol; italics indicates an assessment method for perceived physical disability; ${ }^{*}$ Calculated as: [studies reporting positive effect(s) in functional performance or physical activity assessments]/[total number of functional performance or

physical activity assessments]; \#Calculated as: [studies reporting positive effect(s) in self -reported physical disability assessments]/[total number of self -reported

physical activity assessments]; \#Calculated as: [studies reporting positive effect(s) in self -reported physical disability assessments]/[total
physical disability assessments]; ${ }^{\circ}$ Calculated as: [studies reporting positive effect(s) in other outcomes]/[total number of other outcomes] 


\section{AIMS OF THE STUDY}

This research focuses on community-dwelling men and women aged 60 and over who had sustained a recent hip fracture. The purpose of this thesis was to investigate the effects of a three-month resistance training program as well as a one-year individually tailored extended multi-component home-based physical rehabilitation program on physical disability. In addition, this research aimed at defining the associations of functional balance and balance confidence in relation to physical disability among older people recovering from a hip fracture. The specific aims of the thesis were to determine:

1. Associations of postural balance and balance confidence with physical disability among community-dwelling older people who have sustained a hip fracture (Study I).

2. The effects of a three-month individually-tailored progressive resistance training program on physical disability among community-dwelling older people with a previous hip fracture (Study II).

3. The effects of a one-year individually tailored multi-component homebased physical rehabilitation program on physical disability among community-dwelling older people with a recent hip fracture (Studies III \& IV). 


\section{METHODS}

\subsection{Study design and participants}

This thesis reports the results of two RCTs entitled "The effects of strength training on muscle strength, asymmetry in lower limb muscle strength and mobility in older men and women with a history of hip fracture" (HIP ASYMMETRY; ISRCTN34271567) and "Promoting mobility after hip fracture" (PROMO; ISRCTN53680197). The combined (HIP ASYMMETRY + PROMO) baseline data set includes information on 159 men and women aged 60 and over measured 6 weeks to 7.5 years post hip fracture. Summary of the research designs and participants is shown in Table 2.

The HIP ASYMMETRY trial aimed at investigating the prevalence and functional consequences of asymmetrical lower limb muscle strength deficit and to examine the effects of intensive training on these problems. The PROMO trial was designed and developed to test a rehabilitation program aiming to restore mobility and functional capacity in older people recovering from a hip fracture. Figure 1 summarizes the time lines and the rehabilitation interventions of the studies. The flow chart of the HIP ASYMMETRY study is illustrated in Figure 2 and the flow chart of the PROMO study in Figure 3. The detailed protocol of the PROMO study is explained in Figure 4.

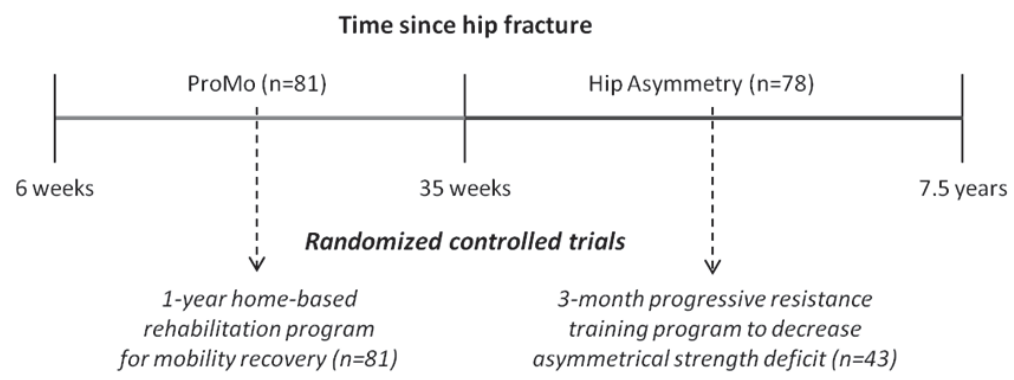

FIGURE 1 Simplified study designs in the HIP ASYMMETRY and PROMO trials. 


\subsubsection{HIP ASYMMETRY (Studies I \& II)}

The HIP ASYMMETRY study comprises of 60 to 85 -year-old men and women with a hip fracture sustained on average three years earlier (range 6 months-7.5 years). All 452 surviving patients with a hip fracture in the years 1998-2004 were identified using the patient records of the Central Finland Central Hospital. Those willing to participate were interviewed over the telephone $(n=132)$. Patients not living independently, with neurological and progressive severe illnesses, inability to walk outdoors without another person's assistance, moderate or severe memory problems (MMSE <21) or suffering from alcoholism were excluded. Of the 78 people participating in the laboratory assessments, those without contraindications for the progressive resistance training $(n=43)$ participated in a RCT investigating the effects of three months' supervised resistance training on physical disability. They were randomly assigned either to the training $(n=22)$ or control $(n=21)$ group. Data was collected in two phases in 2004-2005, owing to the small number of eligible subjects in 2004. In 2005, at the same time of year (August - December), the study was repeated using the same protocol, infrastructure, and training. The only difference was the enlargement of the recruitment area from the city of Jyväskylä and surrounding communities to the complete Central Finland hospital district. The data were pooled for analysis.

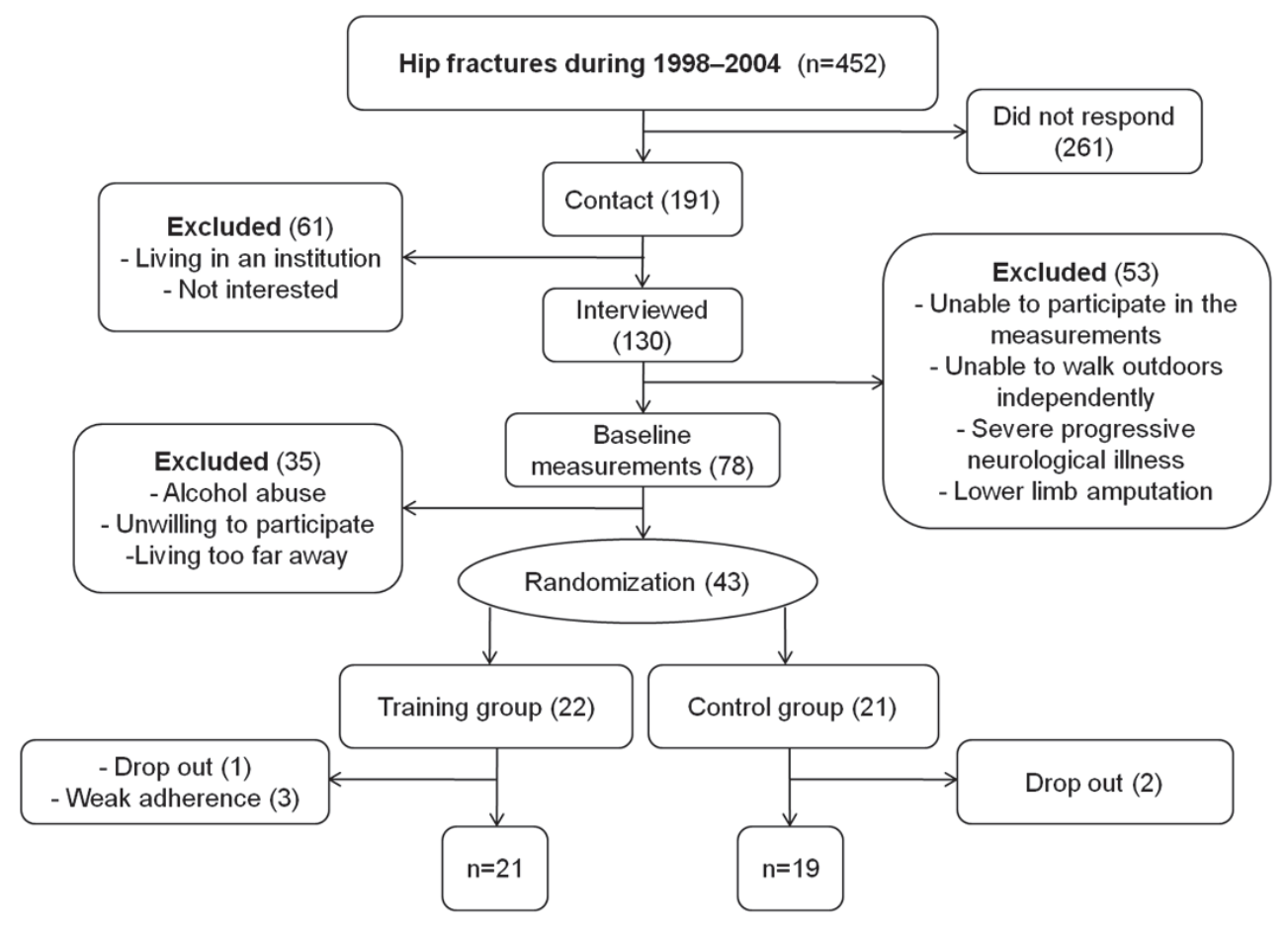

FIGURE 2 Flow chart of the HIP ASYMMETRY (Studies I, II). 


\subsubsection{PROMO (Studies I, III \& IV)}

In the PROMO study, all consecutive patients operated on for a hip fracture were screened for eligibility by staff of the physiotherapy department of the Central Finland Central Hospital. The target group comprised ambulatory and community-dwelling men and women aged 60 and over who had received surgery for a femoral neck or pertrochanteric fracture (ICD code S72.0 or S72.1) in 2008-2010 at the Jyväskylä Central Hospital and who were resident in the city of Jyväskylä or in eight neighboring municipalities $(n=296)$. Time since fracture was on average 10 weeks (range 6 to 34 weeks). All potential participants received a letter informing then about the study. During the inpatient period at the health care centre, a researcher visited the patients who had expressed interest in participating $(\mathrm{n}=161)$. Patients living in an institution or confined to bed at the time of the fracture, suffering from severe memory problems (Mini Mental State Examination, MMSE<18) (Folstein, Folstein \& McHugh 1975), alcoholism, severe cardiovascular, pulmonary or progressive (i.e neoplasm, amyotrophic lateral sclerosis) disease, para- or tetraplegic or severe depression (Beck Depression Inventory, BDI-II >29) (Scogin et al. 1988) were excluded from the study. In total, 81 community-dwelling older people with a recent hip fracture (18 men and 63 women) participated in a RCT investigating the effects of a one-year physical rehabilitation program on physical disability. Of them, 40 were randomly assigned to the intervention and 41 to the control group.

TABLE 2 Summary of the research designs, study participants, and main outcomes.

\begin{tabular}{|c|c|c|c|c|c|}
\hline Study & Data & $\mathbf{n}$ & Design & Participants & Main outcome \\
\hline $\mathrm{I}$ & $\begin{array}{l}\text { HIP ASYMMETRY } \\
\text { Baseline }(\mathrm{n}=78) \\
+ \text { PROMO }(\mathrm{n}=81)\end{array}$ & 159 & $\begin{array}{l}\text { Cross- } \\
\text { sectional }\end{array}$ & $\begin{array}{l}\text { Community-dwelling } \\
\text { people aged } 60 \text { and } \\
\text { over (6wks-7yrs post } \\
\text { hip fracture) }\end{array}$ & $\begin{array}{l}\text { Physical disability } \\
\text { measured with a } \\
\text { questionnaire }\end{array}$ \\
\hline II & HIP ASYMMETRY & 43 & RCT & $\begin{array}{l}\text { Community-dwelling } \\
\text { people aged } 60 \text { to } 85 \\
\text { with a previous hip } \\
\text { fracture }\end{array}$ & $\begin{array}{l}\text { Physical disability } \\
\text { measured with a } \\
\text { validated } \\
\text { questionnaire }\end{array}$ \\
\hline III & PROMO & 81 & $\begin{array}{l}\text { Cross- } \\
\text { sectional }\end{array}$ & $\begin{array}{l}\text { Community-dwelling } \\
\text { people aged } 60 \text { and } \\
\text { over recovering from } \\
\text { hip fracture }\end{array}$ & $\begin{array}{l}\text { Study design, health } \\
\text { status, demographics, } \\
\text { physical characteristics } \\
\text { and living habits }\end{array}$ \\
\hline IV & PROMO & 81 & RCT & $\begin{array}{l}\text { Community-dwelling } \\
\text { people aged } 60 \text { and } \\
\text { over recovering from } \\
\text { hip fracture }\end{array}$ & $\begin{array}{l}\text { Physical disability } \\
\text { measured with a } \\
\text { questionnaire }\end{array}$ \\
\hline
\end{tabular}




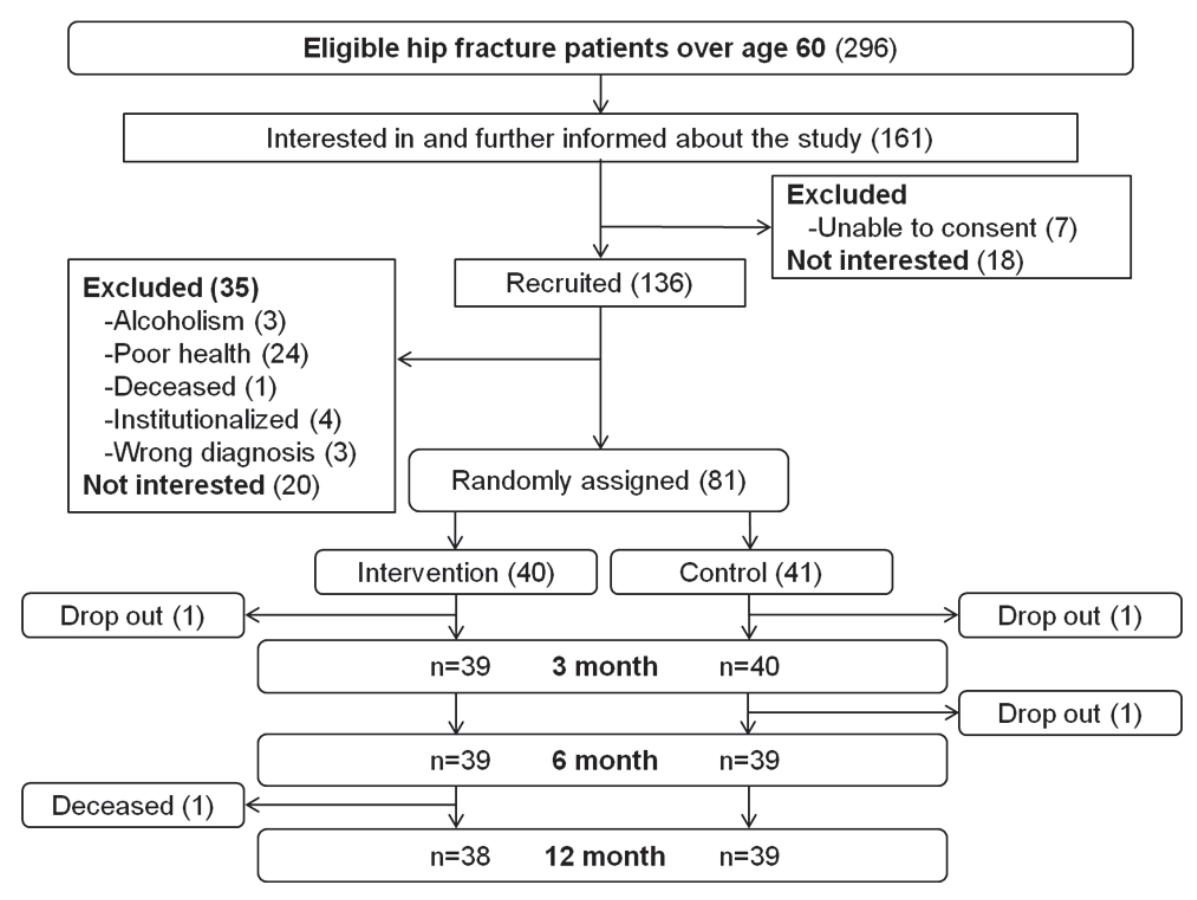

FIGURE 3 Flow chart of the PROMO (Studies I, III \& IV).

\subsection{Randomization and blinding}

Participants who gave their informed consent underwent a baseline assessment prior to randomization. A statistician not involved in the recruitment or assessments developed the group allocation schedule using a computergenerated random number sequence and stored the list off-site. In the HIP ASYMMETRY study the groups were randomized in blocks of gender and stratified by average age. In the PROMO study men and women and those with internal fixation or arthroplasty were randomized by blocks which were randomly arranged within blocks of 10 . In both studies the study group assignment was enclosed in sealed envelopes and the study coordinator performed the randomization by drawing lots from the blocks. The PROMO study was single-blinded. The researchers who collected the outcome measures and recorded the data were blinded to the group allocation. The HIP ASYMMETRY study was only partially single-blinded, since not all of the researchers who collected the outcome measures and recorded the data were blinded to group allocation. To ensure blinding, participants were asked not to disclose their group allocation to the assessors and other participants. Those assigned to the intervention and the research physiotherapists delivering the interventions could not be blinded to the intervention group allocation. 


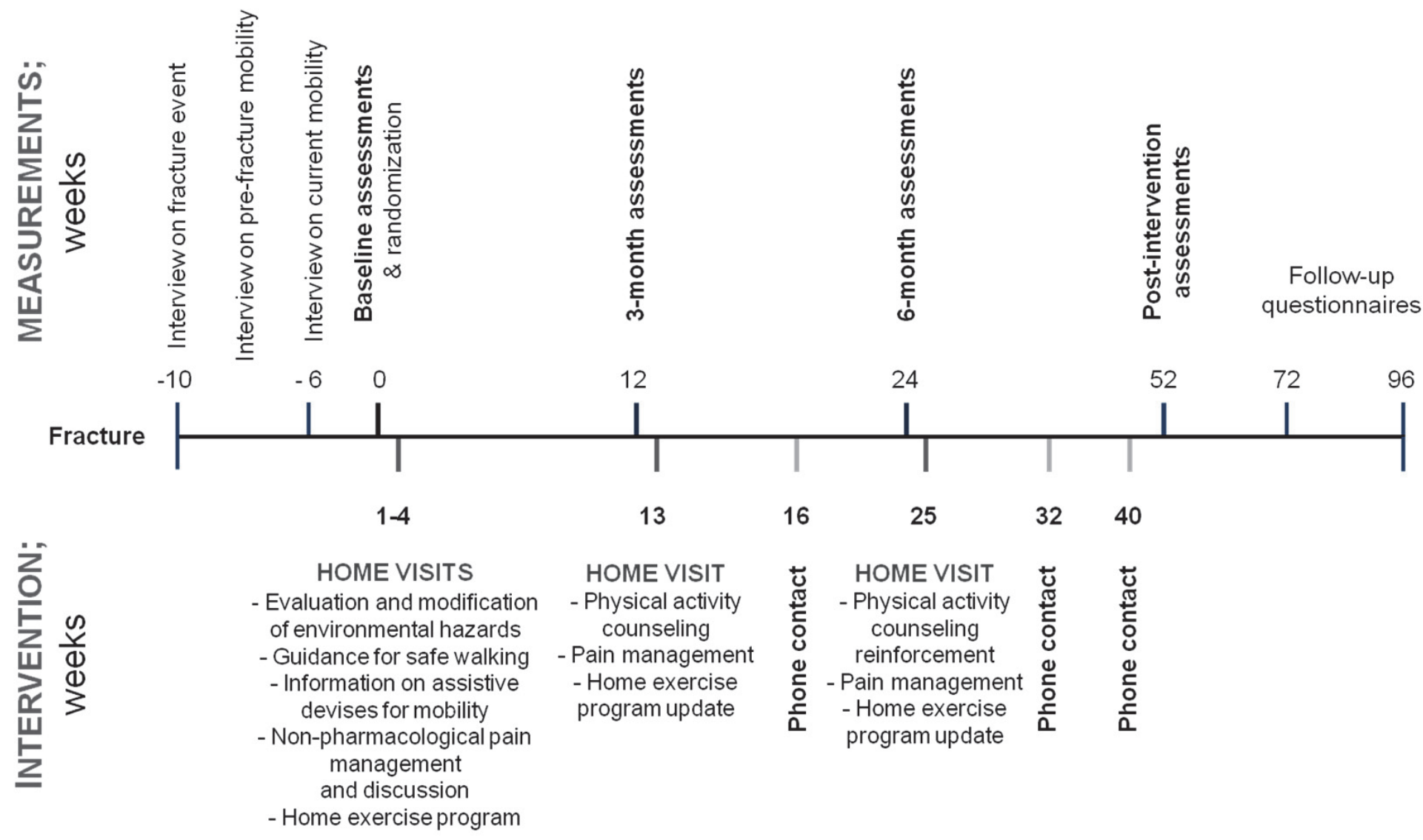

FIGURE 4 Protocol of the PROMO study (Studies I, III \& VI). 


\subsection{Sample size}

\section{HIP ASYMMETRY study}

Power calculations were performed based on the knowledge from prior studies by Häkkinen et al. (1995), Skelton et al. (1995), and Sipilä et al. (1996) indicating that three months of strength training increased muscle strength by $15-37 \%$ among healthy older women. In the Hip Asymmetry trial, the expected change for the muscle strength was thus set to $25 \%$. Power calculations indicated that a minimum of 30 subjects would need to be included in both study groups to detect significant changes in the main outcome measures (muscle force, power, balance) at $\alpha=0.05$ and $\beta=0.20$ (power $80 \%$ ). Despite the prolonged and intensive recruitment, the design was slightly underpowered with 22-24 persons per group.

\section{PROMO study}

Pretrial power calculations were based on earlier published longitudinal data on mobility recovery after a hip fracture. In the study by Visser et al. (2000), 45.3\% of the community-dwelling participants were independent in more demanding mobility tasks (chair rising, walking one block and negotiating stairs) before the fracture. Twelve months after a hip fracture less than one-third of them $(20.7 \%$ of the total sample) had regained their pre-fracture level of mobility. The purpose of the present study was to restore the pre-fracture level of mobility by means of the PROMO rehabilitation program (Sipilä et al. 2011). To detect the expected difference between the study groups in mobility recovery at $a=0.05$ and $\beta=0.20$ (based on percentages calculated from the study by Visser et al. (2000), a minimum of 44 subjects were needed in each study group. Sample size was calculated using an online sample size calculator available from (DSS researcher's toolkit; https://www.dssresearch.com/KnowledgeCenter). The design was slightly underpowered with $40-41$ persons per group.

\subsection{Ethics}

Both RCTs were performed in accordance with the Declaration of Helsinki and approved by the Ethics Committee of the Central Finland Health Care District (HIP ASYMMETRY on October 14 ${ }^{\text {th }}, 2004$ and PROMO on December 18 $8^{\text {th }}, 2007$ ). Written information on the study was given to all participants. Participants signed a written informed consent prior to participation. Proxy consent was not permitted. Those who were interested in the study had an opportunity to discuss with a researcher what participation would involve before signing the informed consent and granting permission for their medical records to be viewed. The participants could, at any point, refuse to participate further. 
TABLE 3 Summary of the measurement methods and variables used in the study including references and reliability.

\begin{tabular}{|c|c|c|c|}
\hline Variables & Study & Methods and reference & Reliability and reference \\
\hline \multicolumn{4}{|l|}{ Physical disability } \\
\hline Activities of daily living (cat) & I-IV & Modified Katz ADL Index (Katz et al. 1963) & $\mathrm{a}=0.84-0.94$ (Reijneveld et al. 2007) \\
\hline Instrumental activities of daily living (cat) & I-IV & Modified IADL Index (Lawton et al. 1969) & $\begin{array}{l}a=0.94-0.99 \text { (Hokoishi et al. 2001, } \\
\text { Vergara et al. 2012) }\end{array}$ \\
\hline Balance confidence (sum score) & I, III \& IV & $\begin{array}{l}\text { Activities-specific Balance Confidence Scale } \\
\text { (Powell et al. 1995) }\end{array}$ & $\mathrm{a}=0.95$ (Talley et al. 2008) \\
\hline Functional balance (sum score) & I, III \& IV & Berg Balance Scale (Berg et al. 1992) & $\mathrm{a}=0.97$ (Berg et al. 1995) \\
\hline \multicolumn{4}{|l|}{ Health status } \\
\hline Presence of chronic conditions (n) & I-IV & Medical examination and medical records & \\
\hline Use of prescription medication (n) & III \& IV & Medical examination and medical records & \\
\hline Fracture status (cat) & I-IV & Medical records & \\
\hline Date and type of surgery (cat) & I-IV & Medical records & \\
\hline Hemoglobin level $(\mathrm{g} / \mathrm{l})$ & III & Blood count & \\
\hline Human C-reactive protein (hCRP) & III & Blood count & \\
\hline Depressive mood (sum score) & I, III \& IV & $\begin{array}{l}\text { Beck Depression Inventory BDI-II } \\
\text { (Scogin et al. 1988) }\end{array}$ & $a=0.90$ (Storch et al. 2004) \\
\hline Cognitive status (sum score) & I-IV & $\begin{array}{l}\text { Mini-Mental State Examination, MMSE } \\
\text { (Folstein et al. 1975) }\end{array}$ & $\mathrm{a}=0.70$ (Lopez et al. 2005) \\
\hline Smoking status (cat) & III & Questionnaire, self-report & \\
\hline Self-rated health (cat) & III & Questionnaire, self-report (Eriksson et al. 2000) & $\mathrm{r}=0.91$ (Patrick et al. 1973) \\
\hline Need for emergency room services (n) & IV & Questionnaire, self-report & \\
\hline \multicolumn{4}{|l|}{ Physical characteristics } \\
\hline Body height (cm) & III & Medical examination & \\
\hline Body weight (kg) & III & Medical examination & \\
\hline Body composition & III & Bioimpedance (BC-418, TANITA, Tokyo, Japan) & $\mathrm{r}=0.88$ (Demura et al. 2005) \\
\hline Body mass index, BMI $\left(\mathrm{kg} / \mathrm{m}^{2}\right)$ & III & Calculated as: [body weight]/[body height $]^{2} \times 100$ & (Continues) \\
\hline
\end{tabular}




\begin{tabular}{|c|c|c|c|}
\hline Variables & Study & Methods and reference & Reliability and reference \\
\hline \multicolumn{4}{|l|}{ Demographics } \\
\hline Age (years) & I-IV & Medical records & \\
\hline Sex (cat) & I-IV & Medical records & \\
\hline Living conditions (cat) & III & Self-report & \\
\hline Income $(€)$ & III & Self-report & \\
\hline Education (cat) & III & Self-report & \\
\hline \multicolumn{4}{|l|}{ Muscle force and power } \\
\hline Maximal knee extension strength (Newton) & I, III \& IV & $\begin{array}{l}\text { Dynamometer chair (Metitur Ltd, Palokka, } \\
\text { Finland) (Rantanen et al. 1999) }\end{array}$ & CV 6\% (Sipilä et al. 1996) \\
\hline Maximal hand grip strength (Newton) & III & Dynamometer (Metitur Ltd, Palokka, Finland) & $\mathrm{r}=0.91$ (Rantanen et al. 1999) \\
\hline Leg extension power $(\mathrm{W})$ & III & Nottingham Power Rig (Portegijs et a.1 2009) & $\begin{array}{l}\text { CV 6-8\% (Lamb et al. 1995, } \\
\text { Tiainen et al. 2005) }\end{array}$ \\
\hline \multicolumn{4}{|l|}{ Mobility } \\
\hline Physical performance (sum score) & III & $\begin{array}{l}\text { Short Physical Performance Battery (SPPB) } \\
\text { (Guralnik et al. 1994) }\end{array}$ & $\mathrm{r}=0.83-0.89$ (Freire et al. 2012) \\
\hline Mobility limitation (cat) & III & Questionnaire, self-report (Visser et al. 2000) & \\
\hline Walking speed (m/s) & III & Photocells & $\begin{array}{l}\text { CV 5\% (Rantanen et al. 1997); } \\
\text { r=0.90 (Bohannon 1997) }\end{array}$ \\
\hline Use of walking aids outdoors (cat) & I, III \& IV & Questionnaire, self-report & \\
\hline \multicolumn{4}{|l|}{ Physical activity } \\
\hline Standardized question (cat) & II \& III & Modified Scale of Grimby (Grimby 1986) & \\
\hline \multicolumn{4}{|l|}{ Pain } \\
\hline Offending pain on the fractured side (cat) & I, II, IV & Questionnaire, self-report & \\
\hline Summed lower-limb pain in 5 locations (cat) & III & Questionnaire, self-report & \\
\hline Average temperature & IV & $\begin{array}{l}\text { Climatological statistics of Finland 1981-2010 } \\
\text { (Pirinen et al. 2012) }\end{array}$ & (Continues) \\
\hline
\end{tabular}




\begin{tabular}{llll}
\hline Variables & Study & Methods and reference & Reliability and reference \\
\hline Falls & & & \\
$\quad$ Indoor falls (n) & IV & Questionnaire, self-report \\
Outdoor falls (n) & IV & Questionnaire, self-report & \\
\hline
\end{tabular}

cat=categorical variable; $n=$ number; $a=$ Cronbach's alpha; $r=$ correlation coefficient 


\subsection{Measurements and assessments}

Described next are the measurements and assessments used in the HIP ASYMMETRY and PROMO studies. First the most central methods are described, followed by the various other descriptive, confounding and mediating factors. A summary of the measurement methods with references and reliability coefficients is presented in Table 3.

\subsubsection{Physical disability}

Physical disability was assessed by a validated questionnaire estimating perceived difficulties in basic (ADL) and instrumental activities of daily living (IADL). Both scales are commonly used and have been shown to be valid predictors of functioning among older people (Gaugler et al. 2007). Test-retest reliability for both scales is high (Wang, Sheu \& Protas 2007). The modified Finnish questionnaire included six questions on ADL (eating, transferring in and out of bed, dressing, bathing, cutting toe nails, and toileting (Katz \& Akpom 1976, Laukkanen et al. 2001).

The questionnaire used in the PROMO study included eight IADL items (preparing meals, doing laundry, coping with light housework, coping with heavy housework, handling medication, using the telephone, using public transportation, and handling finances) (Laukkanen et al. 2001, Lawton \& Brody 1969). In the HIP ASYMMETRY study the questionnaire contained nine IADL items (all the foregoing items plus shopping). In general, there were four to five response categories: 1) Able to manage without difficulty, 2) Able to manage with some difficulty, 3) Able to manage with major difficulty, 4) Able to manage only with the help of another person, and 5) Unable to manage even with help. In the HIP ASYMMETRY study only the first four categories (1-4) were used for the ADL items.

Sum scores were calculated for both ADL and IADL. In Stydy I the original categorical variables were dichotomized at first into: 1) No difficulty (category 1) and 2) Difficulty (categories 2-5). Subsequently, two sum scores were composed: an ADL score (ranging from 0-6) and an IADL score (ranging from $0-8$ ). The sum score indicated the number of tasks in which the participant reported difficulty. In Studies II and IV, the sum scores were composed from the original categorical variables, with theoretical ranges for ADL of 0-24 (in the HIP ASYMMETRY study) and 0-30 (in the PROMO study) and for IADL of 045 (in the HIP ASYMMETRY study) and 0-40 (in the PROMO study). A higher score indicated more difficulty. For the supplementary analysis, the categorical variables were re-coded into three categories: 1) No difficulty (category 1), 2) Some difficulty (categories 2 and 3), and 3) Major difficulty (categories 4 and 5). 


\subsubsection{Balance confidence}

A modified Finnish version of the Activities-specific Balance Confidence (ABC) Scale (Powell \& Myers 1995, Mänty et al. 2007) was used to assess confidence in performing specific activities without losing balance or becoming unsteady. In the literature, the terminology used to describe the outcome of the ABC Scale varies, but both balance confidence and falls-related self-efficacy have been used. Balance confidence can be considered as a surrogate for fear of falling, (Powell \& Myers 1995). In this study we refer to the ABC Scale as a measure of balance confidence. The original ABC Scale consists of 16 items. The Subjects are requested to describe how confident they are in carrying out different tasks, indoors and outdoors. Answers to each question were rated from 1 (no confidence) to 10 points (total confidence). The total score ranges from 16 to 160 a higher score indicating better balance confidence. Previous studies have demonstrated the reliability (Cronbach's $\mathrm{a}=0.95-0.97$ ) and validity of the $\mathrm{ABC}$ Scale in older populations (Powell \& Myers 1995, Talley, Wyman \& Gross 2008).

In the modified Finnish version of the ABC Scale the questions 14 and 15 which originally dealt with stepping onto or off an escalator holding (question 14) or not holding (question 15) onto a railing were replaced as follows: 14) How confident are you that you will not lose your balance or become unsteady when you cycle and there is only a little traffic on the road? 15) How confident are you that you will not lose your balance or become unsteady when you cycle and there is a lot of traffic on the road and no cycle track?

\subsubsection{Functional balance}

Functional balance was assessed by the Berg Balance Scale (Berg et al. 1992) which evaluates the ability to perform 14 different tasks such as standing up, sitting down, reaching and turning around oneself, looking over the shoulders and standing on one foot. The ability to perform each task is rated from 0 (incapable) to 4 (safe and independent). The total score ranges between 0 and 56, higher scores indicating better functional balance. The BBS has been shown to be a valid instrument and has high intra-rater $(\alpha=0.98)$ and inter-rater reliability $(a=0.97)$ (Berg, Wood-Dauphinee \& Williams 1995).

\subsubsection{Other descriptive, mediating and confounding factors}

\section{Health status}

During a medical examination performed by a nurse and physician, presence of chronic conditions, use of prescription medication, fracture status, and date and type of surgery were confirmed according to a pre-structured questionnaire, current prescriptions, and medical records obtained from the patient's local hospital and health care center. Contraindications for participation in the muscle strength and balance assessments were evaluated by the physician (Haskell et al. 2007). Cognitive status was assessed by the Mini-Mental State Examination (MMSE), which is a brief 30-point questionnaire used for screening 
cognitive impairment (Folstein, Folstein \& McHugh 1975). Depressive mood was assessed by the Beck Depression Inventory (BDI-II), which is a 21question multiple-choice self-report inventory used for measuring the severity of depression (Scogin et al. 1988). A BDI-II score $>29$ was considered to indicate severe depression. Smoking status was assessed with a question (never, former, current smoker). In addition, in the PROMO study human C-reactive protein (hCRP) and hemoglobin level were assessed by blood count. Need for emergency room services were self-reported at 3, 6 and 12 months with a questionnaire after the previous assessment.

\section{Physical characteristics}

Body height $(\mathrm{m})$ and weight $(\mathrm{kg})$ were measured using standard procedures and body mass index (BMI) was calculated as:

$\frac{\text { bodyweight }}{[\text { body height }]^{2}} \times 100$.

Body composition was assessed with Bioimpedance devise with eight polar electrodes (BC-418, TANITA, Tokyo, Japan).

\section{Demographics}

Demographics included age, sex, living conditions, income, and education. They were assessed by self-report and from medical records.

\section{Muscle force and power}

Muscle strength refers to the amount of force a muscle can produce with a single maximal effort (Enoka 1994). Moreover, muscle strength can be defined as a combination of muscle force and power and muscle power as a product of force and movement velocity (Enoka 1994). Isometric muscle force (Newton) for knee extension was measured on the fractured side by an adjustable dynamometer chair (Metitur Ltd, Palokka, Finland) (Portegijs et al. 2009). During the measurement the ankle was attached to a strain-gauge system with the knee angle fixed at $60^{\circ}$ from full extension. Participants were encouraged to extend the leg as hard as possible. After two to three practice trials, measurements were performed at least three times until no further improvement occurred. Each contraction was maintained for two to three seconds. The inter-trial rest period was 30 seconds. The performance of the highest maximal force was used for analysis. Maximal hand grip strength was measured from the dominant hand with a dynamometer (Metitur Ltd, Palokka, Finland). Leg extension power was measured with the Nottingham Power Rig for both legs (Portegijs et al. 2009).

\section{Mobility}

Physical performance was assessed by Short Physical Performance Battery (SPPB), including $2.44 \mathrm{~m}$ habitual walking speed, five timed chair rises and standing balance tests (Guralnik et al. 1994). Mobility limitation was assessed by 
interviewing the subjects on their ability to get in and out of bed, rise from a chair, walk across a room, walk one block, and climb stairs (Visser et al. 2000). Walking speed was assessed with 10-meter walking test (Sipilä et al. 1996). In addition, self-reported difficulty in walking outdoors, walking $500 \mathrm{~m}$, walking 2 $\mathrm{km}$ and climbing one flight of stairs was assessed by a questionnaire. Use of walking aids outdoors was assessed by the question: "Do you use walking aids when you go outdoors? The response alternatives were Yes/No.

\section{Physical activity}

Current level of physical activity was assessed by a standardized question (Grimby 1986) with slight modifications. The question comprised seven alternative responses: 1) mainly resting, 2) most activities performed sitting down, 3) light physical activity twice a week at the most, 4) moderate physical activity about $3 \mathrm{~h}$ a week, 5) moderate physical activity at least $4 \mathrm{~h}$ a week or heavy physical activity $\leq 4 \mathrm{~h}$ a week, 6) physical exercise or heavy leisure time activity several times a week, and 7) competitive sports several times a week. No one reported participation in competitive sports (category 7). In Study III, those who reported doing only light physical activity or mainly sitting or resting were considered sedentary (categories 1-3) while those who reported being fairly physically active for at least three hours a week were considered physically active (categories 4-6). For additional analysis (unpublished) the scale was re-coded into three categories: 1) Sedentary/Minor physical activity (categories 1-2), 2) Light physical activity (category 3), 3) Moderate/Heavy physical activity (categories 4-6).

\section{Pain}

Offending pain in the lower back and lower limbs was assessed by two questions "Have you experienced pain in the lower back, hip, knee, ankle or foot on your left/right side? Has the pain compromised your mobility?" The response alternatives were 1) No, 2) Yes, but it is not offending pain, 3) Yes, and it is offending. A new variable "offending pain in the fractured side" was composed based on the answers.

\section{Average temperature}

Average temperature of the month in which the respective assessment took place was derived from average monthly temperature data, collected in the years 1981-2010 daily at 12 O'clock at a local weather station in Jyväskylä (Pirinen et al. 2012).

\section{Falls}

Indoor and outdoor falls were self-reported retrospectively with a question:

"Have you experienced a fall during the last three/six months? 


\subsection{Interventions}

\subsubsection{Standard care (Studies II, III \& IV)}

All Finnish residents have state health insurance. Each municipality organizes primary health care including inpatient rehabilitation, ward care and an outpatient clinic for their residents at local health care centers. After a proximal femoral fracture, patients living in Central Finland are operated on at the Central Finland Central Hospital (serves 23 municipalities) and transferred, typically within the first post-operative days, to the local health care centre of their municipality for inpatient care and rehabilitation. The inpatient rehabilitation period ranges from one week to few months, depending on the patient's health status and care needs.

Because the baseline measurements of the HIP ASYMMETRY study were carried out on average 3.4 years after the hip fracture, information regarding standard care was not collected. The control group of the HIP ASYMMETRY study did not receive any intervention. Participants were encouraged to continue their lives as usual and maintain their pre-study level of physical activity during the 12-week trial.

At baseline in the PROMO study, information on standard care after the hip fracture was collected by interviewing all the participants. Seventy percent of all the participants received a written home exercise program from the hospital or health care center. The exercise program was the same for both the intervention and the control groups (68\% vs. $71 \%, \mathrm{p}=0.813)$. Typically the program included five to six exercises, including ankle flexion and extension, knee flexion and extension, hip abduction and extension in supine, sitting and/or standing positions with no additional resistance. None of the participants receiving the home exercise program were followed up and the program was not updated. Of all participants 12 received a referral to physiotherapy ( 5 in the intervention and 7 in the control group) while the remainder were given no further instructions regarding rehabilitation. Participants in the control group were encouraged to continue their lives as usual.

\subsubsection{Individually tailored progressive resistance training (Study II)}

The training group in the HIP ASYMMETRY study participated in individually tailored progressive strength-power training in a senior gym. The training focused on the muscles of the lower limbs, the aim being to reduce asymmetrical strength deficit and to increase the strength and power of the lower-limb muscles (Portegijs et al. 2008). The training was done twice a week (1-1.5 h) for 12 weeks in groups of 4-8 persons and was supervised by an experienced physiotherapist. Training intensity was adjusted individually throughout the training period based on the last 1-RM estimation. The weaker leg was trained first in every exercise, and more sets and repetitions and/or a 
higher resistance were used. A physician was consulted for all pain and other medical symptoms emerging during the training period. This was done to ascertain which of the symptoms were likely to be related to the training and whether they affected the training. The training protocol for both legs is displayed in more detail in Table 4.

Each training session included both strength and power exercises and started with a 10-minute warm-up sitting on a chair. Pneumatic resistance equipment (Ab Hur Oy, Kokkola, Finland) was used for the leg press, knee flexion, and hip abduction and adduction exercises. Exercises were performed with as large a range of motion (ROM) as possible without pain during the performance. The training equipment allowed ROM to be limited for each leg individually. The ankle plantar flexion exercises, rising to the toes and returning the heel onto the ground, were performed with a weighted vest in front of a mirror while holding a handrail. In the strength exercise, the participant stood on one leg. If necessary, the other foot was allowed to touch the floor for balance. In the power exercise, participants stood on both legs for safety reasons. The first two training sessions were used to familiarize the participants with the facility, equipment, and staff. The exercises were performed with low loads, and the correct movement technique was ensured. In the following sessions, the 1-RM was estimated. The assessment, one exercise at a time, was repeated during the weeks six, seven and eight. The 1-RM was estimated from a 3- to 6-RM test by using a conversion table (McDonagh \& Davies 1984) for the leg press, knee flexion, and hip abduction and adduction exercises trained by using pneumatic resistance equipment (Ab Hur Oy, Kokkola, Finland). When tolerated, the training intensity was progressively increased throughout the training period.

\section{Weaker leg for training}

The weaker leg was trained more intensively to reduce the difference between the legs in muscle strength and power. For each participant, the weaker leg was defined according to maximal knee extension strength, maximal rate of force production, and maximal leg extension power. The weaker leg was defined as the leg that had lower values in at least 2 of the measures. A difference between the legs was calculated using the formula:

$\frac{\mid \text { difference between legs } \mid}{\text { best result }} \times 100 \%$.

A difference of less than 5\% was not considered meaningful.

\section{Power training}

The aim of this training component was to increase muscle force and movement velocity by a high-velocity regimen. Because the participants represented a clinical population, relatively low resistance was used for safety reasons. The leg press and ankle plantar flexion power exercises were performed early in the training session in sets of 12 repetitions (see Table 4), and the concentric phase 
of the contraction was performed as fast as possible. The leg press exercise for the weaker leg consisted of 3-4 sets and for the stronger leg of 2-3 sets with a resistance of $40 \%$ to $50 \%$ of the 1-RM. The ankle plantar flexion exercise was performed standing on both legs in 2-3 sets by using a weighted vest with $0 \%$ to $10 \%$ of baseline body weight.

\section{Strength training}

The aim of this training component was to increase muscle strength by using conventional strength-training protocols (Sipilä et al. 1996, Ferri et al. 2003). Strength exercises were performed at a slower pace with fewer repetitions (weaker leg: 2-3 sets of 8 repetitions; stronger leg: 1-2 sets of 10 repetitions) and higher resistance (see Table 4). The leg press, knee extension, and hip abduction and adduction exercises were performed with a resistance of $60 \%$ to $80 \%$ of the 1-RM for the weaker leg and $50 \%$ to $70 \%$ of the 1-RM for the stronger leg. From the eighth week onwards, the leg press strength exercise was performed only once a week. The ankle plantar flexion strength exercise was performed standing on one leg with $0 \%$ to $15 \%$ of body weight; if necessary, the other foot was allowed to touch the floor for balance.

\subsubsection{PROMO - Individually tailored multi-component home-based rehabilitation program (Studies III \& IV)}

Intervention included standard care and the PROMO rehabilitation program. PROMO was an individually tailored year-long home-based physical activity and rehabilitation intervention implemented in the participants' homes. The intervention aimed at restoring mobility after a hip fracture. It began on average within one week after the baseline measurements and included four to six home visits and three to five phone calls by an experienced research physiotherapist (see Figure 4). Written tailored materials for each participant were provided.

Evaluation and modification of environmental hazards and guidance for safe walking

During the first face-to-face session, evaluation and modification of environmental hazards and guidance for safe walking were done according to the guidelines issued by the National Public Health Institute of Finland (Mänty et al. 2007). Participants' concerns regarding fear of falling, satisfaction with assistive devices for physical functioning and potential benefits of hip protectors were also considered.

\section{Non-pharmacological pain management}

An individual non-pharmacological pain management evaluation took place in the second face-to-face session and was repeated at three (fourth home visit) and six months (fifth home visit). The pain management sessions included a structured interview. In addition, participants' knowledge of pain relief and the 
strategies they perceived as effective in reducing pain were discussed (Barry et al. 2005).

\section{Individual progressive home exercise program}

The individual progressive home exercise program was also launched during the second home visit. It comprised strengthening exercises for the lower limb muscles, balance training and stretching and functional exercises. The duration of one exercise session was approximately 30 minutes. For the strengthening and stretching exercises, the expected total number of exercise sessions during the one-year intervention was 156 (three times a week, 52 weeks in a year) and for the balance exercises 130 (two to three times a week, 52 weeks in a year). For the functional exercises, which were performed only for the first twelve weeks two to three times a week, the equivalent number was 30 .

The home exercise program was updated four to five times with a more intensive and demanding protocol. The first update occurred after one week (third home visit) and subsequently after one (fourth home visit), three (fifth home visit), six (sixth home visit), and nine months (phone call). For eleven participants only five home visits were scheduled. During the intervention, progression in the strengthening exercises was increased with resistance bands of three different strengths. All participants kept a daily exercise diary in which they marked the exercises they performed and the Borg Scale for each exercise. Participants were asked to mail their exercise diaries to the research physiotherapist monthly.

\section{Physical activity counseling}

Individual motivational face-to-face physical activity counseling (Mänty et al. 2009) took place after three months (fourth home visit) at the subjects' homes. Counseling was a onetime session followed by phone calls at four and eight months and a face-to-face meeting at six (sixth home visit) months to promote and encourage subjects to physical activity. In addition, an extra motivational conversation was provided at twelve months after the final laboratory measurements. 
TABLE 4 Training Protocol for the weaker leg and stronger leg for strength and power exercises performed with resistance equipment (leg press, knee flexion, and hip abduction and adduction) or a weighted vest (ankle plantar flexion) (HIP ASYMMETRY; Study II).

\begin{tabular}{|c|c|c|c|c|c|c|c|c|}
\hline \multirow[b]{3}{*}{ Training mode } & \multicolumn{4}{|l|}{ Strength } & \multicolumn{4}{|l|}{ Power } \\
\hline & \multicolumn{2}{|l|}{ Weaker leg } & \multicolumn{2}{|l|}{ Stronger leg } & \multicolumn{2}{|l|}{ Weaker leg } & \multicolumn{2}{|l|}{ Stronger leg } \\
\hline & $\begin{array}{l}\text { Volume } \\
\text { (set/repetition) }\end{array}$ & $\begin{array}{l}\text { Resistance } \\
(\%)\end{array}$ & $\begin{array}{l}\text { Volume } \\
\text { (set/repetition) }\end{array}$ & $\begin{array}{l}\text { Resistance } \\
(\%)\end{array}$ & $\begin{array}{l}\text { Volume } \\
\text { (set/repetition) }\end{array}$ & $\begin{array}{l}\text { Resistance } \\
(\%)\end{array}$ & $\begin{array}{l}\text { Volume } \\
\text { (set/repetition) }\end{array}$ & $\begin{array}{l}\text { Resistance } \\
(\%)\end{array}$ \\
\hline \multicolumn{9}{|c|}{ Resistance equipment } \\
\hline First period $^{1}$ & $2 / 8$ & $60-70^{3}$ & $1 / 10$ & $50-60^{3}$ & $3 / 12$ & $40^{3}$ & $2 / 12$ & $40^{3}$ \\
\hline Second period ${ }^{2}$ & $2-3 / 8$ & $70-80^{3}$ & $1-2 / 10$ & $60-70^{3}$ & $3-4 / 12$ & $40-50^{3}$ & $2-3 / 12$ & $40^{3}$ \\
\hline \multicolumn{9}{|l|}{ Weighted vest } \\
\hline First period & $2 / 8$ & $0^{4}$ & $1 / 10$ & $0^{4}$ & $2 / 12^{5}$ & $0^{4}$ & & \\
\hline Second period & $2-3 / 8$ & $10-15^{4}$ & $1-2 / 10$ & $10-15^{4}$ & $2-3 / 12^{5}$ & $10^{4}$ & & \\
\hline
\end{tabular}

1The period between the first and second 1-RM estimation; ${ }^{2}$ The period after the second 1-RM estimation; ${ }^{3}$ Percentage of the 1-RM; 4 Percentage of the baseline body weight; ${ }^{5}$ Both legs trained simultaneously 


\subsection{Statistical methods}

Means, standard deviations, medians, frequencies, and percentage values for the descriptive variables were calculated. The assumption of normality was assessed graphically and tested with the Kolmogorov-Smirnov test. The significance of differences between the intervention and control group was tested by Fisher's Exact test for discrete variables, by Independent Samples ttest for normally distributed data, and by the Mann-Whitney U-test for nonnormally distributed continuous data. The intention-to-treat (ITT) principle was followed in the analysis to assess the effect of the interventions on our primary outcome; physical disability. The ITT principle stipulates that all participants who are randomized must be included in the statistical analysis and analyzed in the groups to which they were randomly assigned, regardless of whether they actually satisfied the entry criteria and regardless of whether they received or adhered to the allocated intervention (Fisher et al. 1990). All tests of significance were two-tailed and set at a p-value of $<0.05$.

Training compliance in the HIP ASYMMETRY study was calculated as:

$\frac{\text { Session attended }}{\text { Sessions of fered }} \times 100 \%$.

Compliance with the PROMO intervention was calculated as:

$\frac{\text { Amount of performed exercises }}{\text { Expected number of exercises }} \times 100 \%$.

Additionally, the mean relative changes in the PROMO study in disability sum scores between the baseline and different follow-up assessments were calculated using the formula:

$\frac{[\text { Follow-up }]-\text { Baseline }}{\text { Baseline }} \times 100 \%$.

Differences in the mean relative changes (i.e. effect) between the study groups and standard errors (SE) were also calculated. The principal statistical analyses carried out in this study are described next.

\section{Negative Binomial Regression}

The associations between balance confidence and physical disability as well as between functional balance and physical disability were assessed by negative binomial regression, which is a generalization of the Poisson regression that accounts for the over dispersion detected in Poisson models. The negative binomial regression model takes into account the tendency for disability to be a cumulative phenomenon and that having difficulty in one activity makes having difficulty in two or more activities more likely. Therefore observations of an increasing number of difficulties are non-independent of each other. With 
this approach, it is possible to enter the Poisson-distributed count variable for the number of difficulties in the models. The risk values are expressed as incidence rate ratios (IRR) obtained by exponentiation of the regression coefficients $(\exp [\beta])$ and their $95 \%$ confidence intervals $(\mathrm{CI})$. The expression:

$100 \times(I R R-1)$

indicates the percentage change in the ADL and IADL scores relative to the $\mathrm{ABC}$ or BBS score. The first model was adjusted for age and gender and the second model additionally for time since fracture, offending pain on the fractured side, number of chronic diseases, maximal force of the fractured leg, and the use of walking aids outdoors. Finally, both the ABC and BBS scores were included simultaneously in the negative binomial regression model.

\section{Covariance Analysis}

The effect of the progressive resistance training on physical disability was assessed by covariance analysis (ANCOVA), with baseline value as a covariate. Covariance is a measure of how much two variables change together and the strength of the relationship between them. ANCOVA is a general linear model which blends analysis of variance (ANOVA) and regression. ANCOVA evaluates whether the population means of a dependent variable are equal across the levels of a categorical independent variable. In addition, it statistically controls for the effects of other continuous variables that are not of primary interest, known as covariates. Participants with missing data were excluded from the analysis.

\section{Spearman's rank correlation coefficient}

The association between balance confidence and functional balance was assessed with Spearman's rank correlation coefficient (Spearman's rho, $\rho$ ) which is a nonparametric measure of statistical dependence between two variables. It assesses how well the relationship between two variables can be described using a monotonic function. Spearman's coefficient is appropriate for both continuous and discrete variables, including ordinal variables. A Spearman correlation of zero indicates that there is no correlation. When two variables are perfectly monotonically related, the Spearman correlation coefficient is +/ -1 .

\section{General Estimation Equations}

To analyze the effects of the PROMO intervention on physical disability, physical activity and balance confidence, generalized estimating equation (GEE) models were constructed. The effects of progressive resistance training on balance confidence were also assessed with GEE models. Since the ADL and IADL sum scores were not normally distributed, square root transformations were applied and used in the GEE models. The GEE methodology allowed us to analyze whether the participants in the intervention group had a lower prevalence of, or higher recovery from, physical disability compared with the control group. The interaction term (group by time) represents the difference in 
time-related change in the proportion of participants reporting physical disability in the intervention versus control group. In a case of missing data (in the ITT analyses a maximum of eight cases missing at one time point) the GEE methodology uses maximum-likelihood estimation (MLE), which provides estimates for the model's parameters by finding particular parametric values that make the observed results the most probable.

We adjusted the GEE models for age and additionally one of the following at a time: number of chronic diseases, time since fracture, pain in the fractured limb, balance confidence, functional balance, and the average monthly temperature. In addition to the ITT analyses, we carried out per-protocol analyses in which those who were suspended (i.e. told to have a break) from training by a physician or exercising with low frequency (performed less than $45 \%$ of the expected exercises) were excluded, but only at issuing time point. The GEE models of the categorical variables did not withstand adjusting for potential confounders, owing to too few observations in some of the categories. However, we calculated corrected p-values for single ADL/IADL items using the FDRTOOL-package in $\mathrm{R}$ version 2.15 .2 to avoid false positive results in multiple comparisons (Strimmer 2008).

\section{Statistical software}

Regression modeling in Study I was performed using STATA 12 statistical software. In all the other analyses, the latest available version of SPSS or PASW statistical software for Windows (SPSS Inc., Chicago, US) was used. SPSS version 17.0 was used to analyze the results in Study II and the PASW version 19.0 was used in Studies III and IV. 


\section{RESULTS}

\subsection{Sample characteristics}

The baseline characteristics of the older people with a previous hip fracture in all three study samples (HIP ASYMMETRY, PROMO, and pooled data set) are shown in Table 5. Participants in the HIP ASYMMETRY study were on average 75 years old whereas in the PROMO study the participants were on average four years older. Time since fracture was on average 3.4 years in the HIP ASYMMETRY study, 70 days in the PROMO study, and 1.7 years in the pooled data set. In all the data sets the majority $(73 \%)$ of the participants were women. The participants in the PROMO study had more difficulties in ADL and IADL compared to those in the HIP ASYMMETRY study. They were also weaker (max. strength of the fractured limb $175.3 \pm 73.1$ vs. $242.3 \pm 105.6 \mathrm{~N}$ ), scored lower on the ABC ( $88.3 \pm 30.5$ vs. $104.2 \pm 28.5)$ and BBS ( $42.1 \pm 9.5$ vs. $49.8 \pm 5.7)$, and had lower physical activity level (93\% vs. $42 \%$ were sedentary).

The characteristics of the study participants in the pooled data set $(n=159)$, stratified by physical functional capacity, are presented in Table 6. Participants who were considered to have decreased functional capacity (difficulty in four or more ADL or IADL) had shorter recovery time from fracture (1.3 \pm 1.6 vs. 2.4 \pm 2.6 years). In addition, they suffered more often from offending pain (64\% vs. $45 \%)$, had lower maximum strength of the fractured limb $(186.4 \pm 79.8$ vs. $241.5 \pm 111.6 \mathrm{~N})$, and used more often walking aids outside the home $(85 \%$ vs. $42 \%)$. Moreover, they scored lower on the ABC (79.2 \pm 27.9 vs. $111.4 \pm 26.6)$ and BBS (41.0 \pm 9.9 vs. $42.9 \pm 5.4)$, and were more often physically sedentary $(87 \%$ vs. $59 \%$ ) compared to those with good functional capacity (difficulty in less than four basic ADL or IADL).

The training and control groups in the HIP ASYMMETRY study were comparable with respect to gender (total 14 men, 29 women), age (74.4 \pm 6.7 years), number of chronic diseases $(3 \pm 1)$, body mass index (BMI; $26.5 \pm 3.7$ $\left.\mathrm{kg} / \mathrm{m}^{2}\right)$, time since fracture (3.4 \pm 2.2 years), and self-reported health $(69 \%$ reported excellent health). Additionally, the groups did not differ in level of 
physical activity (58\% physically active), pain (59\% reported offending pain in the fractured lower limb) or cognitive status (average MMSE score: 26; range 21-29) at baseline. The baseline ADL sum score was $1.8(\mathrm{SD}=2.0)$ in the training group and $1.7(1.8)$ in the control group $(\mathrm{p}=0.695)$. The corresponding values for IADL were $3.9(2.2)$ and 3.4 (2.4) for the training and control groups respectively $(\mathrm{p}=0.955)$.

At baseline of the PROMO study, the intervention and control groups did not differ in demographics, chronic diseases, time elapsed since fracture, operation type, ADL or IADL score, pain, strength, BBS, ABC or physical activity level. In general, less than $10 \%$ experienced major difficulty in the following ADL: eating, getting in and out of bed, dressing, and toileting. However, $20 \%$ of the participants faced major difficulty in bathing and $57 \%$ in cutting toe nails. In IADL more difficulty was experienced. Coping with heavy housework was found the most difficult IADL task, with $60 \%$ of the participants reporting major difficulty. The next most challenging IADL were doing laundry (30\% of the participants reported major difficulty), coping with light house work (32\%) and using public transportation (44\%). In preparing meals, handling medication and handling finances approximately $20 \%$ experienced major difficulty. Least difficulty was reported in using the telephone (2\%).

\subsection{Associations of balance confidence and functional balance with physical disability (Study I)}

The IRR's and 95\% CI's for ADL and IADL disability relative to balance confidence and functional balance in the pooled data set are shown in Table 7. A higher $\mathrm{ABC}$ score was associated with a lower risk for ADL disability (fully adjusted IRR 0.99; 95\% CI 0.98-0.99). Theoretically, this indicates that e.g. a 10point increase in the $\mathrm{ABC}$ score decreased the risk for ADL disability by 10 percent. The association between balance confidence and IADL disability was similar $(0.99 ; 0.98-0.99)$. Furthermore, a higher BBS score was associated with lower risk for ADL $(0.98 ; 0.96-0.99)$ and IADL disability $(0.98 ; 0.97-0.99)$ in the fully adjusted models. Theoretically, this indicates that, e.g., a 10-point increase in the BBS score decreased the risk for ADL and IADL disability by $20 \%$.

The ABC and BBS scores correlated highly, but not fully (Spearman $\rho=0.69$ ), and the $A B C$ score explained $48 \%$ of the variation in BBS score $\left(\mathrm{R}^{2}=0.476\right)$. However, placing the $\mathrm{ABC}$ and $\mathrm{BBS}$ scores together in the same regression model with ADL or IADL did not materially change their individual IRR's (Table 7), although in the fully adjusted models the associations between the BBS score and ADL and IADL disability were attenuated. 
TABLE $5 \quad$ Baseline characteristics of older people with a previous hip fracture.

\begin{tabular}{|c|c|c|c|c|c|c|}
\hline \multirow{2}{*}{\multicolumn{2}{|c|}{$\mathrm{n}$}} & \multicolumn{2}{|l|}{$\begin{array}{l}\text { HIP } \\
\text { ASYMMETRY } \\
+ \text { PROMO } \\
\text { Study I }(\mathrm{n}=159)\end{array}$} & \multicolumn{2}{|l|}{$\begin{array}{l}\text { HIP } \\
\text { ASYMMETRY } \\
\text { Study II }(n=43)\end{array}$} & \multirow{2}{*}{$\begin{array}{l}\text { PROMO } \\
\begin{array}{l}\text { Studies III \& IV } \\
(\mathrm{n}=81)\end{array} \\
\begin{array}{l}\text { Mean } \pm \text { SD; } \\
\mathrm{n}(\%)\end{array}\end{array}$} \\
\hline & & $\begin{array}{l}\text { Mean } \pm \text { SD; } \\
\mathrm{n}(\%)\end{array}$ & $\mathrm{n}$ & $\begin{array}{l}\text { Mean } \pm \mathrm{SD} ; \\
\mathrm{n}(\%)\end{array}$ & $\mathrm{n}$ & \\
\hline Age (years) & 159 & $77.4 \pm 7.2$ & 43 & $74.4 \pm 6.7$ & 81 & $79.4 \pm 7.2$ \\
\hline Gender: women & 159 & $116(73)$ & 43 & $29(67)$ & 81 & $63(78)$ \\
\hline Time since fracture (years/days) & 159 & $1.7 \pm 2.1$ years & 43 & $3.4 \pm 2.2$ years & 81 & $69.6 \pm 28.3$ days \\
\hline Number of chronic diseases & 156 & $3 \pm 2$ & 43 & $2 \pm 1$ & 79 & $3 \pm 2$ \\
\hline BMI & 154 & $26.0(3.9)$ & 43 & $26.5 \pm 3.7$ & 76 & $25.4 \pm 3.7$ \\
\hline Operation type & 159 & & 43 & & 81 & \\
\hline Internal fixation & & $74(47)$ & & $22(51)$ & & $38(47)$ \\
\hline Arthroplasty & & $85(54)$ & & $21(49)$ & & $43(53)$ \\
\hline MMSE score & 158 & $25.8(2.8)$ & 43 & $26.3 \pm 2.2$ & 80 & $25.2 \pm 4.0$ \\
\hline $\begin{array}{l}\text { Number of ADL difficulty } \\
\text { (range 0-6) }\end{array}$ & 158 & $2 \pm 2$ & 42 & $1 \pm 1$ & 81 & $3 \pm 2$ \\
\hline $\begin{array}{l}\text { Number of IADL difficulty } \\
\text { (range } 0-8 / 9 \text { ) }\end{array}$ & 155 & $3 \pm 2$ & 40 & $2 \pm 2$ & 81 & $4 \pm 2$ \\
\hline Offending pain/fractured side & 159 & $61(38)$ & 43 & $19(44)$ & 81 & $38(47)$ \\
\hline Max strength/fractured $\operatorname{limb}(\mathrm{N})$ & 142 & $208.3 \pm 96.4$ & 40 & $257.1 \pm 111.1$ & 72 & $175.3 \pm 73.1$ \\
\hline BBS (total score) & 152 & $44.1 \pm 9.3$ & 42 & $49.8 \pm 5.7$ & 78 & $42.1 \pm 9.5$ \\
\hline ABC (total score) & 156 & $91.5 \pm 32.3$ & 43 & $104.2 \pm 28.5$ & 80 & $88.3 \pm 30.5$ \\
\hline Physically sedentary & 158 & $120(76)$ & 43 & $19(42)$ & 80 & $74(93)$ \\
\hline
\end{tabular}

Continuous variables are expressed as mean $\pm \mathrm{SD}$; Categorical variables are expressed as number (\%); MMSE=Mini-Mental State Examination; ADL=activities of daily living; IADL=instrumental activities of daily living; BBS=Berg Balance Scale; $A B C=$ Activitiesspecific Balance Confidence Scale 
TABLE Characteristics of older people with a previous hip fracture in the HIP ASYMMETRY $(n=78)$ and PROMO $(n=81)$ studies stratified by functional capacity; Good functional capacity was defined as difficulty in less than four basic or instrumental activities of daily living; Decreased functional capacity was defined as difficulty in four or more basic or instrumental activities of daily living.

\begin{tabular}{|c|c|c|c|c|c|}
\hline & & $\begin{array}{l}\text { Good functional } \\
\text { capacity } \\
(\mathrm{n}=62 ; 39 \%)\end{array}$ & & $\begin{array}{l}\text { Decreased } \\
\text { functional capacity } \\
(\mathrm{n}=97 ; 61 \%)\end{array}$ & \\
\hline & $\mathrm{n}$ & Mean \pm SD; n (\%) & $\mathrm{n}$ & Mean \pm SD; $\mathrm{n}(\%)$ & $\mathrm{p}^{*}$ \\
\hline Age (years) & 62 & $76.0 \pm 7.2$ & 97 & $78.3 \pm 7.2$ & $0.601^{\#}$ \\
\hline Gender: women & 62 & $45(73)$ & 97 & $71(73)$ & $1.000^{\circ}$ \\
\hline Body mass index $\left(\mathrm{kg} / \mathrm{m}^{2}\right)$ & 61 & $25.3 \pm 3.3$ & 93 & $26.5 \pm 4.1$ & $0.491^{\#}$ \\
\hline Number of chronic diseases & 61 & $3 \pm 2$ & 95 & $4 \pm 2$ & 0.224 \\
\hline MMSE (total score) & 62 & $25.8 \pm 2.9$ & 96 & $25.8 \pm 2.8$ & 0.953 \\
\hline Operation type & 62 & & 97 & & $0.746^{\circ}$ \\
\hline Internal fixation & & $30(48)$ & & $44(45)$ & \\
\hline Arthroplasty & & $32(52)$ & & $53(55)$ & \\
\hline Time since fracture (years) & 62 & $2.4 \pm 2.6$ & 97 & $1.3 \pm 1.6$ & 0.021 \\
\hline Offending pain/fractured side & 62 & $28(45)$ & 97 & $33(34)$ & $0.183^{\circ}$ \\
\hline Max strength/fractured limb $(\mathrm{N})$ & 57 & $241.5 \pm 111.6$ & 97 & $186.4 \pm 79.8$ & 0.001 \\
\hline Use of walking aids outdoors & 62 & $28(45)$ & 97 & $82(85)$ & $<0.001^{\circ}$ \\
\hline BBS (total score) & 58 & $49.2 \pm 5.4$ & 97 & $41.0 \pm 9.9$ & $<0.001$ \\
\hline ABC (total score) & 59 & $111.4 \pm 26.6$ & 97 & $79.2 \pm 29.7$ & $<0.001$ \\
\hline Physically sedentary & 61 & $36(59)$ & 97 & $84(87)$ & $<0.001^{\circ}$ \\
\hline
\end{tabular}

Continuous variables are expressed as mean $\pm \mathrm{SD}$; Categorical variables are expressed as number (\%); *Mann-Whitney U-test, except: \#Independent Samples t-test; ${ }^{\circ}$ Fisher's Exact test; $\mathrm{BBS}=$ Berg Balance Scale; $\mathrm{ABC}=$ Activities-specific Balance Confidence Scale 
TABLE 7 IRR's and 95\% CI's for physical disability in the negative binomial regression model with ABC and BBS scores separately and together in the same model (HIP ASYMMETRY + PROMO; Study I).

\begin{tabular}{|c|c|c|c|c|c|c|c|c|c|}
\hline & \multirow[b]{2}{*}{ Covariates in the model } & \multicolumn{4}{|l|}{ ADL } & \multicolumn{4}{|l|}{ IADL } \\
\hline & & Model 1* & $\mathrm{p}$ & Model 2** & $\mathrm{p}$ & Model 1* & $\mathrm{p}$ & Model 2** & $\mathrm{p}$ \\
\hline \multirow[t]{6}{*}{$\mathrm{ABC}$} & & $0.99(0.98-0.99)$ & $<0.001$ & $0.99(0.98-0.99)$ & $<0.001$ & $0.99(0.98-0.99)$ & $<0.001$ & $0.99(0.98-0.99)$ & $<0.001$ \\
\hline & Time since fracture & & & $0.87(0.81-0.94)$ & $<0.001$ & & & $0.90(0.85-0.96)$ & $<0.001$ \\
\hline & Offending pain/fractured limb & & & $1.94(1.05-1.72)$ & 0.020 & & & $1.27(1.04-1.56)$ & 0.017 \\
\hline & Number of chronic diseases & & & $1.06(0.99-1.13)$ & 0.071 & & & $1.04(0.98-1.09)$ & 0.170 \\
\hline & Max force/fractured limb & & & $1.00(0.99-1.00)$ & 0.981 & & & $1.00(0.99-1.00)$ & 0.586 \\
\hline & Use of walking aids outdoors & & & $1.62(1.12-2.34)$ & 0.010 & & & $1.66(1.23-2.25)$ & $<0.001$ \\
\hline \multirow[t]{6}{*}{ BBS } & & $0.96(0.95-0.98)$ & $<0.001$ & $0.98(0.96-0.99)$ & $<0.001$ & $0.96(0.95-0.97)$ & $<0.001$ & $0.98(0.97-0.99)$ & $<0.001$ \\
\hline & Time since fracture & & & $0.88(0.82-0.94)$ & $<0.001$ & & & $0.91(0.86-0.96)$ & $<0.001$ \\
\hline & $\begin{array}{l}\text { Offending pain/fractured } \\
\text { limb }\end{array}$ & & & $1.38(1.08-1.78)$ & 0.011 & & & $1.31(1.08-1.61)$ & 0.007 \\
\hline & Number of chronic diseases & & & $1.06(0.99-1.14)$ & 0.095 & & & $1.04(0.99-1.10)$ & 0.149 \\
\hline & Max force/fractured limb & & & $1.00(0.99-1.00)$ & 0.651 & & & $1.00(0.99-1.00)$ & 0.567 \\
\hline & Use of walking aids outdoors & & & $1.85(1.29-2.65)$ & $<0.001$ & & & $1.90(1.42-2.54)$ & $<0.001$ \\
\hline $\mathrm{ABC}$ & & $0.99(0.98-0.99)$ & $<0.001$ & $0.99(0.98-0.99)$ & 0.009 & $0.99(0.98-0.99)$ & $<0.001$ & $0.99(0.98-0.99)$ & $<0.001$ \\
\hline \multirow[t]{6}{*}{ BBS } & & $0.98(0.96-0.99)$ & 0.015 & $0.98(0.97-1.00)$ & 0.055 & $0.99(0.97-0.99)$ & 0.009 & $0.99(0.97-1.00)$ & 0.118 \\
\hline & Time since fracture & & & $0.87(0.81-0.94)$ & $<0.001$ & & & $0.90(0.85-0.96)$ & $<0.001$ \\
\hline & $\begin{array}{l}\text { Offending pain/fractured } \\
\text { limb }\end{array}$ & & & $1.34(1.04-1.72)$ & 0.022 & & & $1.27(1.03-1.55)$ & 0.021 \\
\hline & Number of chronic diseases & & & $1.04(0.98-1.12)$ & 0.180 & & & $1.03(0.97-1.09)$ & 0.323 \\
\hline & Max force/fractured limb & & & $1.00(0.99-1.00)$ & 0.471 & & & $1.00(0.99-1.00)$ & 0.320 \\
\hline & Use of walking aids outdoors & & & $1.61(0.11-2.35)$ & 0.013 & & & $1.62(1.19-2.19)$ & 0.002 \\
\hline
\end{tabular}

*Adjusted for age and gender; **Adjusted for age and gender and additionally for five potential confounders;

$\mathrm{ABC}=$ Activities-specific Balance Confidence Scale; BBS=Berg Balance Scale 


\subsection{Feasibility of the interventions}

\subsubsection{Feasibility of progressive resistance training (Study II)}

During the 12-week resistance training period, short-term adjustments for load or training frequency were made for six participants following consultation with a physician. In two cases, the reasons for adjustments were musculoskeletal problems and in one case chest pain, both of which were likely to be related to the training. In addition, one participant developed prolonged radicular pain in one of the lower limbs after the training period. For two participants, poor compliance with the training (based on the number of sessions attended) was caused by health-related problems that were present before the beginning of the trial and for one participant poor compliance was due to of an unrelated wrist fracture. Training compliance overall was excellent, with a mean of $91 \%$. Excluding the three participants with rather poor compliance $(48 \%$ to $72 \%$ ), the mean rate of training compliance was $97 \%$. In the control group, one participant dropped out for personal reasons and one participant because of dissatisfaction with the randomization outcome. In the training group, one participant dropped out for personal reasons, and another participant refused to participate in the training immediately after randomization owing to personal life changes. However, this participant participated in the post-trial measurements.

\subsubsection{Feasibility of multi-component home-based rehabilitation (Study IV)}

The PROMO intervention was well tolerated and no intervention-related adverse events occurred. Only one woman dropped out of the intervention group for non-health-related personal reasons before the three-month follow-up. Of the 40 participants in the intervention group, nine were suspended (i.e. told to have a break) by a physician for medical reasons. During the first six months, four participants were suspended. Two of them returned to the intervention (revision operation and femoral fracture: ICD code S72.4) and two never returned (pulmonary embolism and pneumonia + new hip fracture). In addition, five participants were permanently suspended during the final six months (pubic bone fracture, urinary tract infection, cerebral infarction, cardiac failure, and sacrum strain fracture). One of the suspended participants died before the twelve-month measurements owing to cardiac failure. In comparison, in the control group there were two drop-outs (for personal reasons), four revision operations, and no new hip fractures.

To assess possible adverse events of the intervention in more detail, we also analyzed falls and use of emergency room services during the intervention. During the one-year study, the number of participants who sustained a fall after the previous assessment varied between 26 and 33\% with no difference between the intervention and control groups. During the first three months of the study, 
$3 \%$ of the participants in the intervention group and $13 \%$ of those in the control group needed emergency room services. Thereafter, approximately $8 \%$ of the participants in the intervention group and $20 \%$ of the controls reported use of emergency room services during the last 3 to 6 months. No significant difference was observed between the study groups. These results indicate that the intervention did not cause excessive adverse events.

The means and standard deviations of the number of exercises performed, expected number of exercise sessions, and exercise compliance are presented in Table 8. In general, compliance was higher during the first six months at $61 \%$ for strengthening, $53 \%$ for stretching, $65 \%$ for balance, and $69 \%$ for functional exercises. During the final six months, the corresponding values were 39\%, 37\%, and $43 \%$ (functional exercises were instructed to be done during the first twelve weeks only). Overall exercise compliance was $61 \%$ during the first six months, $40 \%$ during the final six months, and $54 \%$ across the whole twelve-month period. Five participants were deemed to exercise with low frequency (i.e. total number of all exercises less than $45 \%$ of the expected amount). Two of them reported no exercises at all during the one-year intervention.

Compliance with the physical activity counseling, which was part of the intervention, was excellent. One participant, who was suspended from week 13 onwards, did not receive any counseling session. All the others received at least the first face-to-face session. Therefore compliance with the first face-to-face session was $98 \%$ and thereafter it was 90\% (first phone contact), 88\% (second face-to-face), and $88 \%$ (second phone contact), and $83 \%$ (third phone contact).

\subsection{Effects of the interventions on physical disability}

\subsubsection{Effects of progressive resistance training (Study II)}

The effects of resistance training on physical disability are presented in Table 9 (single items) and Figure 5 (sum scores). The most obvious changes were observed in transferring in and out of bed and in coping with heavy housework. Six persons in the training group had difficulties in transferring in and out of bed at baseline but no one reported difficulties at the post-trial assessments. Similarly, in heavy housework seven persons in the training group reported less difficulty at the post-trial than baseline assessments. In the control group, no such improvement was observed. The ADL sum score improved significantly in the training group $(p=0.034)$. The relative changes were $9.0 \%$ for the ADL and $13.2 \%$ for the IADL sum scores. The respective values in the control group were $2.6 \%$ and $8.1 \%$. 
Mean number and standard deviation of exercises, and exercise compliance (PROMO; Study IV).

\begin{tabular}{|c|c|c|c|c|c|c|c|c|c|}
\hline \multirow[b]{2}{*}{ Exercises } & \multicolumn{3}{|l|}{ 1-6 months } & \multicolumn{3}{|c|}{ 7-12 months } & \multicolumn{3}{|l|}{ 1-12 months } \\
\hline & $\begin{array}{l}\text { Mean } \\
(\mathrm{SD})\end{array}$ & $\begin{array}{l}\text { Expected } \\
\text { number of } \\
\text { exercises }\end{array}$ & $\begin{array}{l}\text { Compliance } \\
\%\end{array}$ & Mean (SD) & $\begin{array}{l}\text { Expected } \\
\text { number of } \\
\text { exercises }\end{array}$ & $\begin{array}{l}\text { Compliance } \\
\%\end{array}$ & Mean (SD) & $\begin{array}{l}\text { Expected } \\
\text { number of } \\
\text { exercises }\end{array}$ & $\begin{array}{l}\text { Compliance } \\
\%\end{array}$ \\
\hline Strengthening & $47.9(34.0)$ & 78 & 61.4 & $30.1(32.5)$ & 78 & 38.6 & $78.0(62.7)$ & 156 & 50.0 \\
\hline Stretching & $41.2(35.1)$ & 78 & 52.8 & $29.2(32.8)$ & 78 & 37.4 & $70.4(64.6)$ & 156 & 45.1 \\
\hline Balance & $43.6(29.8)$ & 65 & 67.1 & $39.2(30.7)$ & 65 & 60.3 & $72.4(56.4)$ & 130 & 55.7 \\
\hline Functional* & $20.8(16.6)$ & 30 & 69.3 & $\sim$ & $\sim$ & $\sim$ & $\sim$ & $\sim$ & $\sim$ \\
\hline Total & 152.3 (109.6) & 251 & 60.7 & $87.4(96.3)$ & 221 & 39.5 & 239.8 (195.2) & 442 & 54.3 \\
\hline
\end{tabular}

*Functional exercises were performed only during the first 12 weeks; ${ }^{\circ}$ Compliance=[proportion of exercises performed]/[expected number of exercises] ${ }^{\star} 100 \%$ 
TABLE 9 Proportion of self-reported difficulty in ADL/IADL in the training and control groups (HIP ASYMMETRY; Study II).

\begin{tabular}{|c|c|c|c|c|c|}
\hline \multirow[b]{2}{*}{ Category } & \multirow[b]{2}{*}{ Task } & \multicolumn{2}{|c|}{$\begin{array}{l}\text { Training group } \\
(\mathrm{n}=21-22)\end{array}$} & \multicolumn{2}{|c|}{$\begin{array}{l}\text { Control group } \\
(\mathrm{n}=20-21)\end{array}$} \\
\hline & & Baseline & Post-trial & Baseline & Post-trial \\
\hline \multirow[t]{6}{*}{ ADL } & Eating & $1 / 22$ & $1 / 22$ & $2 / 21$ & $3 / 21$ \\
\hline & Transferring in and out of bed 1 & $6 / 22$ & $0 / 22$ & $5 / 21$ & $4 / 21$ \\
\hline & Dressing & $5 / 22$ & $2 / 22$ & $4 / 21$ & $2 / 21$ \\
\hline & Bathing & $4 / 22$ & $2 / 22$ & $1 / 21$ & $0 / 21$ \\
\hline & Cutting toe nails & $14 / 21$ & $14 / 21$ & $11 / 21$ & $11 / 21$ \\
\hline & Toileting & $1 / 22$ & $0 / 22$ & $1 / 21$ & $1 / 21$ \\
\hline \multirow[t]{9}{*}{ IADL } & Preparing food & $5 / 22$ & $2 / 22$ & $3 / 21$ & $1 / 21$ \\
\hline & Doing laundry & $5 / 22$ & $5 / 22$ & $2 / 21$ & $0 / 21$ \\
\hline & Shopping & $8 / 22$ & $5 / 22$ & $9 / 21$ & $7 / 21$ \\
\hline & Coping with light housework & $7 / 22$ & $5 / 22$ & $6 / 21$ & $2 / 21$ \\
\hline & Coping with heavy housework ${ }^{2}$ & $13 / 22$ & $6 / 22$ & $14 / 21$ & $15 / 21$ \\
\hline & Handling medication & $3 / 22$ & $0 / 22$ & $1 / 21$ & $1 / 21$ \\
\hline & Using the telephone & $2 / 22$ & $1 / 22$ & $1 / 21$ & $1 / 21$ \\
\hline & Using public transportation & $11 / 22$ & $6 / 22$ & $7 / 20$ & $7 / 20$ \\
\hline & Handling finances & $1 / 22$ & $0 / 22$ & $2 / 21$ & $1 / 21$ \\
\hline
\end{tabular}

${ }^{1} \mathrm{p}=0.031$ (McNemar within training group); ${ }^{2} \mathrm{p}=0,016$ (McNemar within training group)
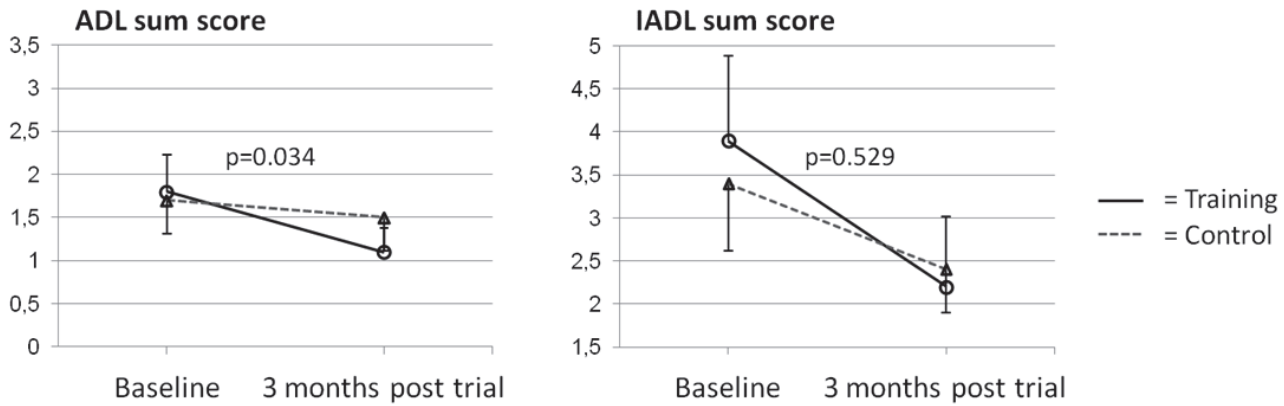

FIGURE 5 ADL and IADL sum scores and standard errors for the training (TG) and control (CG) groups; ANCOVA p-values are adjusted by baseline (HIP ASYMMETRY; Study II). 


\subsubsection{Effects of multi-component home-based rehabilitation (Study IV)}

The results of the individually tailored extended multi-component home-based rehabilitation program on self-reported difficulty in ADL and IADL are described as single items in Table 10 (ADL) and Table 11 (IADL) and as sum scores in Table 12.

Overall, ADL and IADL difficulties decreased in both groups, especially during the first three months (time $\mathrm{p}<0.001$ ). In the ITT analyses positive, however not significant, intervention effects were observed in the ADL or IADL sum scores. The mean differences between groups at three, six and twelve months in the ADL sum score were -0.3 (SD=4.2), -1.1 (6.3), and -0.1 (7.1) points and interaction $p=0.436$ in the crude GEE model (Figure 7.A and Table 12). The corresponding IADL values were -0.9 (9.5), -2.6 (11.7), and -1.7 (11.9); $\mathrm{p}=0.920$ (Figure 7.B and Table 12).

Additionally, when single items were analyzed with the ITT principle, a borderline significant positive intervention effect was observed in preparing meals and handling medication (interaction $\mathrm{p}=0.061$ and $\mathrm{p}=0.061$ ), respectively (Figure 6). In the per-protocol analysis, the mean differences in the disability sum scores between the groups were larger although non-significant (Figure 7.C\&D). The results for the adjusted sum score models remained similar.

Morover, there was a significant improvement in physical activity (interaction $\mathrm{p}=0.005$, unpublished). Overall, time spent on moderate or heavy physical activity increased, whereas sedentary time and time spent on light physical activity decrased.
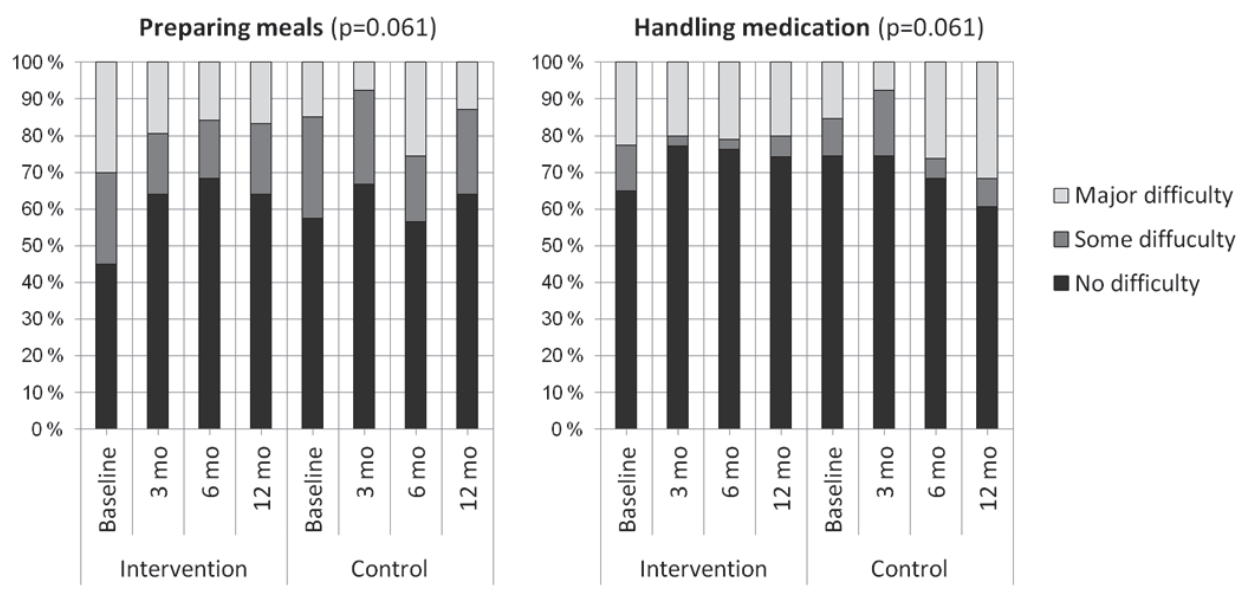

FIGURE 6 Change in self-reported difficulty in preparing meals and handling medication and interaction p-values in the crude GEE models (PROMO; Study IV). 
TABLE $10 \quad$ Number and proportions of participants reporting difficulty in ADL (PROMO; Study IV).

\begin{tabular}{|c|c|c|c|c|c|c|c|c|c|c|}
\hline \multirow[b]{2}{*}{ Task } & \multirow[b]{2}{*}{ Time } & \multicolumn{4}{|c|}{ Intervention $(\mathrm{n}=40)$} & \multicolumn{5}{|c|}{ Control $(n=41)$} \\
\hline & & $\mathrm{n}$ & No & Some & Lots of & $\mathrm{n}$ & No & Some & Lots of & $\mathbf{p}^{*}$ \\
\hline \multirow[t]{4}{*}{ Eating } & Baseline & 40 & $35(88)$ & $4(10)$ & $1(3)$ & 41 & $34(83)$ & $6(15)$ & $1(2)$ & 0.193 \\
\hline & 3 month & 40 & $30(83)$ & $4(11)$ & $2(6)$ & 41 & $36(92)$ & $3(8)$ & 0 & \\
\hline & 6 month & 38 & $32(84)$ & $5(13)$ & $1(3)$ & 39 & $32(82)$ & $6(15)$ & $1(3)$ & \\
\hline & 12 month & 36 & $32(89)$ & $4(11)$ & 0 & 39 & $31(80)$ & $6(15)$ & $2(5)$ & \\
\hline \multirow{4}{*}{$\begin{array}{l}\text { Transferring in } \\
\text { and out of bed }\end{array}$} & Baseline & 40 & $25(63)$ & $13(33)$ & $2(5)$ & 41 & $24(59)$ & $16(39)$ & $1(2)$ & 0.517 \\
\hline & 3 month & 40 & $25(69)$ & $11(31)$ & 0 & 41 & $28(72)$ & $10(26)$ & $1(3)$ & \\
\hline & 6 month & 38 & $27(71)$ & $9(24)$ & $2(5)$ & 39 & $27(69)$ & $10(26)$ & $2(5)$ & \\
\hline & 12 month & 35 & $26(74)$ & $6(17)$ & $3(9)$ & 39 & $31(80)$ & $8(21)$ & 0 & \\
\hline \multirow[t]{4}{*}{ Dressing } & Baseline & 40 & $19(48)$ & $18(45)$ & $3(8)$ & 41 & $22(54)$ & $19(46)$ & 0 & 0.193 \\
\hline & 3 month & 40 & 25 (69) & $10(28)$ & $1(3)$ & 41 & $25(63)$ & $14(35)$ & $1(3)$ & \\
\hline & 6 month & 38 & $26(68)$ & $10(26)$ & $2(5)$ & 39 & $23(59)$ & $13(33)$ & $3(8)$ & \\
\hline & 12 month & 36 & $25(69)$ & 7 (19) & $4(11)$ & 39 & $24(62)$ & $12(31)$ & $3(3)$ & \\
\hline \multirow[t]{4}{*}{ Bathing } & Baseline & 40 & $18(45)$ & $14(35)$ & $8(20)$ & 41 & $20(49)$ & $13(32)$ & $8(20)$ & 0.193 \\
\hline & 3 month & 40 & $24(67)$ & $5(14)$ & 7 (19) & 41 & $24(63)$ & $8(21)$ & $6(16)$ & \\
\hline & 6 month & 38 & $27(71)$ & $8(21)$ & $3(8)$ & 39 & $23(59)$ & $10(26)$ & $6(15)$ & \\
\hline & 12 month & 36 & $25(69)$ & $4(11)$ & 7 (19) & 39 & $25(64)$ & $8(21)$ & $6(15)$ & \\
\hline \multirow[t]{4}{*}{ Toileting } & Baseline & 40 & $30(75)$ & $5(13)$ & $5(13)$ & 41 & $28(68)$ & $13(32)$ & 0 & 0.513 \\
\hline & 3 month & 40 & $29(81)$ & $6(17)$ & $1(3)$ & 41 & 34 (87) & $5(13)$ & 0 & \\
\hline & 6 month & 38 & $32(84)$ & $5(13)$ & $1(3)$ & 39 & $33(85)$ & $5(13)$ & $1(3)$ & \\
\hline & 12 month & 36 & $28(78)$ & $6(17)$ & $2(6)$ & 39 & $33(85)$ & $5(13)$ & $1(3)$ & \\
\hline \multirow[t]{4}{*}{ Cutting toe nails } & Baseline & 40 & $5(13)$ & $7(18)$ & $28(70)$ & 41 & $6(15)$ & $17(42)$ & $18(44)$ & 0.334 \\
\hline & 3 month & 40 & 7 (19) & $11(31)$ & $18(50)$ & 41 & $13(33)$ & $11(28)$ & 15 (39) & \\
\hline & 6 month & 37 & $8(22)$ & $16(43)$ & $13(35)$ & 39 & $13(33)$ & $10(26)$ & $16(41)$ & \\
\hline & 12 month & 36 & 7 (19) & $13(36)$ & $16(44)$ & 39 & 15 (39) & $14(36)$ & $10(26)$ & \\
\hline
\end{tabular}

Data presented as n (\%); *General Estimation Equations, crude model, interaction p-value 
TABLE $11 \quad$ Number and proportions of participants reporting difficulty in IADL (PROMO; Study IV).

\begin{tabular}{|c|c|c|c|c|c|c|c|c|c|c|}
\hline \multirow[b]{2}{*}{ Task } & \multirow[b]{2}{*}{ Time } & \multicolumn{4}{|c|}{ Intervention $(n=40)$} & \multicolumn{4}{|c|}{ Control $(n=41)$} & \multirow[b]{2}{*}{$\mathrm{p}^{*}$} \\
\hline & & $\mathrm{n}$ & No & Some & Lots of & $\mathrm{n}$ & No & Some & Lots of & \\
\hline \multirow[t]{4}{*}{ Preparing food } & Baseline & 40 & $18(45)$ & $10(25)$ & $12(30)$ & 40 & $23(58)$ & $11(28)$ & $6(15)$ & 0.061 \\
\hline & 3 month & 40 & $23(64)$ & $6(17)$ & 7 (19) & 40 & $26(67)$ & $10(26)$ & $3(8)$ & \\
\hline & 6 month & 38 & $26(68)$ & $6(16)$ & $6(16)$ & 39 & $2(56)$ & $7(18)$ & $10(26)$ & \\
\hline & 12 month & 36 & $23(64)$ & $7(19)$ & $6(17)$ & 39 & $25(64)$ & $9(23)$ & $5(13)$ & \\
\hline \multirow[t]{4}{*}{ Doing laundry } & Baseline & 40 & $19(48)$ & $8(20)$ & $13(33)$ & 40 & $21(53)$ & $8(20)$ & $11(28)$ & 0.112 \\
\hline & 3 month & 40 & $23(66)$ & $5(14)$ & $7(20)$ & 40 & $25(63)$ & $10(25)$ & $5(13)$ & \\
\hline & 6 month & 38 & $28(74)$ & $2(5)$ & $8(21)$ & 39 & $23(59)$ & $3(8)$ & $13(33)$ & \\
\hline & 12 month & 36 & $26(72)$ & 0 & $10(28)$ & 39 & $26(67)$ & $7(18)$ & $6(15)$ & \\
\hline \multirow{4}{*}{$\begin{array}{l}\text { Coping with light } \\
\text { housework }\end{array}$} & Baseline & 40 & $15(38)$ & $11(28)$ & $14(35)$ & 40 & $16(40)$ & $12(30)$ & $12(30)$ & 0.121 \\
\hline & 3 month & 40 & $20(56)$ & $10(28)$ & $6(17)$ & 40 & $25(63)$ & $8(20)$ & $7(18)$ & \\
\hline & 6 month & 38 & $26(68)$ & $8(21)$ & $4(11)$ & 38 & $21(55)$ & $9(24)$ & $8(21)$ & \\
\hline & 12 month & 35 & $24(69)$ & $4(11)$ & $7(20)$ & 39 & $21(54)$ & $11(28)$ & 7 (18) & \\
\hline \multirow{4}{*}{$\begin{array}{l}\text { Coping with } \\
\text { heavy housework }\end{array}$} & Baseline & 40 & $3(8)$ & $11(28)$ & $26(65)$ & 40 & $5(13)$ & $12(30)$ & $23(58)$ & 0.233 \\
\hline & 3 month & 40 & $6(17)$ & $13(36)$ & $17(47)$ & 40 & $9(23)$ & $12(30)$ & $19(48)$ & \\
\hline & 6 month & 38 & $6(16)$ & $14(67)$ & $18(47)$ & 39 & $11(28)$ & $7(18)$ & $21(54)$ & \\
\hline & 12 month & 36 & $8(22)$ & $9(25)$ & $19(53)$ & 39 & $12(31)$ & $8(21)$ & $19(49)$ & \\
\hline \multirow{4}{*}{$\begin{array}{l}\text { Handling } \\
\text { medication }\end{array}$} & Baseline & 40 & $26(65)$ & $5(13)$ & $9(23)$ & 39 & $29(74)$ & $4(10)$ & $6(15)$ & 0.061 \\
\hline & 3 month & 40 & 27 (77) & $1(3)$ & $7(20)$ & 39 & $29(74)$ & $7(18)$ & $3(8)$ & \\
\hline & 6 month & 38 & $29(76)$ & $1(3)$ & $8(21)$ & 38 & $26(68)$ & $2(5)$ & $10(26)$ & \\
\hline & 12 month & 35 & $26(74)$ & $2(6)$ & $7(20)$ & 38 & $23(61)$ & $3(8)$ & $12(32)$ & \\
\hline \multirow{4}{*}{$\begin{array}{l}\text { Using the } \\
\text { telephone }\end{array}$} & Baseline & 40 & 38 (95) & $1(3)$ & 183) & 41 & $33(81)$ & $7(17)$ & $1(2)$ & 0.119 \\
\hline & 3 month & 40 & $31(86)$ & $5(14)$ & 0 & 41 & $33(85)$ & $4(10)$ & $2(5)$ & \\
\hline & 6 month & 38 & $33(87)$ & $5(13)$ & 0 & 38 & $34(90)$ & $3(8)$ & $1(3)$ & \\
\hline & 12 month & 36 & $34(94)$ & $1(3)$ & $1(3)$ & 39 & $36(92)$ & $3(8)$ & 0 & \\
\hline \multirow{4}{*}{$\begin{array}{l}\text { Public } \\
\text { transportation }\end{array}$} & Baseline & 39 & $13(33)$ & $7(18)$ & $19(49)$ & 36 & $6(17)$ & $13(36)$ & $17(47)$ & 0.122 \\
\hline & 3 month & 39 & $11(32)$ & $8(24)$ & $15(44)$ & 36 & $14(37)$ & $12(32)$ & $12(32)$ & \\
\hline & 6 month & 36 & $14(39)$ & $9(25)$ & $13(36)$ & 37 & $19(51)$ & 7 (19) & $11(30)$ & \\
\hline & 12 month & 33 & $13(39)$ & $9(27)$ & $11(33)$ & 38 & $18(47)$ & $7(18)$ & $13(34)$ & \\
\hline \multirow[t]{4}{*}{ Handling finances } & Baseline & 40 & $25(63)$ & $7(18)$ & $8(20)$ & 41 & $25(63)$ & $7(18)$ & $8(20)$ & 0.274 \\
\hline & 3 month & 40 & $24(67)$ & $4(11)$ & $8(22)$ & 41 & $24(67)$ & $4(11)$ & $8(22)$ & \\
\hline & 6 month & 38 & $30(79)$ & $1(3)$ & $7(18)$ & 39 & $30(79)$ & $1(3)$ & $7(18)$ & \\
\hline & 12 month & 36 & $29(81)$ & 0 & $7(19)$ & 39 & $29(81)$ & 0 & $7(19)$ & \\
\hline
\end{tabular}

Data presented as n (\%); *General Estimation Equations, crude model, interaction p-value 
TABLE 12 ADL and IADL sum score values, training effects and mean differences between groups (PROMO; Study IV).

\begin{tabular}{|c|c|c|c|c|c|c|c|c|c|}
\hline \multirow[b]{2}{*}{ Category } & \multirow[b]{2}{*}{$\begin{array}{l}\text { Time } \\
\text { point }\end{array}$} & \multicolumn{3}{|c|}{ Intervention $(n=40)$} & \multicolumn{3}{|c|}{ Control $(n=41)$} & \multirow[b]{2}{*}{$\mathrm{p}^{3}$} & \multirow[b]{2}{*}{$\begin{array}{l}\text { Difference } \\
\text { between } \\
\text { groups }\end{array}$} \\
\hline & & $\mathbf{n}$ & $\begin{array}{l}\text { Sum } \\
\text { score }^{1}\end{array}$ & Change $^{2}$ & $\mathbf{n}$ & $\begin{array}{l}\text { Sum } \\
\text { score }^{1}\end{array}$ & Change $^{2}$ & & \\
\hline \multirow[t]{4}{*}{ ADL } & Baseline & 40 & $4.7(3.2)$ & & 41 & $3.9(3.0)$ & & \multirow[t]{4}{*}{0.436} & \\
\hline & 3 month & 36 & $3.4(3.2)$ & $-1.5(2.1)$ & 39 & $3.0(3.0)$ & $-1.2(2.0)$ & & $-0.3(4.2)$ \\
\hline & 6 month & 38 & $3.0(3.2)$ & $-1.7(2.9)$ & 39 & $3.4(3.7)$ & $-0.6(3.1)$ & & $-1.1(6.3)$ \\
\hline & 12 month & 36 & $3.6(4.1)$ & $-1.1(3.9)$ & 39 & $3.0(3.7)$ & $-1.1(2.8)$ & & $-0.1(7.1)$ \\
\hline \multirow[t]{4}{*}{ IADL } & Baseline & 40 & $9.4(7.7)$ & & 41 & $7.8(6.5)$ & & \multirow[t]{4}{*}{0.920} & \\
\hline & 3 month & 36 & $7.1(7.1)$ & $-2.8(4.2)$ & 39 & $5.5(6.0)$ & $-1.9(4.9)$ & & $-0.9(9.5)$ \\
\hline & 6 month & 38 & $6.4(6.6)$ & $-3.1(5.1)$ & 39 & $7.2(7.8)$ & $-0.5(6.2)$ & & $-2.6(11.7)$ \\
\hline & 12 month & 36 & $6.8(7.7)$ & $-2.8(5.8)$ & 39 & $6.5(7.1)$ & $-1.1(5.6)$ & & $-1.7(11.9)$ \\
\hline
\end{tabular}

Data presented as mean (SD); ${ }^{1}$ Higher score indicates more difficulty; ${ }^{2}$ The mean relative changes in the ADL and IADL sum scores between the baseline and different follow-up assessments were calculated as [follow-up - baseline]; a negative value indicates reduction in ADL/IADL disability; ${ }^{3}$ General Estimation Equations, crude model, interaction p-value

INTENTION-TO-TREAT ANALYSIS (A\&B)
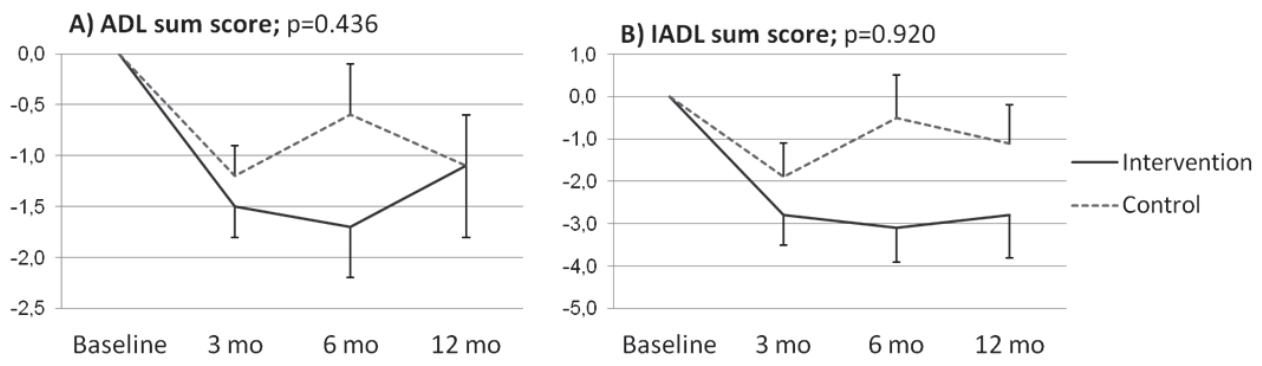

PER-PROTOCOL ANALYSIS (C\&D)
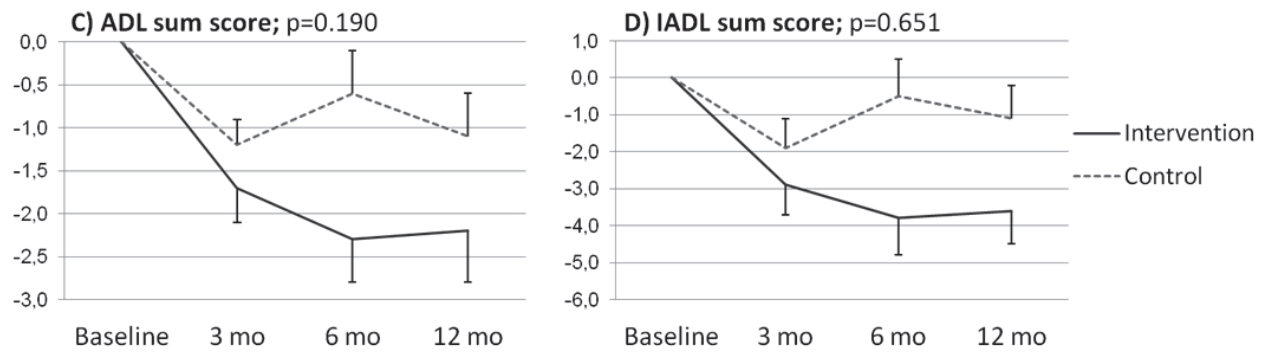

FIGURE 7 Mean changes, standard errors, and interaction p-values for the ADL and IADL sum scores: $A \& B=A l l$ participants; $C \& D=$ Participants who were suspended or exercising with low frequency and therefore excluded from the analysis at issuing time point (PROMO; Study IV). 


\subsection{Effects of the interventions on balance confidence (Studies II \& IV)}

The three-month progressive resistance training did not affect balance confidence (interaction $\mathrm{p}=0.819$, see Figure 9.A). The baseline $\mathrm{ABC}$ score was $107.1(\mathrm{SD}=26.5)$ in the training group and 107.7 (28.1) in the control group. The respective values at the three-month follow-up were 104.4 (30.9) and 105.6 (27.2).

The individually tailored extended multi-component home-based rehabilitation program had no statistically significant effects on balance confidence over the twelve-month period (interaction $p=0.429$, see Figure 9.B). Both groups improved during the first three months but not significantly (time $\mathrm{p}=0.264)$. At baseline, the mean $\mathrm{ABC}$ score in the intervention group was 89.51 (32.5) and at 3, 6, and 12 months the score was 94.0 (33.6), 98.0 (28.9), and 95.8 (34.5). In the control group the corresponding values were 87.2 (28.8), 97.1 (28.9), 95.6 (27.0, and 94.6 (29.2).

A) ABC sum score in Hip Asymmetry

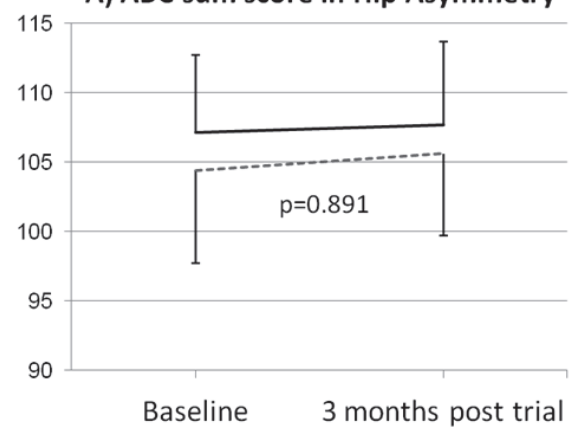

B) ABC sum score in ProMo

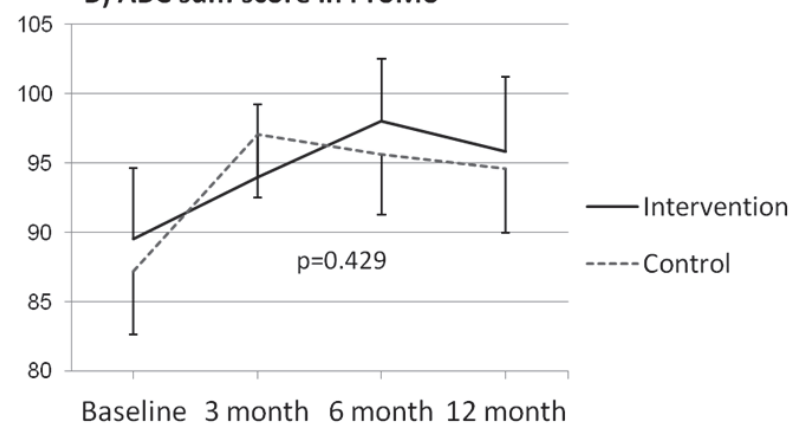

FIGURE 8 Means, standard errors, and interaction p-values in the crude GEE models for ABC sum score in the HIP ASYMMETRY (Study II) AND PROMO (Study IV). 


\section{DISCUSSION}

This research was conducted to examine the effects of two rehabilitation interventions aiming to reduce physical disability after a hip fracture among community-dwelling older people. The effects of a three-month individually tailored progressive resistance training program and the effects of a one-year individually tailored multi-component home-based rehabilitation program on physical disability were investigated. In addition, the associations between balance confidence and functional balance in relation to physical disability were studied. The target group consisted of community-dwelling older men and women who had sustained a previous hip fracture.

This study showed that both the resistance training and individually tailored multi-component home-based rehabilitation program improved independence in daily activities. However, the effects of the home-based rehabilitation were less comprehensive. Moreover, the results suggested that balance confidence and functional balance were both independently associated with perceived physical disability.

\subsection{Effects of the interventions on physical disability}

\subsubsection{Effects of progressive resistance training}

The HIP ASYMMETRY study focused on community-dwelling older people who had sustained a hip fracture on average three years earlier. When this group of older people with a previous hip fracture was compared with sex- and age-matched controls without fracture history, statistically significant differences were observed in coping with daily activities.

After the 3-month progressive resistance training period fewer difficulties, especially in the basic activities of daily living, were reported. In particular, there were fewer self-reported difficulties in transferring in and out of bed and coping with heavy housework. To our knowledge, no other studies have reported significant improvement in ADL or IADL after resistance training 
among older hip fracture patients. Three previous trials have shown that progressive 12-week resistance training may improve muscle force (Hauer et al. 2002, Mangione et al. 2005, Sylliaas et al. 2011, Sylliaas et al. 2012), balance (Sylliaas et al. 2011), and mobility (Hauer et al. 2002, Sylliaas et al. 2011) compared to aerobic training, placebo activities or standard care among older people who have suffered a hip fracture. However, the changes in self-rated disability outcomes were non-significant in any of these studies. This may be due to different timing of the interventions.

Based on earlier studies, recovery in ADL and IADL takes place after recovery in deficits related to performance of mobility tasks (Jette et al. 1987, Magaziner et al. 2000). This recuperation pattern is parallel to the disablement process described by Verbrugge and Jette (1994). Moreover, recovery in daily activities may continue beyond 18 months post fracture (Magaziner et al. 2000). In the study by Hauer et al. (2002) the training intervention started right after hospital discharge. Other trials examining strength training interventions reported that the exercise period begun three to six months after the fracture (Mangione et al. 2005, Sylliaas et al. 2011, Sylliaas et al. 2012). In the HIP ASYMMETRY study, the intervention took place six months to seven and half years after the fracture. Thus natural healing did not affect the results. However, the functional capacity and mobility had reached the level where the recovery of perceived disability was possible.

The improvement observed in transferring in and out of bed and coping with heavy housework is understandable since in both of the daily tasks, muscle strength and power of the lower limbs are required. However, despite the success of rehabilitation few years after the fracture, it is nevertheless important to begin rehabilitation as soon as possible after the surgery to prevent onset of the disablement process. The effects of the same intervention on muscle strength and power have been analyzed and reported earlier (Portegijs et al. 2008). The researchers found that progressive resistance training improved both lower limb muscle force and power, particularly on the weaker side.

The results of the present study are consistent with those of previous studies reporting that sufficient muscle strength is necessary to cope with daily activities (Ferrucci et al. 1997, Jette 2006). In particular, the self-care-related ADL tasks are fundamental for independence in modern society. Nevertheless, only a few studies have been published on the effects of resistance training on physical disability among high-risk groups of older people. However, quite a few studies have investigated the effects of resistance training on physical functional capacity assessed by performance-based measures. Self-reported disability and performance-based functional measures assess different stages of the disablement process (Nagi 1976, Kelly-Hayes et al. 1992, Guralnik et al. 1994). In this study, our primary focus was on perceived physical disability, which is a subjective evaluation of a person's difficulties in daily living. Consequently the results of this study should be considered relevant and significant on the societal level. 
The recent systematic review by Liu and Latham (Liu \& Latham 2010) contributes evidence that progressive resistance training, including strength and the performance of various simple and complex activities, is an effective intervention for improving physical functioning among older people. This is in line with our results. More research, however, is needed on how progressive resistance training can be applied in clinical populations, such as hip fracture patients, as adverse events have not always been adequately reported (Liu \& Latham 2009). For example, in the study by Timonen et al. (2009), while progressive resistance training for ten weeks did not cause any serious adverse events, it had no positive effect either on functional independence in frail older women (Timonen et al. 2006). In our study, no serious adverse events occurred and functional independence improved in the training group.

\subsubsection{Effects of multi-component home-based rehabilitation}

The PROMO study involved community-dwelling older people who had suffered a recent hip fracture. This study reported the effects of a one-year individually tailored multi-component home-based rehabilitation program on perceived physical disability among this target group. In the intention-to-treat analyses, the PROMO intervention had positive, though not significant, effect on physical disability. Additionally, in the more detailed analyses, we found that the intervention tended to reduce perceived difficulty in two IADL tasks: preparing meals and handling medication. Furthermore, in the per-protocol analyses a greater, yet not significant, difference between groups was observed in both the ADL and IADL sum scores.

The results of this study are consistent with earlier findings (Marottoli, Berkman \& Cooney 1992, Leibson et al. 2002) indicating that the consequences of a hip fracture are substantial, since a large number of the participants had some or major difficulty in ADL and IADL. In line with the other studies, most of the recovery in physical functioning occurred within the first three to six months after discharge (Magaziner et al. 2000, Zidén, Kreuter \& Frändin 2010). Some of this recuperation is presumably natural and may occur in the absence of intervention. In our study, the greatest improvement in ADL and IADL occurred during the first three months in both groups.

Much research has been conducted on mobility and physical functioning outcomes (walking, muscle strength/power, balance etc. (Handoll \& Ollivere 2010). However, only a few earlier RCTs have investigated individual multicomponent home-based rehabilitation interventions aiming to improve independence in ADL and IADL in older people who have sustained a hip fracture, and the results have been conflicting. Tinetti et al. (1999) studied the effects of a six-month physical and functional therapy program implemented by a physiotherapist and rehabilitation nursing staff. Tsauo et al. (2005) studied the effects of a twelve-week individualized home-based physical therapy program and Orwig et al. (2011) studied a six-month intervention, comprising an exercise module and a self-efficacy based motivational module, implemented 
by physiotherapists. None of these studies found any significant advantage over standard care.

As far as we know, only two RCTs have indicated that an individually tailored multi-component home-based rehabilitation program has improved independence in daily activities after a hip fracture (Crotty et al. 2002, Crotty et al. 2003, Zidén, Frändin \& Kreuter 2008, Zidén, Kreuter \& Frändin 2010). However, in these studies the intervention started when the participants were inpatients in geriatric wards and involved hospital staff. The interventions focused on supporting discharge and enhancing self-efficacy. Additionally, they comprised home visits by both physical and occupational therapist. In the study by Crotty et al. (2002 \& 2003) a speech pathologist and a social worker also visited the participants. The results of our study are in part similar to those previously reported (Crotty et al. 2002, Crotty et al. 2003, Zidén, Frändin \& Kreuter 2008, Zidén, Kreuter \& Frändin 2010). Although the PROMO intervention did not have a wide-ranging effect on ADL and IADL in the ITT analysis, a positive borderline significant intervention effect was detected in two IADL tasks (preparing meals and handling medication). Additionally, the per protocol analysis showed greater, though non-significant, improvements in ADL and IADL overall.

Differences between study designs and interventions may partially explain the different results obtained by the PROMO study and the studies by Crotty et al. (2002 \& 2003) and Zidén et al. (2008 \& 2010). The ProMo intervention was started right after the baseline laboratory measurements which were carried out as soon as the participants were able to perform the laboratory based mobility test safely. This was on average six weeks after discharge from hospital. All participants had, however, received standard care i.e. an exercise program from the local hospital or health care center before hospital discharge. Additionally, the ProMo intervention took place in the participants' homes, and included visits and phone calls by a physiotherapist. Neither hospital staff nor occupational therapists were involved with the implementation of the intervention.

The borderline significant improvement seen in two separate IADL items in our study is, however, encouraging. Preparing meals is important and essential daily activity for everyone. As described earlier, our intervention included progressive balance exercises. Thus the improvement in preparing meals may have occurred through improved balance resulting in a better standing position and freedom from assistive devices inside the home. This makes functioning in a kitchen more fluent and less effortful. In addition, handling medication is an essential skill for most community-dwelling older people, who consume on average three times the number of medications of younger adults (Gallagher et al. 2008) and use two to six prescribed medications concurrently (Chin et al. 1999). Our intervention also included structured pain management sessions. Consequently, checking the dosage and sufficiency of the prescribed and over-the-counter pain medication may have led to greater ease of handling of other medications. Managing these two foregoing IADL tasks 
reduces the need for home care services and therefore notably reduces healthcare-related costs. Accordingly, the result can be considered clinically valuable. As far as we know, our trial is the first to show the positive effect of an individually tailored multi-component home-based rehabilitation program on independence in these two IADL tasks in community-dwelling older people with a previous hip fracture.

Various individual- and environment-related characteristics can affect to physical disability after a hip fracture. The physical environment and use of assistive devices or other compensatory techniques may have a considerable impact on the ability to perform daily activities (Sallinen et al. 2009, Nyberg et al. 1996, Verbrugge \& Jette 1994, Rosso, Auchincloss \& Michael 2011). The weather can also affect physical disability, particularly in countries like Finland where the climate includes warm summers as well as cold and often snowy and slippery winters (Yang et al. 2010, Deshpande et al. 2008, Ferrucci et al. 1996). In addition, social support given by relatives or friends may contribute to a more active lifestyle among older people with fractures (Huang \& Acton 2009, Shyu et al. 2006, Ekstrom, Dahlin Ivanoff \& Elmstahl 2012). In this study, we assessed the individual's surroundings and home environment as a part of the intervention. Moreover, a physiotherapist suggested minor modifications to the home environment when necessary. We also gathered information on formal and informal support. However, these variables were not included in the present analyses. Nevertheless, the weather was taken into account as a covariate in the GEE modeling, where it was coded as the average monthly temperature.

Encouraging older people to be physically active is essential, since physical activity reduces the risk for disability and the development of dependency (Hirvensalo, Rantanen \& Heikkinen 2000, Boyle et al. 2007). Appropriate physical activity may also reduce fall risk (Liu-Ambrose et al. 2005) potentially by improving muscle strength, balance, coordination, transferring skills, and reaction to environmental hazards (Khan et al. 2001). Moreover, physical activity reduces the risk for several non-communicable diseases (Lee et al. 2012) and increases mental well-being (Fox et al. 2007). Consequently, physically active individuals can achieve more years of active independent living (Franco et al. 2005, Davis \& Fox 2007). However, the majority of older adults fail to meet the health recommendations of $30 \mathrm{~min}$ of moderate to vigorous physical activity on five or more days a week (altogether a minimum of 2.5 hours per week) (Davis \& Fox 2007).

One component of the home-rehabilitation program was physical activity counseling. The counseling proved to be effective, as physical activity in the intervention group increased significantly compared to that in the control group (unpublished). Generally, sedentary time and light physical activity decreased whereas moderate and heavy physical activity increased during the intervention. A prior study by Mänty et al. (2009) has also shown that even a single physical activity counseling session with supportive phone contacts can have a positive effect on mobility. In addition, another recent study suggest that 
exercise adherence after hospital discharge can be increased by enlightening the older adult's knowledge about the benefits of physical activity through exercise, counseling and support from physical therapist (Brovold, Skelton \& Bergland 2012). Our findings are in line with the prior studies.

\subsection{Balance confidence and functional balance as determinants of physical disability}

In the present study among older people with a history of a traumatic accident involving a fall, decreased balance confidence and impaired functional balance were both strong and independent determinants of perceived physical disability. Moreover, adjusting for several known confounders only marginally changed the associations. To our knowledge, this is the first study which has simultaneously examined the associations of balance confidence and functional balance in relation to physical disability among this important group of older people at high risk for losing independence.

Balance confidence was strongly associated with functional balance explaining half of the variation in Berg Balance score. However, including both the Berg Balance score and Activities-specific Balance Confidence score simultaneously in the negative binomial regression model did not materially change the individual incidence rate ratios. This suggests that the Activitiesspecific Balance Confidence Scale and Berg Balance Scale measure partly different phenomena in relation to physical disability. However, assessing balance confidence may provide valuable information when it is not possible to conduct functional balance measurements in laboratory conditions.

Our study, together with the previous studies, indicate that hip fracture patients comprise a special group of older people with impaired functional balance (Sihvonen et al. 2009, Magaziner et al. 2003), low balance confidence (Petrella et al. 2000, McKee et al. 2002), a greater physiological fall risk (Lloyd et al. 2009, Karinkanta et al. 2010) and a high risk for increased physical disability (Magaziner et al. 2003, Jellesmark et al. 2012). Furthermore, our findings are consistent with previous studies pointing out that fear of falling and functional balance are associated with independence in daily activities after a previous hip fracture (Murphy, Williams \& Gill 2002, Ingemarsson et al. 2003, Li et al. 2003, Folden \& Tappen 2007, Deshpande et al. 2008).

In this study neither the progressive resistance training nor multicomponent home-based rehabilitation program had positive effects on balance confidence. Earlier studies have provided inconsistent results on the effects of physical exercise interventions on balance confidence in older hip fracture patients. For instance, in the study by Crotty et al. (2002 \& 2003) a 4-month individually tailored home-based rehabilitation aiming to improve balance confidence and quality of life and to reduce physical and social dependence had no significant effect on balance confidence measured with Activities-specific 
Balance Confidence Scale. However, another RCT which focused on improving balance confidence, physical functioning and daily activity level showed that a 1-month multi-professional home rehabilitation program improved balance confidence measured with the Falls Efficacy Scale and that the positive effects were maintained for 12 months at least post intervention (Zidén, Frändin \& Kreuter 2008, Zidén, Kreuter \& Frändin 2010). The inconsistency of the results may be due to different measures of self-efficacy used in the studies.

Both balance confidence and functional balance have an essential role in coping with daily activities, especially in tasks which require independent maintenance of a standing position or walking e.g. doing heavy housework or preparing meals. However, being in good physical condition does not guarantee good functional capacity, since excessive fear of falling may lead to activity restriction and exercise avoidance (Yardley \& Smith 2002, Deshpande et al. 2008), in turn complicating and delaying the rehabilitation process and resulting in even more severe functional limitations and disability (Cumming et al. 2000, Li et al. 2003, Delbaere et al. 2004). Based on recent research, elevated levels of perceived fall risk may lead to future falls, independent of physiological fall risk (Delbaere et al. 2010a). Consequently, balance training by itself may not be successful without management of fall-related fear. Alternatively, older people with inappropriately low levels of fear of falling might take unnecessary risks in excess of their physical functional capacity (Hadjistavropoulos, Delbaere \& Fitzgerald 2011). Accordingly irrational fear of falling, either too much or too little, deserves more attention when designing and implementing rehabilitation programs.

\subsection{Methodological considerations and limitations}

The strengths of the present study include data on of two randomized controlled trials. Consequently, we were able to study the effects of two different physical rehabilitation protocols on perceived physical disability. Moreover, we succeeded in recruiting a unique clinical group of communitydwelling older people who had sustained a hip fracture. In the HIP ASYMMETRY study, the participants had sustained the hip fracture on average three years earlier and in the PROMO study on average ten weeks earlier. Recruitment was carried out in co-operation with the Central Finland Health Care District. Both the randomized controlled trials reported in this study included a thorough medical examination to ensure safe participation. The training interventions were planned and carried out based on the American College of Sports Medicine guidelines (Haskell et al. 2007). In addition, we included a comprehensive battery of laboratory-based physical and functional assessments. With these assessments we were able to design valid statistical models, with relevant and necessary potential confounders, to estimate the associations of functional balance and balance confidence with physical 
disability as well as the effects of resistance training and home-based rehabilitation on physical disability.

The interventions in this study proved feasible to carry out. No serious adverse events occurred during the three-month strength training or one-year home-exercise period. The overall compliance with the strength training was excellent $(99 \%)$. Only three participants had rather poor compliance and one participant in the intervention group dropped out. Further, the resistance training protocol can be considered potentially cost-effective, since the training was group-based and therefore less costly than individual physical rehabilitation given by a physiotherapist. In the PROMO study, nine participants were suspended for non-intervention-related medical reasons (seven of them permanently). Moreover, five participants exercised with low frequency, yet only one dropped out. The home-based intervention was originally designed to be easy to implement in order that it could be introduced into communal health care without making large demands on resources. Therefore the PROMO rehabilitation was organized with a minimal number of home visits. Compliance with the home exercises was good (on average 55\%) compared to that reported in other studies with similar home-based physical rehabilitation protocols (Tinetti et al. 1999, Sherrington, Lord \& Herbert 2004). This indicates that for most participants the home exercises could easily be performed independently. However, the PROMO intervention group was heterogeneous, as hip fracture patients usually are, and some of the participants might have benefitted from a more supportive intervention with additional home visits and phone contacts.

The physical activity counseling which was part of the intervention in the PROMO study was easily implemented and compliance was excellent $(99 \%)$. During the first six months of the intervention the participants spent on average 2.8 hours a week on the home-exercises. This meets the earlier mentioned physical activity recommendations ( 2.5 hours per week). The physical activity counseling took place after the three-month follow-up assessments. Thereafter, time spent on leisure time physical activity and other voluntary physical activity (hobbies etc.) increased and the time spent with home-exercises decreased.

The lower compliance with the home-based exercises compared to resistance training is to be expected. Each resistance training session was guided by a physical therapist and the training was group-based. In contrast, the home-exercises were carried out alone outside of the home visits by the physiotherapist. However, it should be noted that even lower compliance with home exercises is a better option than no exercise at all. On many occasions, older hip fracture patients cannot participate in rehabilitation that takes place outside the home since they are not able to leave their homes and travel to the rehabilitation facilities. In these situations there is a demand for home-based rehabilitation.

In the HIP ASYMMETRY study, the power calculations were initially done to detect changes in the variables measuring muscle strength and power. 
Moreover, in the PROMO study, the original primary outcomes were mobility limitation, mobility difficulty and mobility recovery. Perceived physical disability was originally planned as a secondary outcome in both RCTs. Therefore the power of the studies may have been too weak to show more explicit training effects in physical disability or balance confidence. Disability and balance confidence were measured with questionnaires, which are less sensitive to change than the performance-based laboratory measurements carried out to detect changes in the primary outcomes. Despite of this, some significant results were found.

The ADL and IADL scales used in this study are commonly utilized validated Finnish translations. However, the number of the response categories was slightly different between the studies ranging from 1 to 4 in the Hip Asymmetry and from 1 to 5 in the ProMo study. Moreover, during the editing process of the questionnaire package used in the ProMo study, one IADL question was left out by accident. Thus the number of IADL questions in the questionnaire was different (8 questions) compared to that of the Hip Asymmetry study (9 questions). Although there were several check outs for the questionnaire package, none of the researchers noticed the mistake until the data collection was completed and data analyses begun. This was an unfortunate mistake, but we considered that it was not a disincentive to analyze the disability data.

The participants in both RCTs were community-dwelling and discharged from the hospital to their own homes. Consequently, they were relatively independent in ADL already at the baseline. Since many of the participants with good functional capacity perceived only a few difficulties in daily activities at baseline, the disability questionnaire used in this study showed a ceiling effect. Therefore detecting an improvement in ADL and IADL independence was challenging. Use of a more sensitive disability scale, such as the Functional Status Questionnaire (Jette 1980) might be expected to overcome the ceiling effect of the assessment scale. On the other hand, it is known that ADL and IADL recovery occurs after mobility recovery and that independence in IADL, in particular, may continue to improve beyond 18 months post fracture (Manton 1988, Magaziner et al. 2000). In the HIP ASYMMETRY study, there was no follow-up to detect long-term effects of the strength training program or maintenance of the outcomes after the three-month assessments. In the PROMO study, the participants are being followed for 24 months. The data follow-up collection is still in process and the results will be reported later. Study IV shows the results for the first twelve months.

The results of this study might somewhat underestimate the effects of the interventions. It is known that persons in worse physical condition often benefit most from rehabilitation. However, in our study the frailest individuals were deliberately excluded. Moreover, the associations between functional balance, balance confidence and physical disability would probably have been stronger, if we had been able to study even frailer hip fracture patients. Furthermore, it is typical in RCTs that those in the control group also begin to increase their 
engagement in exercise during an intervention despite being instructed to maintain their lifestyle as it was before the research period. This also leads to underestimation of the training effects.

Notably, because of the cross-sectional study design reported in Study I, the causality between balance confidence, functional balance, and physical disability remains unclear and the results are largely hypothesis-derived. Therefore, it is possible that disability caused adoption of a sedentary lifestyle, followed by low balance confidence and impaired functional balance. Either way, there is a need for effective physical rehabilitation.

Generalizing the study results to older hip fracture patients should be done cautiously. The participants in our study were community-dwelling, and therefore representative of the elite group of hip fracture patients. Those who were unable to walk independently outdoors or had severe physical or psychological medical conditions were excluded. Nevertheless, we only excluded those who had significant health risks or contraindications for rehabilitation, for instance if a person suffered from a severe cardiovascular, pulmonary or progressive disease and was getting out of breath already when rising from a chair. However, the benefits of the strict inclusion criteria were low drop-out rates.

\subsection{Implications and future directions}

There is lack of scientific evidence on effective strategies to reduce physical disability. More research is needed on how to prevent physical disability and support the rehabilitation process among community-dwelling older people who have suffered a hip fracture. Additionally, it would be worthwhile to study how older people can be encouraged to be physically active even in the presence of fear of falling, impaired balance and increased physical disability. To maximize the effect of interventions aiming to reduce physical disability, factors that moderate or mediate the role of beliefs, emotions, and coping strategies need to be considered (Delbaere et al. 2010a, Liu \& Latham 2010). In particular, physical and functional exercises by themselves may not be successful without management of fall-related fear (Delbaere et al. 2010b, Hadjistavropoulos, Delbaere \& Fitzgerald 2011). Therefore fear of falling deserves more attention in future rehabilitation programs. Also, the importance of environmental contextual factors should be emphasized during post-fracture rehabilitation (Keysor \& Jette 2001).

Fall prevention is an important procedure after every hip fracture since falls are the most common reason for hip fractures (Parkkari et al. 1999, Järvinen et al. 2008). Furthermore, there is increased incidence for a second hip fracture after the first one (Lönnroos et al. 2006, Lloyd et al. 2009). The present guidelines recommend a multi-component fall risk assessment for older people who have experienced a fall-related hip fracture (Pajala 2012, Cadore et al. 2013). In particular, it has been recommended that measures of both physiological and 
perceived fall risk should be included in fall-risk assessments (Liu-Ambrose et al. 2006, Delbaere et al. 2010a). This should assist in the identification of all modifiable risk factors as well as with the implementation of targeted interventions for fall and fracture prevention (Tinetti \& Kumar 2010).

In future research, issues such as training specificity, adequate dosage and duration of the intervention should be taken into account. Additionally, there is a need for RCTs with long enough (18 to 24 months) follow-up and rehabilitation protocols that begin immediately after surgery, in order to detect potentially greater training effects in ADL and IADL. Assessment of the longterm effects of rehabilitation programs as well as maintenance of the positive outcomes is possible only with an adequate follow-up period. We also hypothesize that a more task-oriented rehabilitation approach to daily activities might accrue more definite benefits when the aim is to improve independence in daily activities. The present hypothesis-building results need to be confirmed in a study with sufficient power. In future research, it is essential that responsive outcome measures are used, while a larger sample size would be beneficial to facilitate the statistical analysis and determine whether exercise is actually effective in reducing physical disability.

Since hip fracture patients comprise a heterogeneous group, more research is required to examine what kind of rehabilitation would be effective in different subgroups, e.g. those in good physical condition, frail and diseased, cognitively impaired or mentally ill. It would also be worthwhile to consider how these different subgroups could be identified in hospital wards before discharge home. In conclusion, well-designed high-quality research is needed to better understand the determinants of physical disability as well as to study the effects of specific rehabilitation approaches aiming to reduce disability after a hip fracture.

The results of the present study can be utilized when rehabilitation interventions and guidelines for good practice in older people who have sustained a hip fracture are designed and carried out. Additionally, these results are useful when future research initiatives are considered and executed. 


\section{MAIN FINDINGS AND CONCLUSION}

The main findings and conclusions can be summarized as follows:

1. Decreased balance confidence and impaired functional balance are independent and important determinants of physical disability among older people who have sustained a previous hip fracture. Moreover, the Activities-specific Balance Confidence scale may complement a functional balance assessment and could be used as a screening tool for impaired functional balance in clinical practice when the instant assessment of functional balance is not possible with a performancebased test.

2. The progressive resistance training program reduced self-reported difficulties, especially in the activities of daily living, up to several years after a hip fracture. The most essential improvements occurred in two activities which require muscle strength and power: transferring in and out of bed and coping with heavy housework. The results indicate that resistance training is feasible and beneficial for older people who have suffered a hip fracture.

3. The individually tailored multi-component home-based rehabilitation program did not have a wide-ranging effect on physical disability. However, it tended to reduce difficulty in two instrumental activities of daily living (preparing meals and handling medication) among older people recovering from a recent hip fracture. Managing these two instrumental tasks independently reduces the need for home care services yielding financial and instrumental savings for society. The perprotocol analysis suggests that multi-component home-based rehabilitation may reduce perceived disability more broadly. Potentially, a more task-oriented rehabilitation approach to daily activities might show more definite benefits for disability outcomes. 


\section{YHTEENVETO (FINNISH SUMMARY)}

\section{Kotona asuvien iäkkäiden henkilöiden fyysinen toimintakyky lonkkamur- tuman jälkeen}

Lonkkamurtumat ovat yleisiä tapaturmia ikääntyneillä. Suomessa lonkkamurtumia sattuu vuosittain noin 7000, joista suurin osa yli 50-vuotialle. Tyypillisesti lonkkamurtuma tapahtuu kaatumisen seurauksena, joten kaatumisten riskitekijöitä voidaan pitää myös lonkkamurtumien riskitekijöinä. Luonnollisesti myös luun lujuuteen vaikuttavat tekijät ovat yhteydessä lonkkamurtuman syntymiseen. Vaikka viimeisimpien arvioiden mukaan lonkkamurtumien ilmaantuvuus on kääntynyt laskuun, lonkkamurtumien kokonaismäärän odotetaan nousevan ikääntyneen väestön määrän lisääntyessä. Lonkkamurtumien seurauksia arvioidaan usein rahallisesti. Esimerkiksi yhden lonkkamurtuman hoitokustannukset ensimmäisen vuoden aikana ovat $20000 €$. Usein kuitenkin murtuman vaikutukset myös yksilön toimintakykyyn ovat hyvin laaja-alaisia ja pitkäkestoisia.

Tutkimusten mukaan lonkkamurtuman kokeneista alle puolet kuntoutuu murtumaa edeltäneelle tasolle ja jopa kolmasosa joutuu pysyvästi laitoshoitoon. Tällöin myös lonkkamurtumasta aiheutuvat kustannukset sekä yksilön kokema inhimillinen haitta lisääntyvät merkittävästi. Lonkkamurtuman jälkeistä kuntoutumista heikentää monesti tapaturman aiheuttama voimakas kaatumisen pelko sekä pitkittynyt kipu. Lisäksi heikentynyt tasapaino ja alentunut lihasvoima hidastavat toipumista. Edellä mainittujen tekijöiden yhteisvaikutus johtaa monesti fyysisen aktiivisuuden vähenemiseen, mikä puolestaan edesauttaa liikkumiskyvyn heikkenemistä sekä pitkäaikaisten toiminnanvajausten syntymistä. Tämä noidankehä johtaa pahimmillaan siihen, ettei lonkkamurtumasta toipumassa oleva yksilö lopulta pysty selviytymään itsenäisesti edes päivittäisistä perustoiminnoista. Oikein ajoitetulla ja toteutetulla kuntoutuksella on oletettavasti merkittävä rooli toimintakyvyn elpymisen ja ylläpysymisen kannalta.

Aikaisempien kokeellisten tutkimusten perusteella tiedetään, että progressiivisella voimaharjoitellulla on mahdollista kehittää lihasvoimaa, lihasmassaa ja jopa dynaamista tasapainoa. Lisäksi tutkijat ovat selvittäneet, että tasapainoa harjoittamalla on mahdollista parantaa pystyasennon hallintaa, ylläpitää fyysistä toimintakykyä ja vähentää kaatumisriskiä. Ei kuitenkaan ole varmuutta, ovatko parantunut lihasvoima ja tasapaino suoraan yhteydessä myös kuntoutujan itse arvioimaan toimintakykyyn. Tällä tarkoitetaan yksilön omaa käsitystä siitä, kuinka hyvin hän pystyy suoriutumaan päivittäisistä toiminnoista. Tarvittaisiin enemmän tutkittua tietoa, minkä tyyppisellä kuntoutuksella on mahdollista vaikuttaa lonkkamurtumasta toipumassa olevan yksilön fyysiseen toimintakykyyn. Tällä hetkellä vahvinta näyttöä on geriatrisen laitoskuntoutuksen hyödyistä. Huomattavasti vähemmän on kuitenkin tutkittu avokuntoutusmalleja, erityisesti kotona tapahtuvaa kuntoutusta. Harvojen kotikuntoutuksen vaikutuksia selvittäneiden kokeellisten tutkimusten tulokset ovat olleet keskenään ristiriitaisia. Kuitenkin juuri kotikuntoutus voisi olla optimaalinen vaihto- 
ehto sairaalasta kotiutumisen jälkeen kun fyysinen kunto on vielä heikko ja kotoa poistuminen siksi haasteellista.

Tämän väitöskirjatutkimuksen tavoitteena oli tutkia progressiivisen kolmen kuukauden mittaisen voimaharjoittelun sekä yksilöllisen vuoden kestäneen kotikuntoutuksen vaikutuksia itse arvioituun fyysiseen toimintakykyyn lonkkamurtuman jälkeen. Väitöskirjatutkimuksessa selvitettiin myös toimintakyvyn, tasapainon ja tasapainon varmuuden välisiä yhteyksiä.

Tutkimuksen aineisto kerättiin Jyväskylän yliopiston Terveystieteiden laitoksella toimivassa Gerontologian tutkimuskeskuksessa yhteistyössä KeskiSuomen sairaanhoitopiirin, Jyväskylän kaupungin ja yhdeksän naapurikunnan kanssa vuosina 2004-2005 ja 2008-2012. Tutkimukseen osallistui 159 60vuotiasta tai vanhempaa kotona asuvaa iäkästä henkilöä, joilla oli ollut lonkkamurtuma 6 viikkoa-7,5 vuotta aiemmin. Tutkimukseen sisältyi kaksi satunnaistettua kontrolloitua koetta. Tutkittavista 43 osallistui kolmen kuukauden mittaiseen progressiiviseen ja yksilölliseen fysioterapeutin ohjaamaan voimaharjoitteluun seniorikuntosalilla (Asymmetria). Lisäksi 81 tutkittavaa osallistui vuoden kestäneeseen kotikuntoutukseen (ProMo), johon kuului 5-6 fysioterapeutin kotikäyntiä sekä 3-5 seurantapuhelua. Kotikuntoutukseen sisältyi muun muassa progressiivisia voima-, liikkuvuus- ja tasapainoharjoituksia, liikuntaneuvontaa sekä kotiympäristön turvallisuuden ja apuvälineiden arviointi. Lisäksi kotikäynneillä keskusteltiin kaatumisen pelosta sekä kivun hallintakeinoista. Fyysistä toimintakykyä arvioitiin kyselylomakkeella, jossa tiedusteltiin päivittäisissä perustoiminnoissa (ADL) ja instrumentaalisissa toiminnoissa (IADL) koettuja vaikeuksia 14-15 kysymyksellä. Tasapainon varmuutta arvioitiin ABC-testillä ja toiminnallista tasapainoa Bergin tasapainotestillä. Asymmetria-tutkimuksessa mittaukset tehtiin kaksi kertaa: ennen voimaharjoittelujaksoa sekä sen jälkeen. ProMo-tutkimuksessa mittaukset toistettiin neljä kertaa: alkumittauksissa ennen kuntoutusjakson alkua sekä 3, 6 ja 12 kk kuluttua alkumittauksista.

Tässä tutkimuksessa todettiin, että progressiivinen voimaharjoittelu paransi fyysistä toimintakykyä, kun harjoittelu toteutettiin keskimäärin kolme ja puoli vuotta lonkkamurtuman jälkeen. Erityisesti päivittäisistä perustoiminnoista selviytyminen helpottui. Myös vuoteeseen siirtyminen ja vuoteesta ylösnousu sekä raskaiden taloustöiden tekeminen helpottuivat. Yksilöllisellä kotikuntoutuksella, joka alkoi mahdollisimman pian kotiutumisen jälkeen, ei sen sijaan ollut laaja-alaisia vaikutuksia toimintakykyyn. Kuitenkin sekä ruuanlaitto että lääkkeiden annostelu ja ottaminen helpottuivat, joskaan muutos ei ollut tilastollisesti merkitsevä. Molemmat edellä mainitut toiminnot ovat tärkeitä itsenäisen kotona asumisen kannalta. Tutkimuksessa saatiin lisäksi viitteitä kotikuntoutuksen laaja-alaisemmista vaikutuksista toimintakykyyn, kun analyyseistä jätettiin pois henkilöt, jotka eivät olleet harjoitelleet ohjeiden mukaisesti tai jotka lääkäri oli määrännyt tauolle terveydentilaan liittyvien syiden vuoksi. Tutkimuksessa havaittiin lisäksi, että tasapaino ja tasapainon varmuus olivat voimakkaasti yhteydessä toimintakykyyn. Kun tasapainon varmuutta mittaavan $\mathrm{ABC}$-testin tulos laski kymmenellä pisteellä, riski toimintakyvyn 
heikkenemiseen oli teoreettisesti $10 \%$ suurempi ja $20 \%$ suurempi toiminnallista tasapainoa mittaavan Bergin tasapainotestin tuloksen laskiessa vastaavasti.

Tässä tutkimuksessa fyysistä toimintakykyä arvioitiin kyselylomakkeella, joka ei ole yhtä herkkä muutokselle kuin laboratoriossa toteutettavat liikkumiskykyä ja fyysistä suoristuskykyä mittaavat testit. Alustavien tulosten mukaan yksilöllinen kotikuntoutus on ollut tehokasta liikkumiskyvyn ja fyysisen suorituskyvyn elpymisen kannalta. On myös mahdollista, että enemmän tehtäväorientoituneita harjoitteita sisältävä kuntoutus olisi nyt testattua kotikuntoutusta tehokkaampaa haluttaessa parantaa ikääntyneiden henkilöiden fyysistä toimintakykyä lonkkamurtuman jälkeen. Jatkossa tulisi kiinnittää enemmän huomiota lonkkamurtumapotilaiden erilaisuuteen ja huomioida erityyppisten alaryhmien tarvitseman kuntoutuksen erityispiirteet. Myös harjoittelun oikea ajoitus, annostelu ja kesto on syytä harkita tarkoin. Metodologisesti laadukkaille ja riittävän pitkällä seuranta-ajalla toteutetuille kokeellisille kuntoutustutkimuksille on edelleen tarvetta.

Yhteenvetona voidaan todeta, että kolmen kuukauden voimaharjoittelu auttoi selviytymään paremmin päivittäisistä toiminnoista lonkkamurtuman jälkeen. Tutkimuksessa todettiin myös, että yksilöllisesti suunniteltu moniosainen kotikuntoutus saattaa parantaa lonkkamurtumasta toipuvien ikääntyneiden henkilöiden toimintakykyä. Lisäksi havaittiin, että tasapaino ja tasapainon varmuus olivat kumpikin itsenäisesti ja voimakkaasti yhteydessä päivittäisistä toiminnoista selviytymiseen, joten kaatumisen pelon hoitamiseen on jatkossa syytä kiinnittää enemmän huomiota kuntoutettaessa lonkkamurtumapotilaita. Nyt saatuja tuloksia voidaan hyödyntää suunniteltaessa ja toteutettaessa lonkkamurtumasta toipumassa olevien ikääntyneiden henkilöiden kuntoutusta sekä päivitettäessä lonkkamurtumia koskevia Käypä Hoito -suosituksia. Tuloksista ja tutkimuksen aikana tehdyistä havainnoista on hyötyä myös jatkotutkimushankkeita harkittaessa. 


\section{REFERENCES}

Aalto, A-M., Aro, A.R. \& Teperi, J. 1999. RAND 36 terveyteen liittyvän elämänlaadun mittarina. Mittarin luotettavuus ja suomenkieliset viitearvot (in Finnish). Helsinki. Publications by the Finnish National Institute for Health and Welfare 101.

Abrahamsen, B., van Staa, T., Ariely, R., Olson, M. \& Cooper, C. 2009. Excess mortality following hip fracture: a systematic epidemiological review. Osteoporosis International: 20 (10), 1633-1650.

Akunne, A., Murthy, L. \& Young, J. 2012. Cost-effectiveness of multicomponent interventions to prevent delirium in older people admitted to medical wards. Age and Ageing 41 (3), 285-291.

Applegate, W. B., Blass, J. P. \& Williams, T. F. 1990. Instruments for the functional assessment of older patients. The New England Journal of Medicine 322 (17), 1207-1214.

Barry, L. C., Gill, T. M., Kerns, R. D. \& Reid, M. C. 2005. Identification of painreduction strategies used by community-dwelling older persons. The Journals of Gerontology. Series A, Biological Sciences and Medical Sciences 60 (12), 1569-1575.

Beaupre, L. A., Jones, C. A., Saunders, L. D., Johnston, D. W., Buckingham, J. \& Majumdar, S. R. 2005. Best practices for elderly hip fracture patients. A systematic overview of the evidence. Journal of General Internal Medicine 20 (11), 1019-1025.

Berg, K., Wood-Dauphinee, S. \& Williams, J. I. 1995. The Balance Scale: reliability assessment with elderly residents and patients with an acute stroke. Scandinavian Journal of Rehabilitation Medicine 27 (1), 27-36.

Berg, K. O., Maki, B. E., Williams, J. I., Holliday, P. J. \& Wood-Dauphinee, S. L. 1992. Clinical and laboratory measures of postural balance in an elderly population. Archives of Physical Medicine and Rehabilitation 73 (11), 10731080.

Binder, E. F., Brown, M., Sinacore, D. R., Steger-May, K., Yarasheski, K. E. \& Schechtman, K. B. 2004. Effects of extended outpatient rehabilitation after hip fracture: a randomized controlled trial. JAMA: The Journal of the American Medical Association 292 (7), 837-846.

Borgquist, L., Nilsson, L. T., Lindelow, G., Wiklund, I. \& Thorngren, K. G. 1992. Perceived health in hip-fracture patients: a prospective follow-up of 100 patients. Age and Ageing 21 (2), 109-116.

Boyle, P. A., Buchman, A. S., Wilson, R. S., Bienias, J. L. \& Bennett, D. A. 2007. Physical activity is associated with incident disability in community-based older persons. Journal of the American Geriatrics Society 55 (2), 195-201.

Brovold, T., Skelton, D. A. \& Bergland, A. 2013. Association Between HealthRelated Quality of Life, Physical Fitness and Physical Activity in Older People Recently Discharged from Hospital. Journal of Aging and Physical Activity. [Epub ahead of print]. 
Brovold, T., Skelton, D. A. \& Bergland, A. 2012. The efficacy of counseling and progressive resistance home-exercises on adherence, health-related quality of life and function after discharge from a geriatric day-hospital. Archives of Gerontology and Geriatrics 55 (2), 453-459.

Cadore, E. L., Rodriguez-Manas, L., Sinclair, A. \& Izquierdo, M. 2013. Effects of different exercise interventions on risk of falls, gait ability and balance in physically frail older adults: a systematic review. Rejuvenation Research 16 (2), 105-114.

Cameron, I. D., Gillespie, L. D., Robertson, M. C., Murray, G. R., Hill, K. D., Cumming, R. G. \& Kerse, N. 2012. Interventions for preventing falls in older people in care facilities and hospitals. Cochrane Database of Systematic Reviews 12 (12), CD005465. DOI: 10.1002/14651858.CD005465.pub3.

Chan, K. S., Kasper, J. D., Brandt, J. \& Pezzin, L. E. 2012. Measurement equivalence in ADL and IADL difficulty across international surveys of aging: findings from the HRS, SHARE, and ELSA. The Journals of Gerontology. Series B, Psychological Sciences and Social Sciences 67 (1), 121-132.

Chin, M. H., Wang, L. C., Jin, L., Mulliken, R., Walter, J., Hayley, D. C., Karrison, T. G., Nerney, M. P., Miller, A. \& Friedmann, P. D. 1999. Appropriateness of medication selection for older persons in an urban academic emergency department. Academic Emergency Medicine 6 (12), 1232-1242.

Coons, S. J., Alabdulmohsin, S. A., Draugalis, J. R. \& Hays, R. D. 1998. Reliability of an Arabic version of the RAND-36 Health Survey and its equivalence to the US-English version. Medical Care 36 (3), 428-432.

Cooper, C., Cole, Z. A., Holroyd, C. R., Earl, S. C., Harvey, N. C., Dennison, E. M., Melton, L. J., Cummings, S. R., Kanis, J. A. \& IOF CSA Working Group on Fracture Epidemiology 2011. Secular trends in the incidence of hip and other osteoporotic fractures. Osteoporosis International 22 (5), 1277-1288.

Creditor, M. C. 1993. Hazards of hospitalization of the elderly. Annals of Internal Medicine 118 (3), 219-223.

Crotty, M., Unroe, K., Cameron, I. D., Miller, M., Ramirez, G. \& Couzner, L. 2010. Rehabilitation interventions for improving physical and psychosocial functioning after hip fracture in older people. Cochrane database of systematic reviews 20 (1), CD007624. DOI: 10.1002/14651858.CD007624.pub3.

Crotty, M., Whitehead, C., Miller, M. \& Gray, S. 2003. Patient and caregiver outcomes 12 months after home-based therapy for hip fracture: a randomized controlled trial. Archives of Physical Medicine and Rehabilitation 84 (8), 1237-1239.

Crotty, M., Whitehead, C. H., Gray, S. \& Finucane, P. M. 2002. Early discharge and home rehabilitation after hip fracture achieves functional improvements: a randomized controlled trial. Clinical Rehabilitation 16 (4), 406-413. 
Cumming, R. G., Salkeld, G., Thomas, M. \& Szonyi, G. 2000. Prospective study of the impact of fear of falling on activities of daily living, SF-36 scores, and nursing home admission. The Journals of Gerontology. Series A, Biological Sciences and Medical Sciences 55 (5), M299-305.

Cummings, S. R., Nevitt, M. C., Browner, W. S., Stone, K., Fox, K. M., Ensrud, K. E., Cauley, J., Black, D. \& Vogt, T. M. 1995. Risk factors for hip fracture in white women. Study of Osteoporotic Fractures Research Group. The New England Journal of Medicine 332 (12), 767-773.

Daving, Y., Andrén, E. \& Grimby, G. 2000. Inter-Rater Agreement Using the Instrumental Activity Measure. Scandinavian Journal of Occupational Therapy 7 (1), 33-38.

Daving, Y., Claesson, L. \& Sunnerhagen, K. S. 2009. Agreement in activities of daily living performance after stroke in a postal questionnaire and interview of community-living persons. Acta Neurologica Scandinavica 119 (6), 390-396.

Davis, J. C., Marra, C. A. \& Liu-Ambrose, T. Y. 2011. Falls-related self-efficacy is independently associated with quality-adjusted life years in older women. Age and Ageing 40 (3), 340-346.

Davis, M. G. \& Fox, K. R. 2007. Physical activity patterns assessed by accelerometry in older people. European Journal of Applied Physiology 100 (5), 581-589.

Day, G. A., Swanson, C., Yelland, C., Broome, J., Dimitri, K., Massey, L., Richardson, H. \& Marsh, A. 2001. Surgical outcomes of a randomized prospective trial involving patients with a proximal femoral fracture. ANZ Journal of Surgery 71 (1), 11-14.

de Laet, C. E., van Hout, B. A., Burger, H., Hofman, A. \& Pols, H. A. 1997. Bone density and risk of hip fracture in men and women: cross sectional analysis. British Medical Journal (Clinical Research ed.) 315 (7102), 221-225.

de Luise, C., Brimacombe, M., Pedersen, L. \& Sorensen, H. T. 2008. Comorbidity and mortality following hip fracture: a population-based cohort study. Aging Clinical and Experimental Research 20 (5), 412-418.

de Rekeneire, N., Visser, M., Peila, R., Nevitt, M. C., Cauley, J. A., Tylavsky, F. A., Simonsick, E. M. \& Harris, T. B. 2003. Is a fall just a fall: correlates of falling in healthy older persons. The Health, Aging and Body Composition Study. Journal of the American Geriatrics Society 51 (6), 841-846.

Delbaere, K., Close, J. C., Brodaty, H., Sachdev, P. \& Lord, S. R. 2010a. Determinants of disparities between perceived and physiological risk of falling among elderly people: cohort study. British Medical Journal (Clinical Research ed.) 18 (341), c4165. DOI: http://dx.doi.org/10.1136/bmj.c4165.

Delbaere, K., Close, J. C., Heim, J., Sachdev, P. S., Brodaty, H., Slavin, M. J., Kochan, N. A. \& Lord, S. R. 2010b. A multifactorial approach to understanding fall risk in older people. Journal of the American Geriatrics Society 58 (9), 1679-1685. 
Delbaere, K., Crombez, G., Vanderstraeten, G., Willems, T. \& Cambier, D. 2004. Fear-related avoidance of activities, falls and physical frailty. A prospective community-based cohort study. Age and Ageing 33 (4), 368-373.

Demura, S., Sato, S. \& Kitabayashi, T. 2005. Estimation accuracy of percent total body fat and percent segmental fat measured by single-frequency bioelectrical impedance analysis with 8 electrodes: the effect of difference in adiposity. The Journal of Sports Medicine and Physical Fitness 45 (1), 68-76.

Deshpande, N., Metter, E. J., Lauretani, F., Bandinelli, S., Guralnik, J. \& Ferrucci, L. 2008. Activity restriction induced by fear of falling and objective and subjective measures of physical function: a prospective cohort study. Journal of the American Geriatrics Society 56 (4), 615-620.

Duffy, L., Gajree, S., Langhorne, P., Stott, D. J. \& Quinn, T. J. 2013. Reliability (inter-rater agreement) of the Barthel Index for assessment of stroke survivors: systematic review and meta-analysis. Stroke 44 (2), 462-468.

Duodecim 2011. Hip fracture. Current Care (in Finnish). Guidelines by the Working group appointed by the Finnish Medical Society Duodecim and the Finnish Orthopaedic Association. Summary available online in English: http://www.kaypahoito.fi/web/kh/suositukset/naytaartikkeli/tunnus/c cs00092.

Eastwood, E. A., Magaziner, J., Wang, J., Silberzweig, S. B., Hannan, E. L., Strauss, E. \& Siu, A. L. 2002. Patients with hip fracture: subgroups and their outcomes. Journal of the American Geriatrics Society 50 (7), 1240-1249.

Eisler, J., Cornwall, R., Strauss, E., Koval, K., Siu, A. \& Gilbert, M. 2002. Outcomes of elderly patients with nondisplaced femoral neck fractures. Clinical Orthopaedics and Related Research 399 (7), 52-58.

Ekström, H., Dahlin Ivanoff, S. \& Elmstahl, S. 2012. Does informal support influence social participation of fractured elderly people? Archives of Gerontology and Geriatrics 56 (3), 457-465.

Enoka, R. 1994. Neuromechanical basics of kinesiology. (3rd edition) Champaign, United States: Human Kinetics.

Ferri, A., Scaglioni, G., Pousson, M., Capodaglio, P., Van Hoecke, J. \& Narici, M. 2003. Strength and power changes of the human plantar flexors and the knee extensors in response to resistance training in old age. Acta Physiologica Scandinavica 177 (1), 69-78.

Ferrucci, L., Guralnik, J. M., Buchner, D., Kasper, J., Lamb, S. E., Simonsick, E. M., Corti, M. C., Bandeen-Roche, K. \& Fried, L. P. 1997. Departures from linearity in the relationship between measures of muscular strength and physical performance of the lower extremities: the Women's Health and Aging Study. The Journals of Gerontology. Series A, Biological Sciences and Medical Sciences 52 (5), M275-85.

Ferrucci, L., Guralnik, J. M., Simonsick, E., Salive, M. E., Corti, C. \& Langlois, J. 1996. Progressive versus catastrophic disability: a longitudinal view of the disablement process. The Journals of Gerontology. Series A, Biological Sciences and Medical Sciences 51 (3), M123-30. 
Fiatarone Singh, M. A., Singh, N. A., Hansen, R. D., Finnegan, T. P., Allen, B. J., Diamond, T. H., Diwan, A. D., Lloyd, B. D., Williamson, D. A., Smith, E. U., Grady, J. N., Stavrinos, T. M. \& Thompson, M. W. 2009. Methodology and baseline characteristics for the Sarcopenia and Hip Fracture study: a 5-year prospective study. The Journals of Gerontology. Series A, Biological Sciences and Medical Sciences 64 (5), 568-574.

Fisher, L., Dixon, D., Herson, J., Frankowski, R., Hearon, M. \& Pearce, K. 1990. Intention to treat in clinical trials. In Pearce KE (Ed.) Statistical issues in drug research and development. New York: Marcel Dekker, 331-350.

Folbert, E. C., Smit, R. S., van der Velde, D., Regtuijt, E. M., Klaren, M. H. \& Hegeman, J. H. 2012. Geriatric fracture center: a multidisciplinary treatment approach for older patients with a hip fracture improved quality of clinical care and short-term treatment outcomes. Geriatric Orthopaedic Surgery \& Rehabilitation 3 (2), 59-67.

Folden, S. \& Tappen, R. 2007. Factors influencing function and recovery following hip repair surgery. Orthopaedic Nursing / National Association of Orthopaedic Nurses 26 (4), 234-241.

Folstein, M. F., Folstein, S. E. \& McHugh, P. R. 1975. "Mini-mental state". A practical method for grading the cognitive state of patients for the clinician. Journal of Psychiatric Research 12 (3), 189-198.

Fox, K. M., Cummings, S. R., Williams, E., Stone, K. \& Study of Osteoporotic Fractures 2000. Femoral neck and intertrochanteric fractures have different risk factors: a prospective study. Osteoporosis International 11 (12), 10181023.

Fox, K. R., Stathi, A., McKenna, J. \& Davis, M. G. 2007. Physical activity and mental well-being in older people participating in the Better Ageing Project. European Journal of Applied Physiology 100 (5), 591-602.

Franco, O. H., de Laet, C., Peeters, A., Jonker, J., Mackenbach, J. \& Nusselder, W. 2005. Effects of physical activity on life expectancy with cardiovascular disease. Archives of Internal Medicine 165 (20), 2355-2360.

Freire, A. N., Guerra, R. O., Alvarado, B., Guralnik, J. M. \& Zunzunegui, M. V. 2012. Validity and reliability of the short physical performance battery in two diverse older adult populations in Quebec and Brazil. Journal of Aging and Health 24 (5), 863-878.

Gallagher, P. F., Barry, P. J., Ryan, C., Hartigan, I. \& O'Mahony, D. 2008. Inappropriate prescribing in an acutely ill population of elderly patients as determined by Beers' Criteria. Age and Ageing 37 (1), 96-101.

Gaugler, J. E., Duval, S., Anderson, K. A. \& Kane, R. L. 2007. Predicting nursing home admission in the U.S: a meta-analysis. BioMed Central Geriatrics 19 (7), 13. DOI: 10.1186/1471-2318-7-13.

Gehlbach, S. H., Avrunin, J. S. \& Puleo, E. 2007. Trends in hospital care for hip fractures. Osteoporosis International 18 (5), 585-591.

Gill, T. M., Williams, C. S. \& Tinetti, M. E. 1995. Assessing risk for the onset of functional dependence among older adults: the role of physical performance. Journal of the American Geriatrics Society 43 (6), 603-609. 
Gillespie, L. D., Robertson, M. C., Gillespie, W. J., Sherrington, C., Gates, S., Clemson, L. M. \& Lamb, S. E. 2012. Interventions for preventing falls in older people living in the community. Cochrane Database of Systematic Reviews 12 (9), CD007146. DOI: 10.1002/14651858.CD007146.pub3.

Gine-Garriga, M., Guerra, M., Pages, E., Manini, T. M., Jimenez, R. \& Unnithan, V. B. 2010. The effect of functional circuit training on physical frailty in frail older adults: a randomized controlled trial. Journal of Aging and Physical Activity 18 (4), 401-424.

Giusti, A., Barone, A., Razzano, M., Pizzonia, M. \& Pioli, G. 2011. Optimal setting and care organization in the management of older adults with hip fracture. European Journal of Physical and Rehabilitation Medicine 47 (2), 281-296.

Granger, C. V., Hamilton, B. B., Linacre, J. M., Heinemann, A. W. \& Wright, B. D. 1993. Performance profiles of the functional independence measure. American Journal of Physical Medicine \& Rehabilitation / Association of Academic Physiatrists 72 (2), 84-89.

Grimby, G. 1986. Physical activity and muscle training in the elderly. Acta Medica Scandinavica Supplementum 711, 233-237.

Grimby, G., Andren, E., Daving, Y. \& Wright, B. 1998. Dependence and perceived difficulty in daily activities in community-living stroke survivors 2 years after stroke: a study of instrumental structures. Stroke 29 (9), 18431849.

Grimes, J. P., Gregory, P. M., Noveck, H., Butler, M. S. \& Carson, J. L. 2002. The effects of time-to-surgery on mortality and morbidity in patients following hip fracture. The American Journal of Medicine 112 (9), 702-709.

Gruber-Baldini, A. L., Zimmerman, S., Morrison, R. S., Grattan, L. M., Hebel, J. R., Dolan, M. M., Hawkes, W. \& Magaziner, J. 2003. Cognitive impairment in hip fracture patients: timing of detection and longitudinal follow-up. Journal of the American Geriatrics Society 51 (9), 1227-1236.

Guralnik, J. M., Branch, L. G., Cummings, S. R. \& Curb, J. D. 1989. Physical performance measures in aging research. Journal of Gerontology 44 (5), M141-6.

Guralnik, J. M., LaCroix, A. Z., Branch, L. G., Kasl, S. V. \& Wallace, R. B. 1991. Morbidity and disability in older persons in the years prior to death. American Journal of Public Health 81 (4), 443-447.

Guralnik, J. M., Simonsick, E. M., Ferrucci, L., Glynn, R. J., Berkman, L. F., Blazer, D. G., Scherr, P. A. \& Wallace, R. B. 1994. A short physical performance battery assessing lower extremity function: association with self-reported disability and prediction of mortality and nursing home admission. Journal of Gerontology 49 (2), M85-94.

Hadjistavropoulos, T., Delbaere, K. \& Fitzgerald, T. D. 2011. Reconceptualizing the role of fear of falling and balance confidence in fall risk. Journal of Aging and Health 23 (1), 3-23. 
Hamilton, B. B., Laughlin, J. A., Fiedler, R. C. \& Granger, C. V. 1994. Interrater reliability of the 7-level functional independence measure (FIM). Scandinavian Journal of Rehabilitation Medicine 26 (3), 115-119.

Handoll, H. H., Cameron, I. D., Mak, J. C. \& Finnegan, T. P. 2009. Multidisciplinary rehabilitation for older people with hip fractures. Cochrane Database of Systematic Reviews 7 (4), CD007125. DOI: 10.1002/14651858.CD007125.pub2.

Handoll, H. H. \& Ollivere, B. J. 2010. Interventions for treating proximal humeral fractures in adults. Cochrane Database of Systematic Reviews 8 (12), CD000434. DOI: 10.1002/14651858.CD000434.pub2.

Handoll, H. H., Sherrington, C. \& Mak, J. C. 2011. Interventions for improving mobility after hip fracture surgery in adults. Cochrane Database of Systematic Reviews 16 (3), CD001704. DOI: 10.1002/14651858.CD001704.pub4.

Haskell, W. L., Lee, I. M., Pate, R. R., Powell, K. E., Blair, S. N., Franklin, B. A., Macera, C. A., Heath, G. W., Thompson, P. D. \& Bauman, A. 2007. Physical activity and public health: updated recommendation for adults from the American College of Sports Medicine and the American Heart Association. Medicine and Science in Sports and Exercise 39 (8), 1423-1434.

Hauer, K., Specht, N., Schuler, M., Bartsch, P. \& Oster, P. 2002. Intensive physical training in geriatric patients after severe falls and hip surgery. Age and Ageing 31 (1), 49-57.

Hays, R. D., Sherbourne, C. D. \& Mazel, R. M. 1993. The RAND 36-Item Health Survey 1.0. Health Economics 2 (3), 217-227.

Heinonen, M., Karppi, P., Huusko, T., Kautiainen, H. \& Sulkava, R. 2004. Postoperative degree of mobilization at two weeks predicts one-year mortality after hip fracture. Aging Clinical and Experimental Research 16 (6), 476-480.

Herrick, C., Steger-May, K., Sinacore, D. R., Brown, M., Schechtman, K. B. \& Binder, E. F. 2004. Persistent pain in frail older adults after hip fracture repair. Journal of the American Geriatrics Society 52 (12), 2062-2068.

Hirvensalo, M., Rantanen, T. \& Heikkinen, E. 2000. Mobility difficulties and physical activity as predictors of mortality and loss of independence in the community-living older population. Journal of the American Geriatrics Society 48 (5), 493-498.

Hoenig, H., Rubenstein, L. V., Sloane, R., Horner, R. \& Kahn, K. 1997. What is the role of timing in the surgical and rehabilitative care of communitydwelling older persons with acute hip fracture? Archives of Internal Medicine 157 (5), 513-520.

Hokoishi, K., Ikeda, M., Maki, N., Nomura, M., Torikawa, S., Fujimoto, N., Fukuhara, R., Komori, K. \& Tanabe, H. 2001. Interrater reliability of the Physical Self-Maintenance Scale and the Instrumental Activities of Daily Living Scale in a variety of health professional representatives. Aging \& Mental Health 5 (1), 38-40.

Holviala, J. H., Sallinen, J. M., Kraemer, W. J., Alén, M. J. \& Häkkinen, K. K. 2006. Effects of strength training on muscle strength characteristics, 
functional capabilities, and balance in middle-aged and older women. Journal of Strength and Conditioning Research 20 (2), 336-344.

Host, H. H., Sinacore, D. R., Bohnert, K. L., Steger-May, K., Brown, M. \& Binder, E. F. 2007. Training-induced strength and functional adaptations after hip fracture. Physical Therapy 87 (3), 292-303.

Huang, T. T. \& Acton, G. J. 2009. Ways to maintain independence among Taiwanese elderly adults with hip fractures: a qualitative study. Geriatric Nursing 30 (1), 28-35.

Huusko, T. M., Karppi, P., Avikainen, V., Kautiainen, H. \& Sulkava, R. 2002. Intensive geriatric rehabilitation of hip fracture patients: a randomized, controlled trial. Acta Orthopaedica Scandinavica 73 (4), 425-431.

Häkkinen, A., Heinonen, M., Kautiainen, H., Huusko, T., Sulkava, R. \& Karppi, P. 2007. Effect of cognitive impairment on basic activities of daily living in hip fracture patients: a 1-year follow-up. Aging Clinical and Experimental Research 19 (2), 139-144.

Häkkinen, K. \& Häkkinen, A. 1995. Neuromuscular adaptations during intensive strength training in middle-aged and elderly males and females. Electromyography and Clinical Neurophysiology 35 (3), 137-147.

Imam, B. \& Miller, W. C. 2012. Reliability and validity of scores of a Chinese version of the Frenchay Activities Index. Archives of Physical Medicine and Rehabilitation 93 (3), 520-526.

Ingemarsson, A. H., Frändin, K., Mellström, D. \& Möller, M. 2003. Walking ability and activity level after hip fracture in the elderly--a follow-up. Journal of Rehabilitation Medicine : 35 (2), 76-83.

Jellesmark, A., Herling, S. F., Egerod, I. \& Beyer, N. 2012. Fear of falling and changed functional ability following hip fracture among communitydwelling elderly people: an explanatory sequential mixed method study. Disability and Rehabilitation 34 (25), 2124-2131.

Jette, A. M. 2006. Toward a common language for function, disability, and health. Physical Therapy 86 (5), 726-734.

Jette, A. M. 1987. The Functional Status Index: reliability and validity of a selfreport functional disability measure. The Journal of Rheumatology. 14 (Suppl 15), 15-21.

Jette, A. M. 1980. Functional Status Index: reliability of a chronic disease evaluation instrument. Archives of Physical Medicine and Rehabilitation 61 (9), 395-401.

Jette, A. M. \& Branch, L. G. 1985. Impairment and disability in the aged. Journal of Chronic Diseases 38 (1), 59-65.

Jette, A. M. \& Cleary, P. D. 1987. Functional disability assessment. Physical Therapy 67 (12), 1854-1859.

Jette, A. M., Davies, A. R., Cleary, P. D., Calkins, D. R., Rubenstein, L. V., Fink, A., Kosecoff, J., Young, R. T., Brook, R. H. \& Delbanco, T. L. 1986. The Functional Status Questionnaire: reliability and validity when used in primary care. Journal of General Internal Medicine 1 (3), 143-149. 
Jette, A. M., Harris, B. A., Cleary, P. D. \& Campion, E. W. 1987. Functional recovery after hip fracture. Archives of Physical Medicine and Rehabilitation 68 (10), 735-740.

Jonsson, B., Sernbo, I. \& Johnell, O. 1995. Rehabilitation of hip fracture patients with Parkinson's Disease. Scandinavian Journal of Rehabilitation Medicine 27 (4), 227-230.

Järvinen, T. L., Sievänen, H., Khan, K. M., Heinonen, A. \& Kannus, P. 2008. Shifting the focus in fracture prevention from osteoporosis to falls. British Medical Journal (Clinical Research ed.) 336 (7636), 124-126.

Kamel, H. K., Iqbal, M. A., Mogallapu, R., Maas, D. \& Hoffmann, R. G. 2003. Time to ambulation after hip fracture surgery: relation to hospitalization outcomes. The Journals of Gerontology. Series A, Biological Sciences and Medical Sciences 58 (11), 1042-1045.

Kane, R. L. \& kane, R. A. 1981. A guide through the maze of long-term care. The Western Journal of Medicine 135 (6), 503-510.

Kanis, J. A. 2002. Diagnosis of osteoporosis and assessment of fracture risk. Lancet 359 (9321), 1929-1936.

Kannus, P., Parkkari, J., Koskinen, S., Niemi, S., Palvanen, M., Järvinen, M. \& Vuori, I. 1999. Fall-induced injuries and deaths among older adults. JAMA: The Journal of the American Medical Association 281 (20), 1895-1899.

Kannus, P., Sievänen, H., Palvanen, M., Järvinen, T. \& Parkkari, J. 2005. Prevention of falls and consequent injuries in elderly people. Lancet 366 (9500), 1885-1893.

Karinkanta, S., Piirtola, M., Sievänen, H., Uusi-Rasi, K. \& Kannus, P. 2010. Physical therapy approaches to reduce fall and fracture risk among older adults. Nature Reviews. Endocrinology 6 (7), 396-407.

Karlsson, M. K., Magnusson, H., von Schewelov, T. \& Rosengren, B. E. 2013. Prevention of falls in the elderly-a review. Osteoporosis International 24 (3), 747-762.

Katz, S. \& Akpom, C. A. 1976. 12. Index of ADL. Medical Care 14 (5 Suppl), 116118.

Katz, S., Ford, A. B., Moskowitz, R. W., Jackson, B. A. \& Jaffe, M. W. 1963. Studies of Illness in the Aged. the Index of ADL: a Standardized Measure of Biological and Psychosocial Function. JAMA: The Journal of the American Medical Association 185 (21), 914-919.

Keith, R. A., Granger, C. V., Hamilton, B. B. \& Sherwin, F. S. 1987. The functional independence measure: a new tool for rehabilitation. Advances in Clinical Rehabilitation 1, 6-18.

Kelly-Hayes, M., Jette, A. M., Wolf, P. A., D'Agostino, R. B. \& Odell, P. M. 1992. Functional limitations and disability among elders in the Framingham Study. American Journal of Public Health 82 (6), 841-845.

Keysor, J. J. \& Jette, A. M. 2001. Have we oversold the benefit of late-life exercise? The Journals of Gerontology. Series A, Biological Sciences and Medical Sciences 56 (7), M412-23. 
Khan, K. M., Liu-Ambrose, T., Donaldson, M. G. \& McKay, H. A. 2001. Physical activity to prevent falls in older people: time to intervene in high risk groups using falls as an outcome. British Journal of Sports Medicine 35 (3), 144-145.

Kidd, T. \& Yoshida, K. 1995. Critical review of disability measures: conceptual developments. Physiotherapy Canada 47 (2), 108-119.

Kirke, P. N., Sutton, M., Burke, H. \& Daly, L. 2002. Outcome of hip fracture in older Irish women: a 2-year follow-up of subjects in a case-control study. Injury 33 (5), 387-391.

Kivinen, P., Sulkava, R., Halonen, P. \& Nissinen, A. 1998. Self-reported and performance-based functional status and associated factors among elderly men: the Finnish cohorts of the Seven Countries Study. Journal of Clinical Epidemiology 51 (12), 1243-1252.

Kulmala, J., Sihvonen, S., Kallinen, M., Alén, M., Kiviranta, I. \& Sipilä, S. 2007. Balance confidence and functional balance in relation to falls in older persons with hip fracture history. Journal of Geriatric Physical Therapy 30 (3), 114-120.

Laake, K., Laake, P., Ranhoff, A. H., Sveen, U., Wyller, T. B. \& Bautz-Holter, E. 1995. The Barthel ADL index: factor structure depends upon the category of patient. Age and Ageing 24 (5), 393-397.

Lamb, S. E., Morse, R. E. \& Evans, J. G. 1995. Mobility after proximal femoral fracture: the relevance of leg extensor power, postural sway and other factors. Age and Ageing 24 (4), 308-314.

Latham, N. K., Mehta, V., Nguyen, A. M., Jette, A. M., Olarsch, S., Papanicolaou, D. \& Chandler, J. 2008. Performance-based or self-report measures of physical function: which should be used in clinical trials of hip fracture patients? Archives of Physical Medicine and Rehabilitation 89 (11), 2146-2155.

Laukkanen, P., Karppi, P., Heikkinen, E. \& Kauppinen, M. 2001. Coping with activities of daily living in different care settings. Age and Ageing 30 (6), 489-494.

Lawton, M. P., Moss, M., Fulcomer, M. \& Kleban, M. H. 2003. Multi-level assessment instrument manual for full-length MAI. North Wales PA: Polisher Research Institut.

Lawton, M. P. \& Brody, E. M. 1969. Assessment of older people: selfmaintaining and instrumental activities of daily living. The Gerontologist 9 (3), 179-186.

Lee, I. M., Shiroma, E. J., Lobelo, F., Puska, P., Blair, S. N., Katzmarzyk, P. T. \& Lancet Physical Activity Series Working Group 2012. Effect of physical inactivity on major non-communicable diseases worldwide: an analysis of burden of disease and life expectancy. Lancet 380 (9838), 219-229.

Leibson, C. L., Tosteson, A. N., Gabriel, S. E., Ransom, J. E. \& Melton, L. J. 2002. Mortality, disability, and nursing home use for persons with and without hip fracture: a population-based study. Journal of the American Geriatrics Society 50 (10), 1644-1650. 
Leslie, W. D., O'Donnell, S., Lagace, C., Walsh, P., Bancej, C., Jean, S., Siminoski, K., Kaiser, S., Kendler, D. L., Jaglal, S. \& Osteoporosis Surveillance Expert Working Group 2010. Population-based Canadian hip fracture rates with international comparisons. Osteoporosis International 21 (8), 1317-1322.

Li, F., Fisher, K. J., Harmer, P., McAuley, E. \& Wilson, N. L. 2003. Fear of falling in elderly persons: association with falls, functional ability, and quality of life. The Journals of Gerontology. Series B, Psychological Sciences and Social Sciences 58 (5), P283-290.

Li, F., Harmer, P., Fisher, K. J., McAuley, E., Chaumeton, N., Eckstrom, E. \& Wilson, N. L. 2005. Tai Chi and fall reductions in older adults: a randomized controlled trial. The Journals of Gerontology. Series A, Biological Sciences and Medical Sciences 60 (2), 187-194.

Liu, C. J. \& Latham, N. 2010. Can progressive resistance strength training reduce physical disability in older adults? A meta-analysis study. Disability and Rehabilitation 33 (2), 87-97.

Liu, C. J. \& Latham, N. K. 2009. Progressive resistance strength training for improving physical function in older adults. Cochrane Database of Systematic Reviews 8 (3), CD002759. DOI: 10.1002/14651858.CD002759.pub2.

Liu-Ambrose, T., Khan, K. M., Donaldson, M. G., Eng, J. J., Lord, S. R. \& McKay, H. A. 2006. Falls-related self-efficacy is independently associated with balance and mobility in older women with low bone mass. The Journals of Gerontology. Series A, Biological Sciences and Medical Sciences 61 (8), 832838.

Liu-Ambrose, T. Y., Khan, K. M., Eng, J. J., Gillies, G. L., Lord, S. R. \& McKay, H. A. 2005. The beneficial effects of group-based exercises on fall risk profile and physical activity persist 1 year postintervention in older women with low bone mass: follow-up after withdrawal of exercise. Journal of the American Geriatrics Society 53 (10), 1767-1773.

Lloyd, B. D., Williamson, D. A., Singh, N. A., Hansen, R. D., Diamond, T. H., Finnegan, T. P., Allen, B. J., Grady, J. N., Stavrinos, T. M., Smith, E. U., Diwan, A. D. \& Fiatarone Singh, M. A. 2009. Recurrent and injurious falls in the year following hip fracture: a prospective study of incidence and risk factors from the Sarcopenia and Hip Fracture study. The Journals of Gerontology. Series A, Biological Sciences and Medical Sciences 64 (5), 599609.

Lopez, M. N., Charter, R. A., Mostafavi, B., Nibut, L. P. \& Smith, W. E. 2005. Psychometric properties of the Folstein Mini-Mental State Examination. Assessment 12 (2), 137-144.

Lord, S. R. \& Dayhew, J. 2001. Visual risk factors for falls in older people. Journal of the American Geriatrics Society 49 (5), 508-515.

Lord, S. R., Lloyd, D. G. \& Li, S. K. 1996. Sensori-motor function, gait patterns and falls in community-dwelling women. Age and Ageing 25 (4), 292-299. 
Lord, S. R. \& Sturnieks, D. L. 2005. The physiology of falling: assessment and prevention strategies for older people. Journal of Science and Medicine in Sport / Sports Medicine Australia 8 (1), 35-42.

Lord, S. R., Ward, J. A., Williams, P. \& Anstey, K. J. 1994. Physiological factors associated with falls in older community-dwelling women. Journal of the American Geriatrics Society 42 (10), 1110-1117.

Lönnroos, E., Kautiainen, H., Karppi, P., Huusko, T., Hartikainen, S., Kiviranta, I. \& Sulkava, R. 2006. Increased incidence of hip fractures. A population based-study in Finland. Bone 39 (3), 623-627.

Magaziner, J., Fredman, L., Hawkes, W., Hebel, J. R., Zimmerman, S., Orwig, D. L. \& Wehren, L. 2003. Changes in functional status attributable to hip fracture: a comparison of hip fracture patients to community-dwelling aged. American Journal of Epidemiology 157 (11), 1023-1031.

Magaziner, J., Hawkes, W., Hebel, J. R., Zimmerman, S. I., Fox, K. M., Dolan, M., Felsenthal, G. \& Kenzora, J. 2000. Recovery from hip fracture in eight areas of function. The Journals of Gerontology. Series A, Biological Sciences and Medical Sciences 55 (9), M498-507.

Mahoney, F. I. \& Barthel, D. W. 1965. Functional Evaluation: the Barthel Index. Maryland State Medical Journal 14 (2), 61-65.

Mak, J. C., Cameron, I. D., March, L. M. \& National Health and Medical Research Council 2010. Evidence-based guidelines for the management of hip fractures in older persons: an update. The Medical Journal of Australia 192 (1), 37-41.

Mangione, K. K., Craik, R. L., Tomlinson, S. S. \& Palombaro, K. M. 2005. Can elderly patients who have had a hip fracture perform moderate- to highintensity exercise at home? Physical Therapy 85 (8), 727-739.

Manton, K. G. 1988. A longitudinal study of functional change and mortality in the United States. Journal of Gerontology 43 (5), S153-161.

Marcantonio, E. R., Flacker, J. M., Wright, R. J. \& Resnick, N. M. 2001. Reducing delirium after hip fracture: a randomized trial. Journal of the American Geriatrics Society 49 (5), 516-522.

Marottoli, R. A., Berkman, L. F. \& Cooney, L. M.Jr 1992. Decline in physical function following hip fracture. Journal of the American Geriatrics Society 40 (9), 861-866.

Martin-Lesende, I., Ortiz-Lebaniegos, I., Montalvillo-Delgado, E., Perez-Abad, M., Sanchez-Junquera, P. \& Rodriguez-Andres, C. 2006. Identification of items for creating a questionnaire for the assessment of instrumental activities of daily living (IADL) in elderly patients. Atencion Primaria / Sociedad Espanola de Medicina de Familia y Comunitaria 37 (6), 313-318.

McDonagh, M. J. \& Davies, C. T. 1984. Adaptive response of mammalian skeletal muscle to exercise with high loads. European Journal of Applied Physiology and Occupational Physiology 52 (2), 139-155.

McHorney, C. A., Ware, J. E.,Jr \& Raczek, A. E. 1993. The MOS 36-Item ShortForm Health Survey (SF-36): II. Psychometric and clinical tests of validity in 
measuring physical and mental health constructs. Medical Care 31 (3), 247263.

McKee, K. J., Orbell, S., Austin, C. A., Bettridge, R., Liddle, B. J., Morgan, K. \& Radley, K. 2002. Fear of falling, falls efficacy, and health outcomes in older people following hip fracture. Disability and Rehabilitation 24 (6), 327-333.

Milisen, K., Foreman, M. D., Abraham, I. L., De Geest, S., Godderis, J., Vandermeulen, E., Fischler, B., Delooz, H. H., Spiessens, B. \& Broos, P. L. 2001. A nurse-led interdisciplinary intervention program for delirium in elderly hip-fracture patients. Journal of the American Geriatrics Society 49 (5), 523-532.

Miller, W. C., Deathe, A. B. \& Harris, J. 2004. Measurement properties of the Frenchay Activities Index among individuals with a lower limb amputation. Clinical Rehabilitation 18 (4), 414-422.

Morghen, S., Bellelli, G., Manuele, S., Guerini, F., Frisoni, G. B. \& Trabucchi, M. 2010. Moderate to severe depressive symptoms and rehabilitation outcome in older adults with hip fracture. International Journal of Geriatric Psychiatry 26 (11), 1136-1143.

Morrison, A., Fan, T., Sen, S. S. \& Weisenfluh, L. 2013. Epidemiology of falls and osteoporotic fractures: a systematic review. ClinicoEconomics and Outcomes Research 5, 9-18. DOI: 10.2147/CEOR.S38721.

Muir, S. W. \& Yohannes, A. M. 2009. The impact of cognitive impairment on rehabilitation outcomes in elderly patients admitted with a femoral neck fracture: a systematic review. Journal of Geriatric Physical Therapy 32 (1), 24-32.

Murphy, S. L., Williams, C. S. \& Gill, T. M. 2002. Characteristics associated with fear of falling and activity restriction in community-living older persons. Journal of the American Geriatrics Society 50 (3), 516-520.

Myers, A. M., Holliday, P. J., Harvey, K. A. \& Hutchinson, K. S. 1993. Functional performance measures: are they superior to self-assessments? Journal of Gerontology 48 (5), M196-206.

Mänty, M., Sihvonen, S., Hulkko, T. \& Lounamaa, A. 2007. Iäkkäiden henkilöiden kaatumistapaturmat. Opas kaatumisten ja murtumien ehkäisyyn (in Finnish). Publications by the National Public Health Institute of Finland.

Mänty, M., Heinonen, A., Leinonen, R., Törmäkangas, T., Hirvensalo, M., Kallinen, M., Sakari, R., von Bonsdorff, M. B., Heikkinen, E. \& Rantanen, T. 2009. Long-term effect of physical activity counseling on mobility limitation among older people: a randomized controlled study. The Journals of Gerontology. Series A, Biological Sciences and Medical Sciences 64 (1), 8389.

Nagi, S. Z. 1976. An epidemiology of disability among adults in the United States. The Milbank Memorial Fund Quarterly. Health and Society 54 (4), 439-467.

Neander, G., Adolphson, P., Hedstrom, M., von Sivers, K., Dahlborn, M. \& Dalen, N. 1997. Decrease in bone mineral density and muscle mass after 
femoral neck fracture. A quantitative computed tomography study in 25 patients. Acta Orthopaedica Scandinavica 68 (5), 451-455.

NIH Consensus Development Panel on Osteoporosis Prevention, Diagnosis, and Therapy 2001. Osteoporosis prevention, diagnosis, and therapy. JAMA: The Journal of the American Medical Association 285 (6), 785-795.

Nurmi, I., Narinen, A., Luthje, P. \& Tanninen, S. 2003. Cost analysis of hip fracture treatment among the elderly for the public health services: a 1-year prospective study in 106 consecutive patients. Archives of Orthopaedic and Trauma Surgery 123 (10), 551-554.

Nyberg, L., Gustafson, Y., Berggren, D., Brannstrom, B. \& Bucht, G. 1996. Falls leading to femoral neck fractures in lucid older people. Journal of the American Geriatrics Society 44 (2), 156-160.

Orosz, G. M., Magaziner, J., Hannan, E. L., Morrison, R. S., Koval, K., Gilbert, M., McLaughlin, M., Halm, E. A., Wang, J. J., Litke, A., Silberzweig, S. B. \& Siu, A. L. 2004. Association of timing of surgery for hip fracture and patient outcomes. JAMA: The Journal of the American Medical Association 291 (14), 1738-1743.

Orwig, D. L., Hochberg, M., Yu-Yahiro, J., Resnick, B., Hawkes, W. G., Shardell, M., Hebel, J. R., Colvin, P., Miller, R. R., Golden, J., Zimmerman, S. \& Magaziner, J. 2011. Delivery and outcomes of a yearlong home exercise program after hip fracture: a randomized controlled trial. Archives of Internal Medicine 171 (4), 323-331.

Pajala, S. 2012. Iäkkäiden kaatumisten ehkäisy (in Finnish). Tampere: Juvenes Print - Tampereen Yliopistopaino Oy. Publications by the Finnish National Institute for Health and Welfare 16.

Panel on Prevention of Falls in Older Persons, American Geriatrics Society and British Geriatrics Society 2011. Summary of the Updated American Geriatrics Society/British Geriatrics Society clinical practice guideline for prevention of falls in older persons. Journal of the American Geriatrics Society 59 (1), 148-157.

Parkkari, J., Kannus, P., Palvanen, M., Natri, A., Vainio, J., Aho, H., Vuori, I. \& Järvinen, M. 1999. Majority of hip fractures occur as a result of a fall and impact on the greater trochanter of the femur: a prospective controlled hip fracture study with 206 consecutive patients. Calcified Tissue International 65 (3), 183-187.

Patrick, D. L., Bush, J. W. \& Chen, M. M. 1973. Toward an operational definition of health. Journal of Health and Social Behavior 14 (1), 6-23.

Pelavski Atlas, A. D., Colomina, M. J., De Miguel, M. \& Roige, J. 2009. Centenarians versus patients within the most frequent age range for hip fractures: transfusion practice. Archives of Orthopaedic and Trauma Surgery 129 (5), 685-689.

Penrod, J. D., Boockvar, K. S., Litke, A., Magaziner, J., Hannan, E. L., Halm, E. A., Silberzweig, S. B., Sean Morrison, R., Orosz, G. M., Koval, K. J. \& Siu, A. L. 2004. Physical therapy and mobility 2 and 6 months after hip fracture. Journal of the American Geriatrics Society 52 (7), 1114-1120. 
Perez, J. V., Warwick, D. J., Case, C. P. \& Bannister, G. C. 1995. Death after proximal femoral fracture--an autopsy study. Injury 26 (4), 237-240.

Petrella, R. J., Payne, M., Myers, A., Overend, T. \& Chesworth, B. 2000. Physical function and fear of falling after hip fracture rehabilitation in the elderly. American Journal of Physical Medicine \& Rehabilitation / Association of Academic Physiatrists 79 (2), 154-160.

Pirinen, P., Simola, H., Aalto, J., Kaukoranta, J., Karlsson, P. \& Ruuhela, R. 2012. Tilastoja Suomen ilmastosta 1981-2010 - Climatological statistics of Finland 1981-2010. Helsinki.

Ponzer, S., Tidermark, J., Brismar, K., Soderqvist, A. \& Cederholm, T. 1999. Nutritional status, insulin-like growth factor- 1 and quality of life in elderly women with hip fractures. Clinical Nutrition 18 (4), 241-246.

Portegijs, E., Kallinen, M., Rantanen, T., Heinonen, A., Sihvonen, S., Alén, M., Kiviranta, I. \& Sipilä, S. 2008. Effects of resistance training on lowerextremity impairments in older people with hip fracture. Archives of Physical Medicine and Rehabilitation 89 (9), 1667-1674.

Portegijs, E., Rantanen, T., Kallinen, M., Heinonen, A., Alén, M., Kiviranta, I. \& Sipilä, S. 2009. Lower-limb pain, disease, and injury burden as determinants of muscle strength deficit after hip fracture. The Journal of Bone and Joint Surgery. American volume 91 (7), 1720-1728.

Potter, J. M., Evans, A. L. \& Duncan, G. 1995. Gait speed and activities of daily living function in geriatric patients. Archives of Physical Medicine and Rehabilitation 76 (11), 997-999.

Powell, L. E. \& Myers, A. M. 1995. The Activities-specific Balance Confidence (ABC) Scale. The Journals of Gerontology. Series A, Biological Sciences and Medical Sciences 50A (1), M28-34.

Ramnemark, A., Nilsson, M., Borssen, B. \& Gustafson, Y. 2000. Stroke, a major and increasing risk factor for femoral neck fracture. Stroke 31 (7), 1572-1577.

Rantanen, T. \& Avela, J. 1997. Leg extension power and walking speed in very old people living independently. The Journals of Gerontology. Series A, Biological Sciences and Medical Sciences 52 (4), M225-231.

Rantanen, T., Guralnik, J. M., Foley, D., Masaki, K., Leveille, S., Curb, J. D. \& White, L. 1999. Midlife hand grip strength as a predictor of old age disability. JAMA: The Journal of the American Medical Association 281 (6), $558-560$

Rapp, K., Becker, C., Lamb, S. E., Icks, A. \& Klenk, J. 2008. Hip fractures in institutionalized elderly people: incidence rates and excess mortality. Journal of Bone and Mineral Research : 23 (11), 1825-1831.

Reijneveld, S. A., Spijker, J. \& Dijkshoorn, H. 2007. Katz' ADL index assessed functional performance of Turkish, Moroccan, and Dutch elderly. Journal of Clinical Epidemiology 60 (4), 382-388.

Reuben, D. B., Siu, A. L. \& Kimpau, S. 1992. The predictive validity of selfreport and performance-based measures of function and health. Journal of Gerontology 47 (4), M106-110. 
Roche, J. J., Wenn, R. T., Sahota, O. \& Moran, C. G. 2005. Effect of comorbidities and postoperative complications on mortality after hip fracture in elderly people: prospective observational cohort study. British Medical Journal (Clinical Research ed.) 331 (7529), 1374. DOI: http://dx.doi.org/10.1136/bmj.38643.663843.55.

Rohde, G., Haugeberg, G., Mengshoel, A. M., Moum, T. \& Wahl, A. K. 2010. Two-year changes in quality of life in elderly patients with low-energy hip fractures. A case-control study. BioMed Central Musculoskeletal Disorders 29 (11), 226. DOI: 10.1186/1471-2474-11-226.

Rosso, A. L., Auchincloss, A. H. \& Michael, Y. L. 2011. The urban built environment and mobility in older adults: a comprehensive review. Journal of Aging Research. DOI: 10.4061/2011/816106.

Rubenstein, L. Z. \& Josephson, K. R. 2002. The epidemiology of falls and syncope. Clinics in Geriatric Medicine 18 (2), 141-158.

Sallinen, J., Leinonen, R., Hirvensalo, M., Lyyra, T. M., Heikkinen, E. \& Rantanen, T. 2009. Perceived constraints on physical exercise among obese and non-obese older people. Preventive Medicine 49 (6), 506-510.

Salminen, M., Vahlberg, T., Sihvonen, S., Sjösten, N., Piirtola, M., Isoaho, R., Aarnio, P. \& Kivelä, S. L. 2009. Effects of risk-based multifactorial fall prevention on postural balance in the community-dwelling aged: a randomized controlled trial. Archives of Gerontology and Geriatrics 48 (1), $22-27$.

Salpakoski, A., Portegijs, E., Kallinen, M., Sihvonen, S., Kiviranta, I., Alén, M., Rantanen, T. \& Sipilä, S. 2011. Physical inactivity and pain in older men and women with hip fracture history. Gerontology 57 (1), 19-27.

Scogin, F., Beutler, L., Corbishley, A. \& Hamblin, D. 1988. Reliability and validity of the short form Beck Depression Inventory with older adults. Journal of Clinical Psychology 44 (6), 853-857.

Shah, M. R., Aharonoff, G. B., Wolinsky, P., Zuckerman, J. D. \& Koval, K. J. 2001. Outcome after hip fracture in individuals ninety years of age and older. Journal of Orthopaedic Trauma 15 (1), 34-39.

Sherrington, C. \& Lord, S. R. 1998. Increased prevalence of fall risk factors in older people following hip fracture. Gerontology 44 (6), 340-344.

Sherrington, C. \& Lord, S. R. 1997. Home exercise to improve strength and walking velocity after hip fracture: a randomized controlled trial. Archives of Physical Medicine and Rehabilitation 78 (2), 208-212.

Sherrington, C., Lord, S. R. \& Finch, C. F. 2004. Physical activity interventions to prevent falls among older people: update of the evidence. Journal of science and medicine in sport / Sports Medicine Australia 7 (1 Suppl), 43-51.

Sherrington, C., Lord, S. R. \& Herbert, R. D. 2004. A randomized controlled trial of weight-bearing versus non-weight-bearing exercise for improving physical ability after usual care for hip fracture. Archives of Physical Medicine and Rehabilitation 85 (5), 710-716.

Shyu, Y. I., Tang, W. R., Tsai, W. C., Liang, J. \& Chen, M. C. 2006. Emotional support levels can predict physical functioning and health related quality 
of life among elderly Taiwanese with hip fractures. Osteoporosis International 17 (4), 501-506.

Sihvonen, S., Kulmala, J., Kallinen, M., Alén, M., Kiviranta, I. \& Sipilä, S. 2009. Postural balance and self-reported balance confidence in older adults with a hip fracture history. Gerontology 55 (6), 630-636.

Sihvonen, S., Sipilä, S., Taskinen, S. \& Era, P. 2004. Fall incidence in frail older women after individualized visual feedback-based balance training. Gerontology 50 (6), 411-416.

Sipilä, S., Multanen, J., Kallinen, M., Era, P. \& Suominen, H. 1996. Effects of strength and endurance training on isometric muscle strength and walking speed in elderly women. Acta Physiologica Scandinavica 156 (4), 457-464.

Sipilä, S., Salpakoski, A., Edgren, J., Heinonen, A., Kauppinen, M. A., ArkelaKautiainen, M., Sihvonen, S. E., Pesola, M., Rantanen, T. \& Kallinen, M. 2011. Promoting mobility after hip fracture (ProMo): study protocol and selected baseline results of a year-long randomized controlled trial among community-dwelling older people. BioMed Central Musculoskeletal Disorders 12 (1), 277. DOI: 10.1186/1471-2474-12-277.

Skelton, D. A., Kennedy, J. \& Rutherford, O. M. 2002. Explosive power and asymmetry in leg muscle function in frequent fallers and non-fallers aged over 65. Age and Ageing 31 (2), 119-125.

Skelton, D. A., Young, A., Greig, C. A. \& Malbut, K. E. 1995. Effects of resistance training on strength, power, and selected functional abilities of women aged 75 and older. Journal of the American Geriatrics Society 43 (10), 10811087.

Storch, E. A., Roberti, J. W. \& Roth, D. A. 2004. Factor structure, concurrent validity, and internal consistency of the Beck Depression Inventory-Second Edition in a sample of college students. Depression and Anxiety 19 (3), 187189.

Strimmer, K. 2008. A unified approach to false discovery rate estimation. BioMed Central Bioinformatics 9 (9), 303. DOI: 10.1186/1471-2105-9-303.

Swanson, C. E., Day, G. A., Yelland, C. E., Broome, J. R., Massey, L., Richardson, H. R., Dimitri, K. \& Marsh, A. 1998. The management of elderly patients with femoral fractures. A randomised controlled trial of early intervention versus standard care. The Medical Journal of Australia 169 (10), 515-518.

Sylliaas, H., Brovold, T., Wyller, T. B. \& Bergland, A. 2012. Prolonged strength training in older patients after hip fracture: a randomised controlled trial. Age and Ageing 41 (2), 206-212.

Sylliaas, H., Brovold, T., Wyller, T. B. \& Bergland, A. 2011. Progressive strength training in older patients after hip fracture: a randomised controlled trial. Age and Ageing 40 (2), 221-227.

Talley, K. M., Wyman, J. F. \& Gross, C. R. 2008. Psychometric properties of the activities-specific balance confidence scale and the survey of activities and fear of falling in older women. Journal of the American Geriatrics Society 56 (2), 328-333. 
Tan, M. L., Wee, H. L., Lee, J., Ma, S., Heng, D., Tai, E. S. \& Thumboo, J. 2013. The Short Form 36 English and Chinese versions were equivalent in a multiethnic Asian population. Journal of Clinical Epidemiology 66 (7), 759767.

Tanaka, J., Tokimura, F. \& Seki, N. 2003. Outcomes of hip fracture surgery in patients aged $>$ or $=90$ years. Orthopedics $26(1), 55-58$.

Thumboo, J., Wu, Y., Tai, E. S., Gandek, B., Lee, J., Ma, S., Heng, D. \& Wee, H. L. 2013. Reliability and validity of the English (Singapore) and Chinese (Singapore) versions of the Short-Form 36 version 2 in a multi-ethnic Urban Asian population in Singapore. Quality of Life Research. [Epub ahead of print].

Tiainen, K., Sipilä, S., Alén, M., Heikkinen, E., Kaprio, J., Koskenvuo, M., Tolvanen, A., Pajala, S. \& Rantanen, T. 2005. Shared genetic and environmental effects on strength and power in older female twins. Medicine and Science in Sports and Exercise 37 (1), $72-78$.

Tidermark, J., Zethraeus, N., Svensson, O., Tornkvist, H. \& Ponzer, S. 2002. Femoral neck fractures in the elderly: functional outcome and quality of life according to EuroQol. Quality of Life Research 11 (5), 473-481.

Timonen, L., Rantanen, T., Mäkinen, E., Timonen, T. E., Törmäkangas, T. \& Sulkava, R. 2006. Effects of a group-based exercise program on functional abilities in frail older women after hospital discharge. Aging Clinical and Experimental Research 18 (1), 50-56.

Tinetti, M. E., Baker, D. I., Gottschalk, M., Williams, C. S., Pollack, D., Garrett, P., Gill, T. M., Marottoli, R. A. \& Acampora, D. 1999. Home-based multicomponent rehabilitation program for older persons after hip fracture: a randomized trial. Archives of Physical Medicine and Rehabilitation 80 (8), 916-922.

Tinetti, M. E. \& Ginter, S. F. 1988. Identifying mobility dysfunctions in elderly patients. Standard neuromuscular examination or direct assessment? JAMA: The Journal of the American Medical Association 259 (8), 1190-1193.

Tinetti, M. E., Inouye, S. K., Gill, T. M. \& Doucette, J. T. 1995. Shared risk factors for falls, incontinence, and functional dependence. Unifying the approach to geriatric syndromes. JAMA: The Journal of the American Medical Association 273 (17), 1348-1353.

Tinetti, M. E. \& Kumar, C. 2010. The patient who falls: "It's always a trade-off". JAMA: The Journal of the American Medical Association 303 (3), 258-266.

Tinetti, M. E., Speechley, M. \& Ginter, S. F. 1988. Risk factors for falls among elderly persons living in the community. The New England journal of Medicine 319 (26), 1701-1707.

Tsauo, J. Y., Leu, W. S., Chen, Y. T. \& Yang, R. S. 2005. Effects on function and quality of life of postoperative home-based physical therapy for patients with hip fracture. Archives of Physical Medicine and Rehabilitation 86 (10), 1953-1957.

Verbrugge, L. M. \& Jette, A. M. 1994. The disablement process. Social Science \& Medicine 38 (1), 1-14. 
Vergara, I., Bilbao, A., Orive, M., Garcia-Gutierrez, S., Navarro, G. \& Quintana, J. M. 2012. Validation of the Spanish version of the Lawton IADL Scale for its application in elderly people. Health and Quality of Life Outcomes 30 (10), 130. DOI: 10.1186/1477-7525-10-130.

Visser, M., Harris, T. B., Fox, K. M., Hawkes, W., Hebel, J. R., Yahiro, J. Y., Michael, R., Zimmerman, S. I. \& Magaziner, J. 2000. Change in muscle mass and muscle strength after a hip fracture: relationship to mobility recovery. The Journals of Gerontology. Series A, Biological Sciences and Medical Sciences 55 (8), M434-40.

Vrantsidis, F., Hill, K. D., Moore, K., Webb, R., Hunt, S. \& Dowson, L. 2009. Getting Grounded Gracefully: effectiveness and acceptability of Feldenkrais in improving balance. Journal of Aging and Physical Activity 17 (1), 57-76.

Wade, D. T., Legh-Smith, J. \& Langton Hewer, R. 1985. Social activities after stroke: measurement and natural history using the Frenchay Activities Index. International Rehabilitation Medicine 7 (4), 176-181.

Wang, C. Y., Sheu, C. F. \& Protas, E. 2007. Construct validity and physical performance of older adults in different hierarchical physical-disability level. Journal of Aging and Physical Activity 15 (1), 75-89.

Ware, J.Jr, Kosinski, M. \& Keller, S. D. 1996. A 12-Item Short-Form Health Survey: construction of scales and preliminary tests of reliability and validity. Medical Care 34 (3), 220-233.

Ware, J. E.JJ \& Sherbourne, C. D. 1992. The MOS 36-item short-form health survey (SF-36). I. Conceptual framework and item selection. Medical Care $30(6), 473-483$.

Wieser, M. \& Haber, P. 2007. The effects of systematic resistance training in the elderly. International Journal of Sports Medicine 28 (1), 59-65.

World Health Organization, W. 1994. Assessment of fracture risk and its application to screening for postmenopausal osteoporosis: Report of a WHO study group. 843. Geneva, Switzerland.

Wu, C. Y., Chuang, L. L., Lin, K. C. \& Horng, Y. S. 2011. Responsiveness and validity of two outcome measures of instrumental activities of daily living in stroke survivors receiving rehabilitative therapies. Clinical Rehabilitation 25 (2), 175-183.

Yang, X., Telama, R., Hirvensalo, M., Hintsanen, M., Hintsa, T., Pulkki-Raback, L., Mansikkaniemi, K., Viikari, J. S., Keltikangas-Järvinen, L. \& Raitakari, O. T. 2010. Sustained involvement in youth sports activities predicts reduced chronic job strain in early midlife. Journal of Occupational and Environmental Medicine 52 (12), 1154-1159.

Yardley, L. \& Smith, H. 2002. A prospective study of the relationship between feared consequences of falling and avoidance of activity in communityliving older people. The Gerontologist 42 (1), 17-23.

Zidén, L., Frändin, K. \& Kreuter, M. 2008. Home rehabilitation after hip fracture. A randomized controlled study on balance confidence, physical function and everyday activities. Clinical Rehabilitation 22 (12), 1019-1033. 
Zidén, L., Kreuter, M. \& Frändin, K. 2010. Long-term effects of home rehabilitation after hip fracture - 1-year follow-up of functioning, balance confidence, and health-related quality of life in elderly people. Disability and Rehabilitation 32 (1), 18-32. 


\section{APPENDIX: Online search criteria}

\section{MEDLINE}

1. exp Femur/

2. Fractures, Bone/ or exp Fracture Fixation/ or Fracture Healing/

3. and $/ 1-2$

4. ((hip* or pertrochant* or intertrochant* or trochanteric or subtrochanteric or extracapsular* or ((femur* or femoral*) adj3 (neck or proximal))) adj4 fracture* ${ }^{*}$.tw. 5. exp Human Activities/

6. exp "Outcome and Process Assessment (Health Care)" /

7. Health Facilities/or Ambulatory Care Facilities/ or Community Health Centres/ or Outpatient Clinics, Hospital/ or Rehabilitation Centres

8. Community Health Services/ or Counselling/ or Home Care Services/ or Health Services For The Aged/ or Social Work/ or Exp Nursing Care/ or Home Care Services/ or Home Nursing/

9. exp Comprehensive Health Care/ or Continuity of Patient Care/ or Patient Care Team/

10. (functional status or functional outcome* or ambulation)

11. exp Health Status/ or Recovery of Function/

12. ((geriatric or inter?disciplinary or multi?disciplinary or early or post?operative or post?surgical or home* or intensive or accelerated or intervention or functional) adj2 (intervention or care or rehabilitation or program* or approach or group or recovery)) 13. Rehabilitation/ or Early Ambulation/ or Exp Exercise Therapy/ or Occupational Therapy/ or Rehabilitation, Vocational/

14. Health Education/ or Patient Education as Topic/

15. Patient Care/ or Aftercare/ or Ambulatory Care/ or Day Care/ or Postoperative Care/

16. Postoperative Period/

17. Outpatients/

18. Self Efficacy/

19. psychosocial

20. or/5-19

21. exp Aged/

22. older people

23. or $/ 21-22$

24. Randomized Controlled Trial

25. Controlled Clinical Trial

26. randomized

27. placebo

28. Clinical Trials as Topic/

29. randomly

30. trial

31. or/24-30

32. Humans/

33. and /31-32

42. ( 3 or 4 ) and 20 and 23 and 33 


\section{PEDRO}

Abstract \& title: fracture*

Body part: thigh or hip

Method: clinical trial 


\title{
ORIGINAL PUBLICATIONS
}

\section{I}

\section{BALANCE CONFIDENCE AND FUNCTIONAL BALANCE ARE ASSOCIATED WITH PHYSICAL DISABILITY AFTER HIP FRACTURE}

\author{
by \\ Johanna Edgren, Anu Salpakoski, Taina Rantanen, Ari Heinonen, Mauri Kallinen, \\ Mikaela B von Bonsdorff, Erja Portegijs, Sanna Sihvonen \& Sarianna Sipilä \\ Gait \& Posture 2013; 37(2):201-205. DOI: 10.1016/j.gaitpost.2012.07.001.
}

Reproduced with kind permission by Elsevier Inc. 


\section{Balance confidence and functional balance are associated with physical disability after hip fracture}

Johanna Edgren ${ }^{\mathrm{a}, *}$, Anu Salpakoski ${ }^{\mathrm{a}}$, Taina Rantanen ${ }^{\mathrm{a}}$, Ari Heinonen ${ }^{\mathrm{b}}$, Mauri Kallinen ${ }^{\mathrm{c}}$, Mikaela B. von Bonsdorff ${ }^{a}$, Erja Portegijs ${ }^{a}$, Sanna Sihvonen ${ }^{d}$, Sarianna Sipilä ${ }^{a}$

\footnotetext{
a Gerontology Research Center and Department of Health Sciences, University of Jyväskylä, Finland Department of Health Sciences, University of Jyväskylä, Finland ¿Department of Physical and Rehabilitation Medicine, Central Finland Central Hospital, Jyväskylä, Finland
d JAMK University of Applied Sciences, Jyväskylä, Finland
}

\section{A R T I C LE I NFO}

Article history:

Received in revised form 26 June 2012

Accepted 3 July 2012

Functional capacity

Fracture

Fear of falling

Postural balance

\begin{abstract}
A B S T R A C T
Background: This cross-sectional study investigated the associations between balance confidence, functional balance, and physical disability among older people after hip fracture.

Material and methods: The study utilizes baseline data of two randomized controlled trials (ISRCTN34271567 and ISRCTN53680197). The participants were 159 community-dwelling over 60year-old people. Health, fracture status, the date and type of surgery, and contraindications for participation were assessed in a clinical examination. Balance confidence was assessed by the Activitiesspecific Balance Confidence Scale $(A B C)$ and functional balance by the Berg Balance Scale. Physica disability was assessed by a questionnaire containing 14 questions on perceived difficulty in basic (ADL) and instrumental activities of daily living (IADL). Two sum scores were composed: ADL score (range 0-6) and IADL score (range $0-8$ ). Isometric knee extension force was measured using a dynamometer. Pain and use of walking aids were assessed by a questionnaire. The negative binomial regression analysis was used to analyze the associations.

Results: A higher ABC score was associated with a lower risk for ADL (IRR 0.99; 95\% CI 0.98-0.99) an IADL disability $(0.99 ; 0.98-0.99)$ in the fully adjusted models. Also a higher BBS score was associated with a lower risk for $\mathrm{ADL}(0.98 ; 0.96-0.99)$ and IADL disability $(0.98 ; 0.97-0.99)$ in the fully adjusted models.

Conclusion: Decreased balance confidence and impaired functional balance are associated with physical disability in older people after hip fracture.
\end{abstract}

@ 2012 Elsevier B.V. All rights reserved.

\section{Introduction}

Hip fracture is a common and severe trauma in older people, leading to balance impairments, decreased muscle strength, and loss of independence in daily activities $[1,2]$. It is also known that only half of the hip fracture patients regains their pre-fracture level of functional ability [2] and $15 \%$ will be institutionalized permanently [3]. Long-lasting mobility limitation after hip fracture may lead to prolonged physical disability as well as new injurious

" Corresponding author at: Gerontology Research Center and Department of Health Sciences, University of Jyväskylä, P.O. Box 35 (Viv), 40014 University of Jyväskylä, Finland. Tel.: +358 40 8053565; fax: +358 14260200

E-mail addresses: johanna.edgren@jyu.fi (J. Edgren), anu.salpakoski@jyu. (A. Salpakoski), taina.rantanen@jyu.fi (T. Rantanen), ari.heinonen@jyu. (A. Heinonen), mauri.kallwong nna.sihvonen@jamk.fi sarianna sipila@jyu.fi (S. Sipilä). falls and fractures [2]. The incidence of hip fractures increases with age and the total number of fractures is expected to rise due to aging of the population [4].

Although only $5 \%$ of all falls cause a fracture, approximately $95 \%$ of all hip fractures are caused by a fall $[5,6]$. The risk factors for falls interact with each other and large individual variation exists. The risk of falling increases rapidly with the number of risk factors Impaired functional balance is considered the most common risk factor for further falls and fractures after a previous hip fracture [7]. Balance control has also a fundamental role in various activities of daily living especially in those that require independent standing or walking. Furthermore, those who have had a fall with a traumatic consequence often experience fear of falling even years after the incident [7]. Additionally, fear of falling has been strongly associated with future falls $[8,9]$.

One method of operationalizing fear of falling is to assess self-reported balance confidence using the Activities-specific Balance Confidence Scale (ABC) described by Powell and Myers 
[10]. Decreased balance confidence has been associated with poor functional balance, increased disability, and reduced quality of life in community-dwelling older people $[8,11,12]$. Individuals with low balance confidence and balance impairments are also likely to reduce their physical and social activity, which in turn predicts the onset of disability [13]. Based on our clinical experience, self efficacy and balance confidence are low in hip fracture patients efficacy and balance confidence are low in hip fracture patients
who have suffered a traumatic fall accident, which might who have suffered a traumatic fall accident, which might
drastically slow down or disable the rehabilitation process. At the moment the scientific evidence regarding the association between balance confidence and rehabilitation outcome after hip fracture is insufficient.

To the best of our knowledge there are no other studies that have simultaneously examined associations of low balance confidence and balance impairments in relation to physical disability, in older people who have suffered a hip fracture. However, these associations should be studied to better understand the factors potentially affecting the recovery and rehabilitation processes after hip fracture. The purpose of this study was to investigate the associations between decreased balance confidence, impaired functional balance, and physical disability among older people who have sustained a previous hip fracture.

\section{Material and methods}

\subsection{Participants}

This cross-sectional study pooled the baseline data of two randomized controlled trials (ISRCTN34271567 and ISRCTN53680197). In both studies the participants were recruited from the Central Finland health care district with identical inclusion and exclusion criteria [14,15]. Patient records at the Central Finland central hospital were reviewed (in the fall of the Central Finland central hospital were reviewed (in the fall of the over 60 -years-old, ambulatory and community-dwelling people who were living in the city of Jyväskylä or the neighboring municipalities, and had been operated for femoral neck or trochanteric fracture (ICD code S72.0 or S72.1). All potential participants $(n=748)$ were informed of the study by a written participants $(n=748)$ were informed of the study by a written
information letter. Those willing to participate $(n=293)$ were interviewed over the telephone or met during the inpatient period at the health care center to ensure their suitability for the study. The exclusion criteria were: inability to move outdoors without assistance of another person, amputation of a lower limb, severe progressive or neurological diseases, alcoholism and severe memory problems (Mini Mental State Examination, MMSE $<18$ [16]). The pooled analysis includes information collected from 159 participants (113 women, 46 men) who had sustained a hip fracture on average 1.7 years earlier. Measurements were performed in the same research center using the same equipment and protocols. The Ethical Committee of the Central Finland health care district approved both studies. Before the laboratory assessments all participants gave their written informed consent.

\subsection{Methods}

2.2.1. Review of the medical data and health status

During a medical examination performed by a nurse and physician, the presence of chronic conditions, the use of prescription medication, fracture status, and the date and type of surgery were confirmed according to a pre-structured questionnaire, current prescriptions, and medical records obtained from the local hospital and health care centers. Contraindications for participation in muscle strength and balance assessments were evaluated by the physician [17].
2.2.2. Balance confidence

A modified Finnish version of the Activities-specific Balance Confidence Scale (ABC $[10,18]$ ) was used to assess confidence in performing specific activities without becoming unsteady. Balance confidence can be regarded as a measure of fear of falling [10]. The modified ABC scale consists of 16 items. Subjects are requested to describe, how confident they are in carrying out different tasks, describe, how confident they are in carrying out different tasks,
indoors and outdoors. Answers for each question were rated from 1
(no confidence) to 10 points (total confidence). The total score ranges from 16 to 160 and higher scores indicate better balance confidence.

2.2.3. Functional balance

Functional balance was assessed by the Berg Balance Scale (BBS [19]) which evaluates the ability to perform 14 different tasks such as standing up, sitting down, reaching and turning around oneself, looking over the shoulders and standing on one foot. The ability to perform each task is rated from 0 (incapable) to 4 (safe and independent). The total score ranges between 0 and 56 and higher scores indicate better functional balance.

\subsubsection{Physical disability}

Physical disability was assessed by a validated questionnaire [20] estimating perceived difficulties in basic (ADL) and instrumental activities of daily living (IADL). The questionnaire included six questions on ADL (eating, transferring from/to bed, dressing, bathing, cutting toe nails, and toileting $[20,21]$ ) and eight questions on IADL (preparing food, doing laundry, coping with light house work, coping with heavy house work, handling medication, using the telephone, using public transportation, and handling finances $[20,22])$. There were five response categories: (1) I manage without difficulties; (2) with some difficulties; (3) with lots of difficulties; (4) I can not manage without assistance of another person and (5) I can not manage even when assisted. The original categorical variables were dichotomized: (a) without difficulty (category 1 ) and (b) difficulty (categories 2-5). Subsequently, two sum scores were composed: ADL score (ranging from 0 to 6 ) and IADL score (ranging from 0 to 8 ). Higher scores indicate more difficulty.

\subsubsection{Confounders}

Isometric muscle force $(\mathrm{N})$ for knee extension was measured on the fractured side by an adjustable dynamometer chair (Metitur Ltd. [23]). During the measurement the ankle was attached to a strain-gauge system with the knee angle fixed at $60^{\circ}$ from full extension. Participants were encouraged to extend the leg as hard as possible. After two to three practice trials, measurements were performed at least three times until no further improvement occurred. Each contraction was maintained for two to three seconds. The inter-trial rest period was $30 \mathrm{~s}$. The performance of the highest maximal force was used for analysis.

Pain on the fractured side was assessed by two questions: "Have you experienced pain in the lower back, hip, knee, ankle or foot on your left/right side? Has the pain compromised your mobility?" The response alternatives were: (1) no; (2) yes, but it is not offending; (3) yes, and it is offending. A new variable "offending pain of the fractured side" was composed based on the answers. The use of walking aids outdoors was assessed by the question: "Do you use walking aids when going outdoors?" Response alternatives were yes/no.

\subsubsection{Statistical analysis}

The means, standard deviations, frequencies, and percentage values were calculated for the background variables. The associations between balance confidence and physical disability as well as between functional balance and physical disability were assessed by negative binomial regression which is a generalization of the 
Poisson regression that accounts for the over dispersion detected in Poisson models. The negative binomial regression model takes into account that disability tends to be a cumulative phenomenon and that having difficulty in one activity makes it more likely to have difficulty in two or more activities. Thus, the observations of the increasing number of difficulties are non-independent of each other. With this approach, it is possible to enter the Poisson-distributed With this approach, it is possible to enter the Poisson-distributed
count variable for the number of difficulties in the models. The risk count variable for the number of difficulties in the models. The risk
values are expressed as incidence rate ratios (IRR) obtained by values are expressed as incidence rate ratios (IRR) obtained by
exponentiation of the regression coefficients $(\exp [\beta])$, and their $95 \%$ confidence intervals (CI). The expression $100 \times($ IRR - 1) indicates the percentage change in ADL and IADL scores relative to ABC or BBS score. The crude model was adjusted for age and gender and the score. The crude model additionally for time since fracture, offending pain on second model additionally for time since fracture, offending pain on
the fractured side, number of chronic diseases, maximal force of the fractured leg, and the use of walking aids outdoors. Finally, both ABC and BBS scores were included simultaneously in the negative binomial regression model.

The Kolmogorov-Smirnov test was used to test the normality of distributions. Only the ABC score was normally distributed. Thus, the Spearman correlation was used to analyze the association between the ABC and BBS. The Spearman $\rho$ was raised to the second power to express the coefficient of determination $\left(R^{2}\right)$ for $\mathrm{ABC}$ relative to BBS. Regression modeling was performed using STATA 12 statistical software. All other analyses were performed using PASW Statistics 18.

\section{Results}

The average age of the participants was $77.4(\mathrm{SD}=7.2)$ years and the mean time elapsed since the fracture was $1.7(2.1)$ years.

Table 1

Table 1
Characteristics of older people with a previous hip fracture.

\begin{tabular}{lc}
\hline & $n=159$ \\
\hline Age (year) & $77.4 \pm 7.2$ \\
Gender: female, $n$ (\%) & $116(73)$ \\
Time since fracture (year) & $1.7 \pm 2.1$ \\
Number of chronic diseases & $3 \pm 2$ \\
Operation type, $n$ (\%) & \\
Internal fixation & $74(47)$ \\
Arthroplasty & $85(53)$ \\
Offending pain/fractured side, $n$ (\%) & $93(59)$ \\
Maximal force/fractured limb (N) & $208.3 \pm 96.3$ \\
Use of walking aids outdoors, $n$ (\%) & $110(69)$ \\
BBS (total score) & $44.1 \pm 9.3$ \\
ABC (total score) & $91.5 \pm 32.3$ \\
Median of the ADL sum score (range) & $1(0-6)$ \\
Median of the IADL sum score (range) & $3(0-8)$ \\
\hline
\end{tabular}

All means are expressed: \pm SD; BBS: Berg Balance Scale; $A B C$ : Activities-specific All means are expressed: $\triangle \mathrm{SD}$; BBS: Berg Balance Scale; $\mathrm{ABC}$ : Activities-specific
Balance Confidence Scale; ADL: activities of daily living; IADL: instrumental activities Balance Confiden daily living.
of
Seventy-three percent was female, $47 \%$ had an internal fixation and $53 \%$ an arthroplasty operation. The mean ABC score was 91.5 (32.3 points, i.e. $58 \%$ of the maximum score. Furthermore, the mean BBS score was 44.1 (9.3) points, i.e. $79 \%$ of the maximum. The median values of ADL and IADL score were one and three, respectively. The participant characteristics are presented in Table 1.

Table 2 shows the IRRs and 95\% CIs for ADL and IADL disability relative to balance confidence and functional balance. A higher $A B C$ score was associated with a lower risk for ADL disability (fully adjusted IRR 0.99; 95\% CI 0.98-0.99). This indicates that e.g. a 10 point increase in $\mathrm{ABC}$ score decreased the risk for ADL disability with $10 \%$. The association between balance confidence and IADL disability was similar $(0.99 ; 0.98-0.99)$. Furthermore, a higher BBS score was associated with a lower risk for ADL $(0.98 ; 0.96-0.99)$ and IADL disability $(0.98 ; 0.97-0.99)$ in the fully adjusted models. This indicates that e.g. a 10-point increase in BBS score decreased the risk for ADL and IADL disability with $20 \%$.

The ABC and BBS scores correlated highly but not fully (Spearman $\rho=0.69$ ) and the $A B C$ score explained $48 \%$ of the variation in BBS score $\left(R^{2}=0.476\right)$. However, placing the $\mathrm{ABC}$ and BBS scores together in the same regression model with ADL or IADL did not materially change their individual IRRs (Table 2). This implies that the $\mathrm{ABC}$ and $\mathrm{BBS}$ represent partly different phenomen and they cannot be considered as surrogate measurements. However, in the fully adjusted models the associations between the BBS score and ADL as well as IADL disability were attenuated.

\section{Discussion}

This cross-sectional study investigated the associations between balance confidence, functional balance, and physical disability in community-dwelling older men and women who had sustained a previous hip fracture. We found an independent association between decreased balance confidence and ADL/IADL disability as well as between impaired functional balance and ADL/ IADL disability. To the best of our knowledge, this is the first study which has simultaneously examined the associations of balance confidence and functional balance with disability in this group of older people with high risk of losing independence.

Balance confidence and functional balance both have an Balance confidence and functional balance both have an
essential role in coping with daily activities. Moreover, among older hip fracture patients, reduced balance confidence and impaired functional balance may complicate and delay the rehabilitation process. In the present study examining older people with a history of traumatic fall accident, we showed that decreased balance confidence was significantly associated with ADL disability. The association between decreased balance ADL disability. The association between decreased balance
confidence and IADL disability was similar. Our results are in line with previous studies pointing out that fear of falling is associated with increased physical disability in community-dwelling older people $[8,11,13]$. The majority of hip fractures are a consequence of

Table 2

IRR's and 95\% Cl's for physical disability (ADL and IADL) in negative binomial regression model with ABC and BBS scores.

\begin{tabular}{|c|c|c|c|c|c|c|c|c|}
\hline & \multicolumn{4}{|l|}{ ADL } & \multicolumn{4}{|l|}{ IADL } \\
\hline & Model $1^{\mathrm{a}}$ & $p$ & Model $2^{\mathrm{b}}$ & $p$ & Model $1^{\text {a }}$ & $p$ & Model $2^{\mathrm{b}}$ & $p$ \\
\hline $\mathrm{ABC}$ & $0.99(0.98-0.99)$ & $<0.001$ & $0.99(0.98-0.99)$ & $<0.001$ & $0.99(0.98-0.99)$ & $<0.001$ & $0.99(0.98-0.99)$ & $<0.001$ \\
\hline BBS & $0.96(0.95-0.98)$ & $<0.001$ & $0.98(0.96-0.99)$ & $<0.001$ & $0.96(0.95-0.97)$ & $<0.001$ & $0.98(0.97-0.99)$ & $<0.001$ \\
\hline $\mathrm{ABC}$ & 0.99 (0.98-0.99) & $<0.001$ & $0.99(0.98-0.99)$ & 0.009 & $0.99(0.98-0.99)$ & $<0.001$ & $0.99(0.98-0.99)$ & $<0.001$ \\
\hline BBS & $0.98(0.96-0.99)$ & 0.015 & $0.98(0.97-1.00)$ & 0.055 & $0.99(0.97-0.99)$ & 0.009 & $0.99(0.97-1.00)$ & 0.118 \\
\hline
\end{tabular}

ABC: Activities-specific Balance Confidence Scale; BBS: Berg Balance Scale.

${ }^{\mathrm{a}}$ Adjusted for age and gender.

(the fractured side, number of chronic diseases, maximal force of the fractured leg, and the use of walking aids outdoors. 
falls $[5,6]$ and falls with traumatic consequences often generate long-lasting fear of falling [8]. On the other hand, fear of falling leads to activity restriction and exercise avoidance, which in turn results in more severe functional limitations and disability. Few randomized controlled trials that have concentrated on methods of reducing fear of falling among hip fracture patients have yielded inconsistent results [24-26]. Thus, there is need for further research in order to develop better rehabilitation practices.

Additionally, our results indicate that also impaired functional balance was significantly associated with both ADL and IADL disability, and adjusting for several known confounders marginally changed the associations. Our findings are consistent with prior studies showing that functional balance is strongly associated with independence in daily activities after hip fracture $[27,28]$. Thus, our study together with prior studies indicate that hip fracture patients comprise a special group of older people who have impaired functional balance and a greater risk for increased physical disability.

As far as we know, this is the first study to show a strong association between decreased balance confidence and physical disability together with impaired functional balance and physical disability in this important clinical group of older people. In our study, balance confidence was strongly associated with functional balance explaining half of the variation in functional balance. However, including both of them simultaneously in the regression model did not materially change the individual IRR's. This suggests that the Activities-specific Balance Confidence Scale and Berg Balance Scale cannot be considered equivalent for each other. Thus, when new rehabilitation practices are developed for hip fracture patients, it should be taken into account that balance training by itself may not be successful without balance confidence management.

The strengths of the present study include firstly that we recruited a unique clinical group of community-dwelling older people who had sustained a hip fracture. The patient records of the Central Finland central hospital were used for this purpose. Secondly, we included a comprehensive battery of laboratory based physical and functional assessments as well as medical review for health and fracture status. By these assessments we were able to design a valid statistical model, with relevant and necessary confounders, to estimate the association between physical disability, balance, and balance confidence.

Some study limitations should be noted. The results of this study cannot be generalized to all hip fracture patients because the participants in the present study were all relatively healthy. They were all community-dwelling and those who were unable to walk independently outdoors or had severe diseases or cognitive independently outdoors or had severe diseases or cognitive problems were excluded. Thus, our results probably underestimate
the association between functional balance, balance confidence, the association between functional balance, balance confidence, and physical disability among older hip fracture patients. If we had been able to study also more frail patients, the association would have been even stronger. Additionally, because of the crosssectional study design, the causality between balance confidence, functional balance, and physical disability remains unclear. Therefore, it is possible that disability caused a sedentary lifestyle and was followed by low balance confidence and impaired functional balance. Either way, there is need for effective physical rehabilitation.

In conclusion, decreased balance confidence and impaired functional balance are important determinants of physical disability in older people who have sustained a hip fracture. Additionally, the $A B C$ scale complements the functional balance assessment and may potentially be used as a screening tool for impaired functional balance in clinical practice when instan assessment of functional balance is not possible. Furthermore, it is essential to examine what kind of interventions are effective in enhancing functional balance and especially balance confidence among older hip fracture patients. It is also important to study what kind of rehabilitation is effective to reduce physical disability and how older people can be encouraged to be physically active even in the presence of fear of falling, balance impairments, and increased physical disability. In the future, long-enough follow-up increased physical disability. In the future, long-enough follow-up
studies with adequate sample size are needed to assess the effects studies with adequate sample size are needed to assess the effects
of different kind of rehabilitation programs as well as the determinants of physical disability after hip fracture.

\section{Acknowledgements}

The Gerontology Research Center is a joint effort between the University of Jyväskylä and the University of Tampere. This study was supported by the Ministry of Education and Culture, National Insurance Institution, Juho Vaino Foundation, and Finnish Cultural Insurance Institution, Juho Vaino Foundation, and Finnish Cultural
Foundation. Study sponsors had no involvement in the study design, in the collection, analysis or interpretation of data, in the writing of the manuscript, or in the decision to submit the manuscript for publication.

\section{Conflict of interest statement}

None declared.

\section{References}

[1] Eastwood EA, Magaziner J, Wang J, Silberzweig SB, Hannan EL, Strauss E, et al. Patients with hip fracture: subgroups and their outcomes. Journal of the American Geriatrics Society 2002;50(7):1240-9.

[2] Magaziner J, Hawkes W, Hebel JR, Zimmerman SI, Fox KM, Dolan M, et al. Recovery from hip fracture in eight areas of function. Journals of Gerontolo Series A Biological Sciences and Medical Sciences 2000;55(9):M498-507.

[3] Nevalainen TH, Hiltunen LA, Jalovaara P. Functional ability after hip fracture among patients home-dwelling at the time of fracture. Central European

Lönnroos E Kautiainen $H$ Karppi $P$.

Increased incidence of hip fractures. A population ainen S, Kiviranta I, et al Bone 2006;39(3):623-7.

[5] Järvinen TL, Sievänen H, Khan KM, Heinonen A, Kannus P. Shifting the focus in fracture prevention from osteoporosis to falls. BMJ 2008;336(7636):124-6. 6] Karinkanta S, Piirtola M, Sievänen H, Uusi-Rasi K, Kannus P. Physical therapy approaches to reduce fall and fracture isk among

77] Sihvonen S, Kulmala J, Kallinen M, Alén M, Kiviranta I, Sipilä S. Postural balance history. Gerontology 2009;55(6):630-6.

[8] Li F, Fisher KJ, Harmer P, McAuley E, Wilson NL. Fear of falling in elderly persons: association with falls, functional ability, and quality of life. Journals of Gerontology Series B Psychological Sciences and Social Sciences 2003;58(5): P283-90.

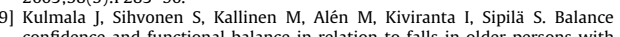
hip fracture history 10] Powell LE, Myers AM. The activities-specific balance confidence (ABC) scale. Journals of Gerontology Series A Biological Sciences and Medical Sciences 1995;50A(1):M28-34.

[11] Murphy SL, Williams CS, Gill TM. Characteristics associated with fear of falling and activity restriction in community-living older persons. Journal of the Amercer

avoidance of activities, falls and physical frailty. A, Cambier D. Fear-related based cohort study. Age and Ageing 2004;33(4):368-73.

[13] Deshpande N, Metter EJ, Lauretani F, Bandinelli S, Guralnik J, Ferrucci L. Activity restriction induced by fear of falling and objective and subjective measures of physical function: a prospective cohort study. Journal of the

[14] Sipilä S, Salpakoski A, Edgren J, Heinonen A, Kauppinen MA, Arkela-Kautiainen M, et al. Promoting mobility after hip fracture (ProMo): study protocol and
selected baseline results of a year-long randomized controlled trial among community-dwelling older people. BMC Musculoskeletal Disorders 2011;12(1):277.

15] Portegijs E, Kallinen M, Rantanen T, Heinonen A, Sihvonen S, Alén M, et al. Effects of resistance training on lower-extremity impairments in older people with hip fracture. Archives of Physical Medicine and Rehabilitation
2008:89(9):1667-74. 
[16] Folstein MF, Folstein SE, McHugh PR. "Mini-mental state". A practical method for grading the cognitive state of patients for the clinician. Journal of Psychiatric Research 1975;12(3):189-98.

[17] Haskell WL, Lee IM, Pate RR, Powell KE, Blair SN, Franklin BA, et al. Physica activity and public health: updated recommendation for adults from the American college of sports medicine and the American heart association. Medicine and Science in Sports and Exercise 2007;39(8):1423-34.

(a) katöiden katumistapaturmat; Opas kaatumisten ja murtumien ehkäisyyn. 2nd ed. Kansanterveyslaitoksen julkaisuja. B 29/2007: 2007. URL: wwwktlf/attachments/ suomi/julkaisut/julkaisusarja_b/2007/2007b29.pdf.

[19] Berg KO, Maki BE, Williams II, Holliday PJ. Wood-Dauphinee SL. Clinical and laboratory measures of postural balance in an elderly population. Archives of Physical Medicine and Rehabilitation 1992;73(11):1073-80.

[20] Laukkanen P, Karppi P, Heikkinen E, Kauppinen M. Coping with activities of daily living in diferent $C$.

21] Katz S, Akpon CA. 12. index of ADL. Medical Care 1976,14(5 Suppl.):116-8. instrumental activities of daily living Gerontologist 1969:9(3):179-86.
[23] Portegijs E, Rantanen T, Kallinen M, Heinonen A, Alén M, Kiviranta I, et al. Lower-limb pain, disease, and injury burden as determinants of muscle 2009;91(7):1720-8.

24] Crotty M, Whitehead CH, Gray S, Finucane PM. Early discharge and home thabilitation after hip fracture achieves functional improvements: a randonized controlled trial. Clinical Rehabilitation 2002;16(4):406-13.

作 geriatric patients after severe falls and hip surgery. Age and Ageing 31(1):49-57.

[26] Ziden L, Frandin K, Kreuter M. Home rehabilitation after hip fracture. A randomized controlled study on balance confidence, physical
function and everyday activities. Clinical Rehabilitation 2008;22(12) 1019-33.

27] Folden S, Tappen R. Factors influencing function and recovery following hip epair surgery. Or. Fopaedic Nursing $2007,26(4) .234-41$.

activity level after hip fracture in the elderly - a follow-up. Joung ability an itation Medicine 2003:35(2):76-83. 
PROMOTING MOBILITY AFTER HIP FRACTURE (PROMO): STUDY PROTOCOL AND SELECTED BASELINE RESULTS OF A YEAR-LONG RANDOMIZED CONTROLLED TRIAL AMONG COMMUNITY-DWELLING OLDER PEOPLE

\author{
by \\ Sarianna Sipilä, Anu Salpakoski*, Johanna Edgren*, Ari Heinonen, Markku \\ Kauppinen, Marja Arkela-Kautiainen, Maija Pesola, Sanna Sihvonen, Taina \\ Rantanen \& Mauri Kallinen *Equal contributors
}

BioMed Central Musculoskeletal Disorders 2011; 7(12):277. DOI: 10.1186/1471-2474-12-277.

Reproduced with kind permission by BioMed Central Ltd. 


\title{
Promoting mobility after hip fracture (ProMo): study protocol and selected baseline results of a year-long randomized controlled trial among community-dwelling older people
}

Sarianna Sipilä ${ }^{1 *}$, Anu Salpakoski ${ }^{1,2 \dagger}$, Johanna Edgren ${ }^{1,2 \dagger}$, Ari Heinonen², Markku A Kauppinen ${ }^{1}$ Marja Arkela-Kautiainen ${ }^{3}$, Sanna E Sihvonen ${ }^{4}$, Maija Pesola ${ }^{5}$, Taina Rantanen ${ }^{1,2}$ and Mauri Kallinen ${ }^{6}$

\begin{abstract}
Background: To cope at their homes, community-dwelling older people surviving a hip fracture need a sufficient amount of functional ability and mobility. There is a lack of evidence on the best practices supporting recovery after hip fracture. The purpose of this article is to describe the design, intervention and demographic baseline results of a study investigating the effects of a rehabilitation program aiming to restore mobility and functional capacity among community-dwelling participants after hip fracture.

Methods/Design: Population-based sample of over 60-year-old community-dwelling men and women operated for hip fracture ( $\mathrm{n}=81$, mean age 79 years, $78 \%$ were women) participated in this study and were randomly allocated into control (Standard Care) and ProMo intervention groups on average 10 weeks post fracture and 6 weeks after discharged to home. Standard Care included written home exercise program with 5-7 exercises for lower limbs. Of all participants, 12 got a referral to physiotherapy. After discharged to home, only $50 \%$ adhered to Standard Care. None of the participants were followed-up for Standard Care or mobility recovery. ProMointervention included Standard Care and a year-long program including evaluation/modification of environmental hazards, guidance for safe walking, pain management, progressive home exercise program and physical activity counseling. Measurements included a comprehensive battery of laboratory tests and self-report on mobility limitation, disability, physical functional capacity and health as well as assessments for the key prerequisites for mobility, disability and functional capacity. All assessments were performed blinded at the research laboratory. No significant differences were observed between intervention and control groups in any of the demographic variables.

Discussion: Ten weeks post hip fracture only half of the participants were compliant to Standard Care. No followup for Standard Care or mobility recovery occurred. There is a need for rehabilitation and follow-up for mobility recovery after hip fracture. However, the effectiveness of the ProMo program can only be assessed at the end of the study.

Trial registration: Current Controlled Trials ISRCTN53680197
\end{abstract}

\section{* Correspondence: sarianna sipila@ijufi}

† Contributed equally

${ }^{1}$ Gerontology Research Centre, University of Jyväskylä, Jyväskylä, Finland

Full list of author information is available at the end of the article

(O) Biomed Central

2011 Sipilä et al; licensee BioMed Central Ltd. This is an Open Access article distributed under the terms of the Creative Commons Attribution License (http://creativecommons.org/licenses/by/2.0), which permits unrestricted use, distribution, and reproduction in 


\section{Background}

Fall-related injuries leading to hospitalization and activity restriction result in adverse health outcomes, mobility limitation and disability which may last years or become permanent [1-3]. For older people, hip fractures are among the most severe consequences of falls [4,5]. Hip fractures cause considerable health care costs during the first post fracture year [6-8]. The cost burden will double or even triple with the subsequent fall and fracture particularly if a home-dwelling person is admitted to permanent institutional care because of the fracture $[8,9]$

Community-dwelling older persons who survive a fracture need special attention. To cope at their homes safely sufficient mobility and functional ability is needed. Only $40 \%$ of hip fracture survivors recover to their pre-fracture ambulatory level and only $20 \%$ recover to the pre-fracture level in advanced mobility tasks $[3,10]$. Safe mobility and participation are challenged by persistent pain [11,12], fear of falling and balance impairments $[13,14]$, lower limb muscle weakness [11], reduced bone mass and impaired bone geometry [15]. Consequently, older communitydwelling people recovering from a hip fracture are at an increased risk for a new fracture, persistent mobility lim itation and disability as well as loss of independence in the near future.

Currently there is insufficient evidence on the best practices supporting recovery after hip fracture [16]. The current research knowledge is mostly based on efficacy driven research in which the effects of highly specified short-term interventions without follow-up have been investigated among a homogenous group of hip fracture participants. These studies have been performed under optimal conditions with specifically designed and arranged training protocols and facilities. Previous efficacy studies have shown that rehabilitation programs including intensive and supervised training sessions with resistance and balance training improve mobility [17-20], physical functioning [18-21] and level of physical activity [22] among older community living persons who have suffered a hip fracture. However, the effects on mobility disability remain unclear.

A rehabilitation program that produces significant effects in an efficacy study may not have same effects under real-world conditions [23]. Moreover, persons who are likely to benefit the most from a program including physical activity are usually excluded from these studies. Travelling to organized and supervised sessions on a weekly basis in a gym with the necessary set-up may be too demanding for many fracture patients $[19,24]$. Therefore, rehabilitation programs aiming to restore mobility after hip fracture need to be implemented and studied in the real-world conditions or close to that. Moreover, participants should not be excluded unless there is an empirical or ethical reason to do so (e.g. possibility for negative side effect of training or main outcomes are impossible to measure) [25]. Home-based individually tailored rehabilitation programs including weight-bearing exercises [26,27], exercises with progressive resistance [28] and a systematic follow-up and support [22] may form the most promising approach to increase the effectiveness of the rehabilitation to prevent mobility disability after hip fracture.

The Promoting Mobility after Hip Fracture (ProMo) study investigates the effects of a year-long individually tailored and home-based rehabilitation program compared to the Standard Care on mobility recovery, physical functional capacity and disability among over 60-year-old community-dwelling men and women who suffered a proximal femoral fracture. The purpose of this article is to describe the recruitment process, design and intervention as well as to present demographic baseline results of this randomized controlled trial.

\section{Methods/Design}

\section{Context}

All Finnish residents have health insurance. In Finland, municipalities are responsible for organizing specialized and primary health care for all people. For example, in Central Finland specialized care is provided by the Central Finland Central Hospital for 23 municipalities with a total population of 273700 . Each municipality organizes primary health care including inpatient rehabilitation, ward care and outpatient clinic for their residents at the local health care centers. After a proximal femoral fracture, patients living in Central Finland are operated at the Central Finland Central Hospital and transferred to the local health care centre of their municipality for inpatient care and rehabilitation typically within the first post-operative days. The inpatient rehabilitation period ranges from one week to few months depending on the health status and care needs.

\section{Design}

This study is a randomized controlled trial (RCT, ISRCTN53680197). Random allocation to the interven tion (ProMo) and control (Standard Care) groups were performed after baseline measurements by the statistician, who was blinded to the study participants and their characteristics. The study group assignments were enclosed in sealed envelopes. Men and women and those operated with internal fixation or arthroplasty were randomized by blocks.

All participants were measured at the laboratory four times; at baseline, three, six and 12 months. After that all participants were followed-up for an additional year to collect data on form of dwelling, mobility limitation, physical functional capacity, mood and quality of life 
with a structured questionnaire. Study design is described in detail in Figure 1.

Pretrial power calculations were based on previously published longitudinal data on mobility recovery after hip fracture. In the study by Visser et al, $45.3 \%$ of the community-dwelling participants were independent in more demanding mobility tasks (chair rising, walking one block and negotiating stairs) before the fracture [10]. Twelve months after hip fracture less than half of them $(20.7 \%$ of the total sample) had regained their pre-fracture level of mobility. The purpose of our study was to restore the prefracture level of mobility by the ProMo rehabilitation program. To detect the expected difference (based on percentages 45.3 and 20.7 from the study by Visser et al) between the study groups in mobility recovery at $\alpha=0.05$ and $\beta=0.20$, a minimum of 44 subjects was needed in each study group. Sample size was calculated using an online sample size calculator available from (DSS researcher's toolkit, http://www.dssresearch.com/KnowledgeCenter/toolkitcalculators/samplesizecalculators.aspx)

\section{Participants and recruitment}

Staff of the physiotherapy department of the Centra Finland Central Hospital reviewed the medical records of all consecutive, over 60-year-old, ambulatory and community-dwelling men and women operated for femoral neck or pertrochanteric fracture (ICD code S72.0 or S72.1, http://www.cdc.gov/nchs/icd.htm) between 1.3.2008 and 31.12.2010 and living in the city of Jyväskylä or in nine neighboring municipalities. All patients fulfilling the inclusion criteria got an information letter on the study ( $\mathrm{n}=296)$. Of them, 161 patient expressed their initial interest in the study and were further visited by the ProMo representative during the inpatient period at the health care centre. Finally, 136 persons were recruited to the study. Patients living in an institution or confined to bed at the time of the fracture suffering from severe memory problems (Mini Mental State Examination, MMSE < 18), alcoholism, severe cardiovascular, pulmonary or progressive (i.e neoplasm, ALS) disease, para-or tetraplegic or severe depression (Beck Depression Inventory BDI-II > 29) were excluded from the study. In total, 18 men and 63 women participated in the study. The flow chart of the study is shown in Figure 2.

\section{Ethical issues}

This project was approved by the Ethics Committee of the Central Finland Health Care District on December 18, 2007 (11/2007). Written information on the study was given to all participants. Participants signed an informed consent prior to participation. Proxy consent was not permitted. Those who were interested in the study had an opportunity to discuss with the researcher before signing the informed consent and giving a permission to review their medical records.

\section{Measurements}

Measurements and analysis will be performed blinded to the study group. Baseline measurements were organized as soon as possible after discharged to home; on average 70 (SD28) days after the hip fracture, 65 (21) days after the hip fracture operation and 42 (23, range 4-153) days after discharge to home. Measurements included a comprehensive battery of laboratory tests and self-report on mobility limitation, disability, physical functional capacity and health, as well as assessments for the key prerequisites of mobility, disability and functional capacity. All assessments were performed at the research laboratory.

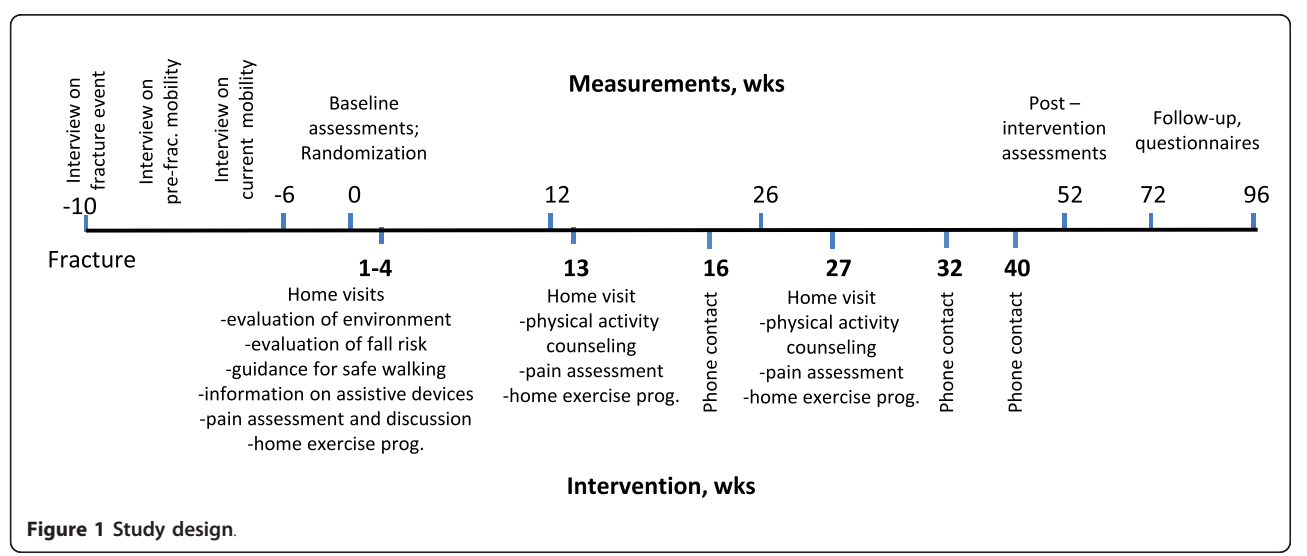




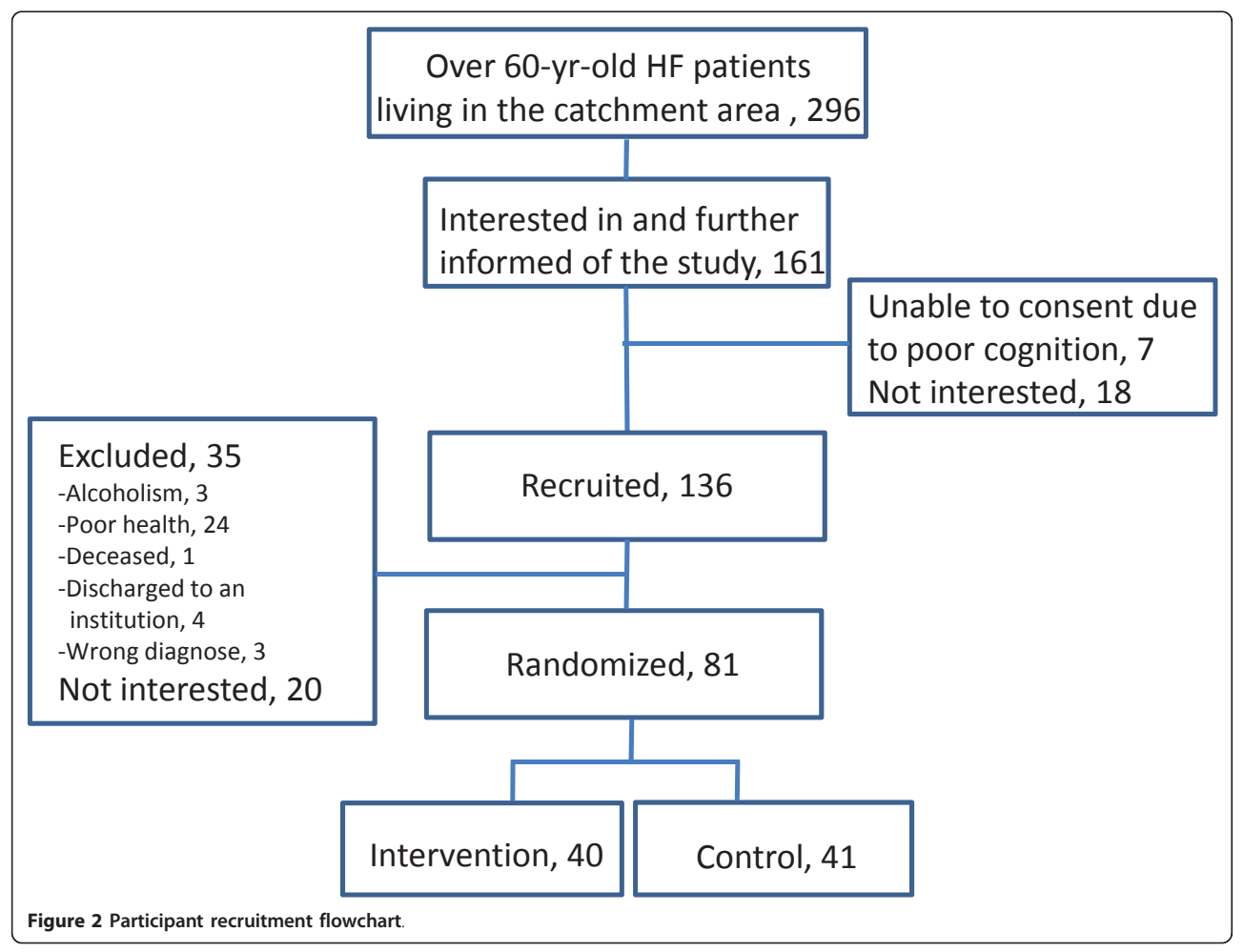

Review of medical data and health status

Each participant was interviewed within 24 hours of the hip fracture with structured questions on the characteris tics of the accident [29]. At baseline, during a medical examination performed by a nurse practitioner and a physician, the presence of chronic conditions, use of prescription medication, fracture status and date, type and date of surgery and lowest post-operation hemoglobin level during hospitalization were confirmed according to a pre-structured questionnaire, current prescriptions and medical records obtained from the local hospital and health care centers. To ascertain safe participation in the measurements and intervention, the physician evaluated contraindications according to ACSM guidelines [30] and acute conditions such as infections (e.g. acute respiratory or urinary tract infection) by blood count, C-reactive protein (hCRP) and hemoglobin $(\mathrm{Hb})$ analysis. Cognitive status was assessed by Mini Mental State Examination (MMSE) [31], and depressive mood by Beck Depression Inventory (BDI-II) [32] at baseline. Self-rated health was determined by the question "How would you describe your health?" using a 4-point scale (very good, good, poor and very poor). Offending musculoskeletal pain in the low back, hip, knee, ankle and foot was assessed by a questionnaire. The question for the musculoskeletal pain was "Have you suffered from pain in the low back, hip, knee, ankle and foot region daily during the preceding month? Has the pain compromised your mobility?" Three alternative response options were: 1) no 2 ) yes, but the pain does not limit mobility 3) yes, the pain limits mobility.

Demographics, physical characteristics and living habits

Demographics included age, sex, living conditions, income and education. Body height and weight were measured using standard procedures and body mass index was calculated (body weight, $\mathrm{kg} /$ body height, $\mathrm{m}^{2 * 100)}$ ). Body composition was assessed with Bioimpedance devise with eight polar electrodes (BC-418, TANITA, Tokyo, Japan). Maximal hand grip strength was measured from the dominant hand with a dynamometer (Metitur Ltd, Palokka, Finland) and bone density and geometry with a peripheral computed tomography [15]. Current level of physical activity 
was assessed by a standardized question with slight modifications [33]. The question included seven alternative responses: 1 ) mainly resting 2 ) most activities performed sitting down 3) light physical activity twice a week at the most 4) moderate physical activity about $3 \mathrm{~h}$ a week 5 ) moderate physical activity at least $4 \mathrm{~h}$ a week or heavy physical activity $\leq 4$ h a week 6 ) physical exercise or heavy leisure time activity several times a week and 7) competitive sports several times a week. No one reported participation in competitive sports. Responses were categorized as sedentary ( 1 to 3 ) and active (4 to 6 ). Smoking status was assessed with a questionnaire (never, former, current smoker).

Main outcomes

The short term primary outcome (at 3 and $6 \mathrm{mo}$ ) is Short Physical Performance Battery (SPPB) including $2.44 \mathrm{~m}$ habitual walking speed, five chair rises timed and standing balance tests [34]. One year primary outcome will be mobility limitation assessed by interviewing the subjects for the ability to getting in and out of bed, rising from a chair, walking across a room, walking one block, and climbing stairs [10]. In addition, self-reports of perceived difficulty in walking outdoors, walking $500 \mathrm{~m}$, walking $2 \mathrm{~km}$ and climbing one flight of stairs will be assessed by questionnaire. Secondary outcomes include physical disability (validated questionnaire) [35], health related quality of life (RAND-36), walking speed over 10 meters [36], isometric knee extension strength for both legs [36] (Metitur Ltd, Palokka, Finland), leg extension power with the Power Rig for both legs [11], functional balance (Berg Balance Scale) [37] and fear of falling (Activities-specific Balance Confidence scale) [38]. Information concerning use of formal and informal care and form of dwelling will be collected by a questionnaire.

\section{Quality assurance}

Our research centre has a long tradition and established methods on mobility and functional capacity assessments among older populations. A standard operation procedure was written before launching the study and then followed up carefully throughout the study. A system with periodical meetings and checks was set up for monitoring the quality of data collection. The personnel performing the measurements were carefully educated by a senior researcher. The same staff engaged in the data collection throughout the study except for the nurse practitioner who was replaced twice during the study. During the laboratory visits, all questionnaires were reviewed by the study coordinator. In case of missing information participants were asked to complete the questionnaire. If the participant was unable to come to the laboratory measurements at some point, self-reports were collected and Short Physical Performance Battery was performed at participants home.

\section{Control condition; Standard care}

At baseline, information on standard care after the hip frac ture was collected by interviewing all participants with structured questions on advice and recommendations concerning rehabilitation they had received at discharge from hospital and/or health care centre. Seventy percent of all participants obtained a written home exercise program with no difference between the intervention and the control groups ( $68 \%$ vs. $71 \%, p=0.813$ ). From those who received a home exercise program, $70 \%$ exercised every day, $21 \%$ on weekly basis and $9 \%$ few times a month or not at all. Typically the program included five to seven exercises including ankle flexion and extension, knee flexion and extension, and hip abduction and extension in supine, sitting and/or standing positions with no additional resistance. None of the participants were followed up for the home exercises and the program was not updated. Of all participants 12 received a referral to physiotherapy ( 5 in the intervention and 7 in the control group) while the rest did not get any further instructions regarding rehabilitation.

\section{ProMo -Intervention}

Intervention includes standard care and ProMo-program which aims to restore mobility after hip fracture. The intervention starts after baseline measurements (Figure 1). ProMo is an individually tailored year-long physical activity and rehabilitation intervention taking place at participants' homes. It includes five to seven home visits by an experienced physiotherapist; the first three visits will be performed within one month followed by a visit three and six months after baseline measurements. If necessary, an additional visit two months after baseline will be performed. The scientific basis for the ProMo arises from a previous systematic review on fall and fracture prevention [39] and interventions that successfully prevented functional decline $[26,40]$ among community-dwelling high risk groups of older people. ProMo comprises two partly overlapping phases. Phase I prepares the basis for the physical rehabilitation and physical activity. The content of Phase I is as follows: 1) Evaluation and modification of environmental hazards known to increase falls risk [41] 2) Guidance for safe walking including readjustment of walking aids and information on shoes and anti-slip shoe devices for icy conditions. In addition, written information on assistive devices and a brochure on hip protectors will be provided. All above mentioned information and brochures have been published before and are available for laypersons as well as for health care professionals 3) Pain assessment and discussions on pain relief strategies that the participants have perceived effective. Regular pain assessment and information on pain management are independently associated with better pain relief in hospitalized patients [42]. Pain assessments will be repeated three and six months after baseline measurements. 
Phase II includes a progressive home exercise program and physical activity counseling. The exercise program comprises strengthening exercises for the lower limbs, balance training in standing position, walking exercises and stretching. The program will be delivered during the second home visit and it will be updated to a more challenging one during each following home visit. Accordingly, during the ProMo -intervention five written, progressive and individually tailored home exercise programs of approximately 30 minutes duration and designed by the PhysioTools software (PhysioTools, Tampere, Finland) will be delivered. Strengthening and stretching exercises will be performed three times week and balance and walking exercises on two to three other days in the week. During the intervention, the resistance for the strengthening exercises will be individually increased with resistance bands with three different strengths.

An individual motivational face-to-face physical activity counseling session $[43,44]$ will be scheduled approximately three months after the baseline measurements. The average duration of this session is 30 minutes. The topics covered during the counseling session include the level of physical activity and participation in physical exercise before the fracture, the persons' interest in returning to previous activities, beginning physical activity or exercise, the willingness to be active in everyday chores, to exercise on one's own or to participate in supervised exercise classes. The problem-solving method will be used to address perceived obstacles to physical activity and to access exercise facilities offered by the municipality. Preexisting written information on the supervised physical activity classes and exercise facilities offered by the municipality will be given. Based on this information, the participant and the physiotherapist together design a personal physical activity plan, which will be signed during the session. After the first face-to-face counseling session, the physiotherapist will support compliance to the program and the behavior change through three phone contacts and one face-to-face session with 1-2 months interval. All participants in the intervention group will keep a physical activity diary on home exercises and physical activities.

\section{Data analysis}

Means, standard deviations and frequencies for the demographic variables were calculated. Normality of the distributions was tested with Shapiro-Wilkinson test. The significance of differences between the intervention and control group was tested by cross-tabulation and chisquare tests in the case of discrete variables, by Student's $\mathrm{t}$-test for independent samples for normally distributed data and by Mann-Whitney U-test for non-normally distributed continuous data. Association between variables was analyzed using Pearson correlation coefficient.
Determinants for mobility limitation and physical disability will be assessed by linear and logistic regression analysis and the theoretical pathway to mobility limitation and physical disability by structural equation modeling. The effects of ProMo will be assessed by intention-to-treat principal using repeated measures ANOVA, covariance analysis and linear mixed models for continuous variables and by general estimation equation for categorical variables.

\section{Characteristics of the participants}

Table 1 summarizes the demographics, physical characteristics, health, living habits, fracture status and the type of operation in the total sample and in the intervention and control groups. No significant differences were observed in any variable between the study groups.

The mean age of the participants was $79(\mathrm{SD} \pm 7)$ years and $78 \%$ of the participants were women. More than half of the subjects were living alone. Poor self-rated health was reported by $41 \%$ of the total sample. The average number of chronic diseases was $3 \pm 2$. The mean MMSE value was $26 \pm 3$ and that of the BDI-II $9 \pm 6$. Offending pain in lower back, hip or knee region on the fractured side was reported by $46 \%$ of the participants. The corresponding value for the non-fractured side was $37 \%$. Nine percent of the participants were current smokers and 92\% were rated sedentary.

The majority of the participants $(\mathrm{n}=71 / 81)$ fell from standing height. Six were able to break the fall e.g. with an outstretched arm. More than half $(\mathrm{n}=43)$ fell indoors and from those 34 participants fell at home. Fifty two participants suffered a femoral neck and 29 a pertrochanteric fracture. Fracture was operated with internal fixation in 38 and with arthroplasty in 43 participant.

\section{Discussion}

The baseline results of our randomized controlled trial emphasize that there is an urgent need to develop longterm rehabilitation strategies for mobility recovery and prevention of mobility disability after hip fracture. According to the patients' own report, only half of them received a home exercise program and followed up the instructions given by the health care personnel on a daily basis. Home exercise programs were not updated and programs did not include any external resistance, walking or balance exercises. Less than $15 \%$ of the participants were referred to physiotherapy, while the rest did not get any further instructions or follow-up for recovery of mobility and functional capacity.

Previous studies have shown poor mobility recovery after hip fracture and some of the studies suggest that this phenomenon may turn out to be permanent $[1,10,45]$ Poor lower limb muscle strength, postural balance and hip pain are associated with poor mobility recovery after hip 
Table 1 Demographics, health and hip fracture status among over 60-year-old men and women after a recent hip fracture (Mean \pm SD, frequency)

\begin{tabular}{|c|c|c|c|c|}
\hline & $\begin{array}{c}\text { All } \\
(\mathrm{n}=76-81)\end{array}$ & $\begin{array}{c}\text { ProMo } \\
(\mathrm{n}=38-40)\end{array}$ & $\begin{array}{c}\text { Control } \\
(\mathrm{n}=38-41)\end{array}$ & $\mathrm{p}^{*}$ \\
\hline$\overline{A g e}, y r$ & $79 \pm 7$ & $80 \pm 8$ & $79 \pm 6$ & 0.251 \\
\hline Body height, $\mathrm{cm}$ & $160.6 \pm 8.9$ & $160.9 \pm 8.9$ & $160.3 \pm 9.1$ & 0.785 \\
\hline Body weight, $\mathrm{kg}$ & $65.8 \pm 11.5$ & $65.8 \pm 11.9$ & $65.9 \pm 11.3$ & 0.968 \\
\hline BMI & $25.5 \pm 3.8$ & $25.3 \pm 3.6$ & $25.6 \pm 3.9$ & 0.710 \\
\hline Poor self-rated health, \% & 41 & 43 & 39 & 0.823 \\
\hline Number of chronic diseases, $\mathrm{n}$ & $3 \pm 2$ & $3 \pm 2$ & $3 \pm 2$ & 0.581 \\
\hline MMSE & $26 \pm 3$ & $26 \pm 3$ & $26 \pm 3$ & 0.686 \\
\hline BDI-II & $9 \pm 6$ & $9 \pm 6$ & $8 \pm 6$ & 0.335\# \\
\hline hCRP at baseline & $7.7 \pm 9.9$ & $8.4 \pm 11.1$ & $7.1 \pm 8.6$ & 0.855\# \\
\hline $\mathrm{Hb}$ at baseline, $\mathrm{g} / \mathrm{l}$ & $128.7 \pm 12.9$ & $127.4 \pm 12.7$ & $130.1 \pm 13.1$ & 0.351 \\
\hline Lowest $\mathrm{Hb}$ after operation, g/l & $98.0 \pm 13.2$ & $97.5 \pm 11.1$ & $98.5 \pm 15.0$ & 0.795\# \\
\hline Smoking, \% & & & & 0.382 \\
\hline - Never & 79 & 85 & 73 & \\
\hline - Former & 12 & 10 & 15 & \\
\hline - Current & 9 & 5 & 12 & \\
\hline Living alone, \% & 59 & 60 & 59 & 1.000 \\
\hline Level of education Elementary school or less, $\%$ & 49 & 54 & 44 & 0.502 \\
\hline Income, $€ /$ month & $1363 \pm 828$ & $1321 \pm 637$ & $1408 \pm 998$ & $0.965 \#$ \\
\hline Physical activity, \% Sedentary & 92 & 95 & 90 & 0.675 \\
\hline \multicolumn{5}{|l|}{ Fracture status } \\
\hline Fall related fracture, \% & 88 & 90 & 85 & 0.737 \\
\hline Site of fracture, \% & & & & 0.645 \\
\hline - Femoral neck & 64 & 68 & 61 & \\
\hline - Pertrochanteric & 36 & 32 & 39 & \\
\hline Type of operation, n & & & & 0.719 \\
\hline - Internal fixation & 38 & 19 & 19 & \\
\hline - Hemiarthroplasty & 33 & 15 & 18 & \\
\hline - Total arthroplasty & 10 & 6 & 4 & \\
\hline
\end{tabular}

*Independent t-test for normally distributed continuous variables, Chi-square for discrete variables

\#Mann-Whitney U for non-normally distributed continuous variables

fracture $[10,45]$. Muscle strength deficit on the fractured side is associated with greater pain on the fractured compared to the non-fractured side [11] and large muscle strength deficit is associated with mobility limitation and balance impairment [46]. Some recovery is expected to occur during the first six months after hip fracture. However, our earlier study showed that community-dwelling older men and women who had suffered a hip fracture on average four years earlier were significantly weaker, had a significant side-to-side difference in lower limb muscle strength $[11,15]$ and had significantly impaired postural balance and balance confidence [14] compared to the age and sex matched controls with no major lower limb injuries. The presence of multiple impairments, pain and poor balance confidence (fear of falling) strongly suggest increased and cumulative risk for loss of mobility in the near future if targeted rehabilitation with follow-up for mobility recovery is not available.
The standard care, in this study, did not include the follow-up for mobility recovery. It included home exercise programs with five to seven exercises mostly for the fractured limb. Programs were not updated to a more challenging one and no additional resistance was used. None of the participants were followed-up for the home exercise program. Variation in the rehabilitation activities and lack of guidelines for mobility limitation and disability prevention after hip fracture has been recognized worldwide $[47,48]$. It has been suggested that better functional outcomes could be achieved with more intensive rehabilitation and promotion of physical activity after hip fracture $[47,48]$.

The aim of the ProMo -intervention is to restore mobility after hip fracture and it was firmly grounded to existing research literature. As we wanted to include all hip fracture patients who could potentially benefit from the rehabilitation, also the weakest and the oldest ones, the 
program was designed to take place at the participants home. The ProMo is a 1-year progressive physical exercise and physical activity counseling program reinforced by advise, support and encouragement for safe walking as well as discussions on fall prevention and pain management strategies. Pain assessment and fear of falling management was regarded as an essential part of the program as older people who had had a hip fracture suffer from residual pain [12,49] and fear of falling [14]. Both pain $[12,50,51]$ and fear of falling [52-54] have been indepen dently associated with mobility limitation, activity restriction, low physical functioning and falls among older populations. To our knowledge and based on a recently updated Cochrane review [16] there is no previously published effectiveness RCT among community-dwelling hip fracture participants including a home-based intervention specifically targeting on mobility recovery and which has mobility limitation and disability as the main outcome. Encouraging evidence on effects of interventions with similar components on the level of physical activity [22] functional capacity [26] and health related quality of life [55] have, however, been reported.

The recruitment process of this study included eligibility screening in multiple phases and there was close collaboration with clinicians at the local hospital and health care centers. In total, 296 patients who fulfilled the inclusion criteria were identified and informed about the study at the hospital. From those approximately half $(n=161)$ were interested in and further informed about the study. From those who expressed initial interest $84 \%(n=136)$ signed informed consent and were enrolled in the study. This was regarded as a sufficient number of participants, allowing a $35 \%$ attrition rate, ending with 44 in each study group. Because our participants were recruited at the clinic (health care centre) prior to discharge to home, we set our safety margin in the attrition rate higher than $20 \%$ which was recommended by Ferrucci et al in their consensus report [56]. We expected some changes in health status, living conditions and willingness to participate to occur already before the baseline measurements. Accordingly, 26\% were further excluded due to poor health, alcoholism and living conditions and 15\% declined participation mostly due to poor self-rated health and tiredness (Figure 1). Finally, 81 men and women were assessed at baseline and randomly assigned into ProMo -intervention and control groups. Despite of careful planning of the study and target of the recruitment period from 24 to 33 months, we did not completely reach the estimated number needed for this study. However, as the intervention is home-based and individually targeted and the main outcomes can be assessed at the participants' home, we trust that the additional drop-out will be small. The demographics of our study participants is comparable to earlier studies involving community dwelling older people recovering from hip fracture; the majority of them are women and the mean age is close to 80 [57]

In conclusion, this report summarized the rationale, procedures and intervention of a 1-year RCT with 1-year follow-up on the effectiveness of home-based rehabilitation program aiming to restore mobility after hip fracture among community-dwelling over 60-year-old men and women. The special feature of the current study is that we reinforce the home exercise program by advice, support and encouragement for safe walking and discussions on fall prevention and pain management strategies. In addition, promotion of using existing exercise and rehabilitation services available for older people in their own community was performed by physical activity counseling. These facilities will be available for the participants also after finishing the project. This intervention study will provide knowledge of the rehabilitation for mobility recovery among community-living older people after hip fracture. However, the effectiveness of the program can only be assessed after the end of the study.

Abbreviations

BDI-I. Beck Depression Inventory; BMI: Body Mass Index; Hb: Hemoglobin hCRP: C-reactive protein; MMSE: Mini Mental State Examination.

\section{Acknowledgements}

We are very thankful to the participants of this study. We would like to thank physiotherapists at the Central Finland Health Care District for the indispensable work for this project. Without your commitment to the recruitment of the participants this study would never have succeeded. We also thank those persons who assisted in data collection; Ms. Veera Farin, Mrs. Suoma Korhonen, Mrs. Hanna-Maija Lapinkero, Mrs. Katri Lihavainen, Mrs. Mervi Matero, Mrs. Tuovi Nykänen, Ms. Jenni Rouhiainen, Ms. Emma Takkinen, Mrs. Leena Tulla. We are thankful to the physicians Jukka Vanhatalo and Pirkko Jäntti for medical screening and professor Urho Kujala and physician Markku Rantalainen for the medical surveillance during the measurements

Funding: This study was supported by The Ministry of Education and Culture, Kela-The Social Insurance Institution of Finland and Juho Vainio Foundation

\section{Author details}

${ }^{1}$ Gerontology Research Centre, University of Jyväskylä, Jyväskylä, Finland. ${ }^{2}$ Department of Health Sciences, University of Jyväskylä, Jyväskylä, Findand. Deparment of Fin ${ }^{4}$ AMK . Finland. JAMK University of Applied Sciences, Jyväskylä, Finland.

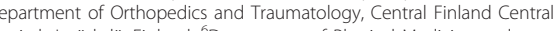
Hespit, Jyisky, Fint

\section{Authors' contributions}

SS developed the idea of conducting the study, recruited the participants, collected and analyzed the data, interpreted the results and wrote the paper. AS recruited the participants, collected the data and wrote the pape $\mathrm{JE}$ collected the data and wrote the paper. AH conceived the idea of the study, interpreted the results and wrote the paper. MAK analyzed the data and wrote the paper. MA-K conceived the idea of the study, recruited the participants, interpreted the results and wrote the paper. SES collected the data, interpreted the results and wrote the paper. MP conceived the idea of the study, recruited the participants, interpreted the results and wrote the paper. TR conceived the idea of the study, interpreted the results and wrote the paper. MK conceived the idea of the study, recruited the participants, collected data, interpreted the results and wrote the paper. All authors read and approved the final manuscript. 
Competing interests

The authors declare that they have no competing interests.

Received: 4 November 2011 Accepted: 7 December 2011 Published: 7 December 2011

References

Fredman L, Magaziner J, Hawkes W, Hebel JR, Fried LP, Kasper J, Guralnik J. Female hip fracture patients had poorer performance-based functioning than community-dwelling peers over 2-year follow-up period. I Clin Epidemiol 2005, 58:1289-98

2. Gill TM, Allore $H G$, Gahbauer EA, Murphy TE: Change in disability after hospitalization or restricted activity in older persons. JAMA 2010 304:1919-28.

3. Magaziner J, Hawkes W, Hebel JR, Zimmerman SI, Fox KM, Dolan M, Felsenthal $G$, Kenzora J: Recovery from hip fracture in eight areas of function. J Gerontol A Biol Sci Med Sci 2000, 55:M498-507.

4. Bentler SE, Liu L, Obrizan M, Cook EA, Wright KB, Geweke JF, Chrischilles EA, Pavlik CE, Wal, Pant $C E$, Wall The aftermath of hip fracture discharge placement, fun, Whio change, and mortality. Am J Epidemio/ 2009, 170:1290-9.

5. Stewart NA, Chantrey J, Blankley SJ, Boulton C, Moran CG: Predictors of 5 year survival following hip fracture. Injury 2011, 42:1253-6.

6. Becker DJ, Yun H, Kilgore ML, Curtis JR, Delzell E, Gary LC, Saag KG, Morrisey MA: Health services utilization after fractures: evidence from Medicare. J Gerontol A Biol Sci Med Sci 2010, 65:1012-20.

7. Haentjens P, Autier P, Barette M, Boonen S: Belgian Hip Fracture Study Group. The economic cost of hip fractures among elderly women. $A$ one-year, prospective, observational cohort study with matched-pair analysis. In J Bone Joint Surg Am. Volume 83-A. Belgian Hip Fracture Study Group; 2001:493-500

8. Nurmi I, Narinen A, Lüthje P, Tanninen S: Cost analysis of hip fracture treatment among the elderly for the public health services: a 1-year prospective study in 106 consecutive patients. Arch Orthop Trauma Surg 2003, 123:551-4

9. Song X, Shi N, Badamgarav E, Kallich J, Varker H, Lenhart G, Curtis JR: Cost burden of second fracture in the US health system. Bone 2011, 48:828-36.

10. Visser M, Harris TB, Fox KM, Hawkes W, Hebel JR, Yahiro JY, Michael R,

Zimmerman SI, Magaziner J: Change in muscle mass and muscle strength after a hip fracture: relationship to mobility recovery. $\rfloor$ Gerontol A Biol $S$ Med Sci 2000, 55:M434-40.

11. Portegijs E, Rantanen T, Kallinen M. Heinonen A. Alen M, Kiviranta I, Sipilä S. Lower-limb pain, disease, and injury burden as determinants of muscle strength deficit after hip fracture. J Bone Joint Surg Am 2009, 91:1720-8.

12. Salpakoski A, Portegijs E, Kallinen M, Sihvonen S, Kiviranta I, Alen M, Rantanen T, Sipilä S: Physical inactivity and pain in older men and women with hip fracture history. Gerontology 2011, 57:19-27.

13. Oude Voshaar RC, Banerjee S, Horan M, Baldwin R, Pendleton N, Proctor R, Tarrier N, Woodward Y, Burns A: Fear of falling more important than pain and depression for functional recovery after surgery for hip fracture in older people. Psychol Med 2006, 36:1635-45.

14. Sihvonen S, Kulmala J, Kallinen M, Alén M, Kiviranta I, Sipilä S: Postural balance and self-reported balance confidence in older adults with a hip fracture history. Gerontology 2009, 55:630-636.

15. Mikkola T, Sipilä S, Portegijs E, Kallinen M, Alén M, Kiviranta I, Pekkonen M, Heinonen A: Impaired geometric properties of tibia in older women with hip fracture history. Osteoporos Int 2007, 18:1083-90.

16. Handoll HH, Sherrington C, Mak JC: Interventions for improving mobility after hip fracture surgery in adults. Cochrane Database Syst Rev 2011, 16 CD001704

17. Mitchell SL, Stott DJ, Martin BJ, Grant SJ: Randomized controlled trial of quadriceps training after proximal femoral fracture. Clin Rehabil 2001, 15:282-90

18. Binder EF, Brown $M$, Sinacore DR, Steger-May K, Yarasheski KE, Schechtman KB: Effects of extended outpatient rehabilitation after hip fracture: a randomized controlled trial. JAMA 2004, 292:837-46.

19. Practure: a randomized controlled trial. JAMA 2004, 292:837-46. Kiviranta I, Sipilä S: Effects of resistance training on lower-extremity impairments in older people with hip fracture. Arch Phys Med Rehabil 2008, 89:1667-74
20. Sylliaas $H$, Brovold $T$, Wyller TB, Bergland A: Progressive strength training in older patients after hip fracture: a randomised controlled trial. Age Ageing 2011, 40:221-7.

21. Edgren J, Rantanen T, Ari Heinonen A, Erija Portegiis E, Markku Alén M, Kiviranta I, Kallinen M, Sipilä S: Effects of progressive resistance training on physical disability among older community-dwelling people with hip fracture history. Aging Clin Exp Res

22. Resnick B, Orwig D. Yu-Yahiro J. Hawkes W, Shardell M Hebel JR Zimmerman S, Golden J, Werner M, Magaziner J: Testing the effectivenes of the exercise plus program in older women post-hip fracture. Ann Behav Med 2007, 34:67-76.

23. Flay BR, Biglan A, Boruch RF, Castro FG, Gottfredson D, Kellam $S$, Mościcki EK, Schinke S, Valentine JC, Ji P: Standards of evidence: criteri for efficacy, effectiveness and dissemination. Prev Sci 2005, 6:151-75.

24. Chang BH, Hendricks AM, Slawsky MT, Locastro JS: Patient recruitment to randomized clinical trial of behavioral therapy for chronic heart failure. BMC Med Res Methodol 2004, 4:8.

25. Kraemer HC: Pitfalls of multisite randomized clinical trials of efficacy and effectiveness. Schizophr Bull 2000, 26:533-41.

26. Gill TM, Baker DI, Gottschalk M, Peduzzi PN, Allore H, Byers A: A program to prevent functional decline in physically frail, elderly persons who live at home. N Engl J Med 2002, 347:1068-74.

27. Sherrington C, Lord SR, Herbert RD: A randomized controlled trial of weight-bearing versus non-weight-bearing exercise for improving physical ability after usual care for hip fracture. Arch Phys Med Rehabil 2004, 85:710-6.

28. Mangione KK, Craik RL, Palombaro KM, Tomlinson SS, Hofmann MT: Home based leg-strengthening exercise improves function 1 year after hip based leg-strengthening exercise improves function 1 year after hip Parkkari J, Kannus P, Palvanen M, Natri A, Vainio J, Aho H, Vuori I,

Jävinen M: Majority of hip fractures occur as a result of a fall and ärvinen M: Majority of hip fractures occur as a result of a fall and
impact on the greater trochanter of the femur: a prospective controlled impact on the greater trochanter of the femur: a prospective control
hip fracture study with 206 consecutive patients. Calcif Tissue Int 1999 hip fractu.

30. Haskell WL, Lee IM, Pate RR, Powell KE, Blair SN, Franklin BA, Macera CA, Heath GW, Thompson PD, Bauman A: Physical activity and public health: updated recommendation for adults from the American College of Sports Medicine and the American Heart Association. Med Sci Sports Exerc 2007, 39:1423-34.

31. Folstein MF, Folstein SE, McHugh PR, "Mini-mental state": A practical method for grading the cognitive state of patients for the clinician. Psychiatr Res 1975, 12:189-98.

32. Beck AT, Steer RA, Ball R, Ranieri W: Comparison of Beck Depression Inventories -IA and -II in psychiatric outpatients. J Pers Assess 1996, 67:588-97

33. Grimby G: Physical activity and muscle training in the elderly. Acta Med Scand 1986, 711(Suppl):233-237.

34. Guralnik JM, Simonsick EM, Ferrucci L, Glynn RJ, Berkman LF, Blazer DG, Scherr PA, Wallace RB: A short physical performance battery assessing lower extremity function: association with self-reported disability and lower extremity function: association with self-reported disability and prediction

35. Laukkanen P, Karppi P, Heikkinen E, Kauppinen M: Coping with activities of daily living in different care settings. Age Ageing 2001, 30:489-94.

36. Sipilä S, Multanen J, Kallinen M, Era P, Suominen H: Effects of strength and endurance training on isometric muscle strength and walking speed in elderly women. Acta Physiol Scand 1996, 156:457-64.

37. Berg K, Wood-Dauphinee S, Williams J, Gayton D: Measuring balance in the elderly: preliminary development of an instrument. Physiother Can 1989, 41:304-311

38. Powell LE, Myers AM: The Activities-specific Balance Confidence (ABC) Scale. J Gerontol A Biol Sci Med Sci 1995, 50A:M28-M34.

39. Stevens JA, Olson $\mathrm{S}$ : Reducing falls and resulting hip fractures among older women. MMWR Recomm Rep 2000, 49:3-12

40. Mänty $M$, Heinonen A, Leinonen R, Törmäkangas $T$, Hirvensalo $M$, Kallinen M, Sakari R, von Bonsdorff MB, Heikkinen E, Rantanen T: Long-term effect of physical activity counseling on mobility limitation among older people: a randomized controlled study. J Gerontol A Biol Sci Med Sci 2009 64:83-9. 
41. Queensland Government: Falls prevention-Best Practice Guidelines for Public Hospitals and State Government Residential Aged Care Facilities Incorporating a Community Integration. Supplement 2003.

42. Bovier PA, Charvet A, Cleopas A, Vogt N, Perneger TV: Self-reported management of pain in hospitalized patients: link between process and management of pain in hospitalized
outcome. Am J Med 2004, 117:569-74.

43. Leinonen R, Heikkinen E, Hirvensalo M, Lintunen T, Rasinaho M, SakariRantala R, Kallinen M, Koski J, Möttönen S, Kannas S, Huovinen P Rantanen T: Customer-oriented counseling for physical activity in older people: study protocol and selected baseline results of a randomizedcontrolled trial (ISRCTN 07330512). Scand J Med Sci Sports 2007, 17:156-64

44. Rasinaho M, Hirvensalo M, Törmäkangas T, Lintunen T, Rantanen T: Effect of physical activity counseling on physical activity of older people in Finland (ISRCTN 07330512). Health Promot Int

45. Shyu YI, Chen MC, Liang J, Wu CC, Su JY: Predictors of functional recovery for hip fractured elders during 12 months following hospital discharge: a prospective study on a Taiwanese sample. Osteoporos int 2004, 15:475-82.

46. Portegijs E, Sipilä S, Alen M, Kaprio J, Koskenvuo M, Tiainen K, Rantanen T: Leg extension power asymmetry and mobility limitation in healthy older women. Arch Phys Med Rehabil 2005, 86:1838-42.

47. Munin MC, Putman K, Hsieh C-H, Smout RJ, Tian W, Dejong G, Horn SD: Analysis of rehabilitation activities within skilled nursing and inpatient rehabilitation facilities after hip replacement for acute hip fracture. $A m$ Phys Med Rehabil 2010, 89:530-540.

48. Talkowski JB, Lenze EJ, Munin MC, Harrison C, Brach JS: Patien participation and physical activity during rehabilitation and future functional outcomes in patients after hip fracture. Arch Phys Med Rehabil functional outcom

49. Herrick C, Steger-May K, Sinacore DR, Brown M, Schechtman KB, Binder EF: Persistent pain in frail older adults after hip fracture repair. $J$ Am Geriatr Soc 2004, 52:2062-8.

50. Leveille SG, Bean J, Ngo L, McMullen W, Guralnik JM: The pathway from musculoskeletal pain to mobility difficulty in older disabled women. Pa 2007, 128:69-77

51. Leveille SG, Jones RN, Kiely DK, Hausdorff JM, Shmerling RH, Guralnik JM, Kiel DP, Lipsitz LA, Bean JF: Chronic musculoskeletal pain and the occurrence of falls in an older population. JAMA 2009, 302:2214-21.

52. Deshpande N, Metter EJ, Bandinelli S, Lauretani F, Windham BG, Ferrucci L: Psychological, physical, and sensory correlates of fear of falling and consequent activity restriction in the elderly: the InCHIANTI study. Am Phys Med Rehabil 2008, 87:354-62

53. Li F, Fisher KJ, Harmer P, McAuley E, Wilson NL: Fear of falling in elderly persons: association with falls, functional ability, and quality of life. Gerontol B Psychol Sci Soc Sci 2003, 58:P283-90.

54. Rochat S, Büla C, Martin E, Seematter-Bagnoud L, Karmaniola A, Aminian K. Piot-Ziegler C, Santos-Eggimann B: What is the relationship between fear of falling and gait in well-functioning older persons aged 65 to 70 years? Arch Phys Med Rehabil 2010, 91:879-84.

55. Tsauo JY, Leu WS, Chen YT, Yang RS: Effects on function and quality of life of postoperative home-based physical therapy for patients with hip life of postoperative home-based physical the

56. Ferrucci L, Guralnik JM, Studenski S, Fried LP, Cutler GB Jr, Walston JD: Ferrucci L, Guralnik JM, Studenski S, Fried LP, Cutler GB Jr, Walston
Interventions on Frailty Working Group. Designing randomized Interventions on Frailty Working Group. Designing randomized,
controlled trials aimed at preventing or delaying functional decline and controlled trials aimed at preventing or delaying functional decline and
disability in frail, older persons: a consensus report. J Am Geriatr Soc disability in frail, older persons: a consensus report. J Am Geriatr Soc 2004, 52:625-34

57. Fiatarone Singh MA, Singh NA, Hansen RD, Finnegan TP, Allen BJ, Diamond TH, Diwan AD, Lloyd BD, Williamson DA, Smith EU, Grady JN, Stavrinos TM, Thompson MW: Methodology and baseline characteristics for the Sarcopenia and Hip Fracture study: a 5-year prospective study. Gerontol A Biol Sci Med Sci 2009, 64:568-74.

Pre-publication history

The pre-publication history for this paper can be accessed here: http://www.biomedcentral.com/1471-2474/12/277/prepub

doi:10.1186/1471-2474-12-277

Cite this article as: Sipilä et al:: Promoting mobility after hip fracture (ProMo): study protocol and selected baseline results of a year-lon randomized controlled trial among community-dwelling older people. BMC Musculoskeletal Disorders 2011 12:277.

\section{Submit your next manuscript to BioMed Centra} and take full advantage of:

- Convenient online submission

- Thorough peer review

- No space constraints or color figure charges

- Immediate publication on acceptance

- Inclusion in PubMed, CAS, Scopus and Google Scholar

- Research which is freely available for redistribution 